Review

\title{
Neuroinflammatory Remodeling of the Anterior Cingulate Cortex as a Key Driver of Mood Disorders in Gastrointestinal Disease and Disorders
}

\author{
CE Matisz * and AJ Guber \\ University of Lethbridge. Canadian Center for Behavioural Neuroscience, 4401 University Drive, W \\ Lethbridge, AB, Canada, T1K 3M4 \\ * Correspondence: chelsea.matisz@uleth.ca
}

Keywords: gut inflammation; neuroinflammation; inflammatory bowel disease; Crohn's disease; ulcerative colitis; irritable bowel syndrome; Celiac disease; functional dyspepsia; anterior cingulate cortex; microglia; sympathetic nervous system; mood disorders; depression; anxiety; cognition

Declarations of interest: none 
Contents

Abstract

1. Introduction

2 Clinical Studies

2.1 Mood disorders and cognitive dysfunction are highly comorbid and correlative in GIDD

2.2 GIDD are associated with changes in cognition

2.3 GIDD drive structural, functional, and connective changes in the brain

Brain-Gut Neuroanatomy

GIDD impact neural processing of pain

GIDD impact neural regions associated with cognition and mentation

2.4 GIDD drive functional, structural, and connective changes in the Anterior Cingulate Cortex

GIDD is associated with increased Anterior Cingulate Cortex activity

GIDD are associated with an increase in ACC metabolism

GIDD are associated with structural changes in the ACC

GIDD is associated with altered connectivity of the ACC

Conclusion

3 Preclinical Studies

3.1 Animal models of GIDD

3.2 Animal models of GIDD induce behavioral changes

3.3 Mechanisms of neuroinflammation: glial cells

3.4 Other players in neuroinflammation: mast cells, T cells, monocytes

3.5 Resolution of neuroinflammation

3.6 Animal models of GIDD drive neural changes

3.7 Animal models of GIDD: Role of the ACC

3.9 Acute versus chronic models of GIDD

3.10 Conclusions

4 Adaptive and maladaptive consequences of ACC inflammation

4.1 Adaptive function of depression and anxiety

4.2 Ethological origin of limbic brain systems-function of the ACC

4.3 Hypothesis for the functional aetiology of depression/anxiety

4.4 Top down: Effects of the brain (ANS) on the gut

4.4.1 Sympathetic Nervous System effects on the gut and brain

4.4.2 Parasympathetic nervous system and the Vagus Nerve

4.4.3 Relationship between the ACC and the ANS

5 Remediation of gut-brain dysfunction

5.1 Pharmacological therapies

5.2 The gut-microbiome and diet

5.4 Stress reduction techniques

5.5 Conclusion
3 


\begin{abstract}
The brain reciprocally communicates with the rest of the body via neural, endocrine, immune, and other systems. This is crucial for coordinating the complex behavioral and physiological responses needed to cope with the many challenges of life. The Anterior Cingulate Cortex (ACC) is a key brain structure involved in assessing rewards and threats, as well as activating appropriate responses. This is a dynamic process that depends on evolving needs and challenges. Important challenges include illness or injury. These typically involve inflammation and pain, which evoke neuroinflammatory processes in the brain to drive sickness behaviours. In the short term, sickness behaviours are considered adaptive, as they promote convalescence (e.g. low mood; lethargy, fatigue, social withdrawal), and enhanced threat appraisal (e.g. anxiety) to combat increased risk/vulnerability associated with sickness. Chronic inflammation, however, appears to remodel the system to inappropriately activate threat-coping responses, resulting in depressive and/or anxious phenotypes. These mood disorders are particularly pronounced in diseases and disorders associated with gut dysfunction, which feature chronic inflammation and altered ACC function. We propose that chronic inflammation remodels ACC physiology such that it errantly predicts heightened danger based on a mental model (a.k.a 'schema') of the world. This evokes chronic activation of threat-coping systems, including endocrine signaling (e.g. adrenaline), and anxiety. Inflammation can be driven by brain systems involving ACC, leading to a feedback-cycle that self-reinforces pathological states. This theory accounts for a wealth of clinical and preclinical data that implicate the ACC in disorders of mood and gastrointestinal function, and reveals a key player in the gut-brain axis that may represent a novel therapeutic target.
\end{abstract}

\title{
1. Introduction
}

Neuroinflammation refers to the suite of cellular and molecular responses generated to restore allostasis in the brain in the face of injury or infection. These processes are well-known to activate in traumatic brain injury, stroke, and neurodegenerative diseases. Neuroinflammation is also activated by peripheral inflammation, which can occur through multiple communication pathways. These pathways have been the subject of excellent reviews (1), and so are described only briefly here. One path involves neural sensory systems. For instance, some fibers of the vagus nerve innervate visceral organs and possess receptors that detect inflammatory cytokines and mediators. This provides a direct sensory pathway to the terminals of the vagus nerve in the brain. Other pathways are chemical. Firstly, circulating cytokines can enter the brain via the circumventricular organs, which lack an intact blood brain barrier. Secondly, cerebral endothelial cells lining the vasculature in the brain are activated by circulating pro-inflammatory mediators. Once activated, they secrete secondary inflammatory messengers into brain tissue. The signaling molecules from endothelial cells and the circulatory system activate signaling pathways in neurons and glial cells to influence a wide array of cellular functions. Similarly, some immune cells enter the brain and chemically interact with neural tissue. For instance, some types of circulating monocytes infiltrate tissues of the central nervous system (CNS) produce pro-inflammatory cytokines, and release chemoattractants that promote recruitment of additional immune cells (2). Finally, recent research has revealed key communication pathways between gut microbiota and the CNS, termed the gut-microbiota-brain axis. For example, gut microbes produce neuroactive metabolites that play a key role in health and disease (3). Gut barrier defects presenting in a variety of inflammatory diseases can allow pathological bacteria and/or their products to enter vascular circulation, and increase inflammation in the brain (4). In sum, neuroinflammation can be driven by many interacting processes. This has profound effects on behavior.

Neuroinflammation leads to the expression of well-defined sickness behaviours that reflect reduced motivation (e.g. hypophagia, anhedonia, social \& physical withdrawal), reduced motor activity (e.g. lethargy, fatigue), and increased threat sensitivity (anxiety, altered threat coping strategies) (5). These transient behaviours are considered an evolutionary adaptive mechanism to 
cope with illness, enhance convalescence, and guard against potential threats during periods of increased vulnerability (6). Although peripheral inflammation is associated with short-lived adaptive behaviours, chronic peripheral inflammatory diseases are associated with long-lasting and deleterious effects on brain function, such as depression, anxiety, and cognitive impairments. Evidence suggests that these changes in mental function may be the consequence of changes engendered by chronic neuroinflammation, rather than by the psychological 'burden of disease' (7). Mood disorders are especially comorbid with gastrointestinal diseases and disorders (GIDD), perhaps given their close association with the gut-microbiota axis. Here we focus on the most common GIDD: Inflammatory Bowel Disease (IBD), Celiac Disease (CeD), Irritable Bowel Syndrome (IBS), and Functional Dyspepsia (FD).

Despite their clinical distinctions and diverse etiologies, GIDD possess several shared features including peripheral inflammation, abnormal gut motility, chronic relapsing and remission of symptoms, and intermittent pain. Although GIDD are associated with some degree of immune activation, often in genetically susceptible individuals, the specific trigger varies. In patients with IBD, gut bacteria and their products trigger an inappropriate and exaggerated immune response, while exposure to dietary gluten drives immunoreactivity in patients with CeD. Although the etiology IBS and FD remain unclear, evidence indicates an array of alterations similar to IBD and $\mathrm{CeD}$, including: gut barrier defects; low grade immune activation; altered gut microbiota; and involvement of the enteric nervous system (8-12). If inflammation or other aspects of shared pathophysiology in GIDD is a primary driver of brain remodeling, we should expect similar changes in mental function to emerge across GIDD. This appears to be the case.

As we review here, GIDD are all highly comorbid with anxiety, depression, and a decline in cognition. GIDD exhibit similar structural and functional changes to the brain, and these are recapitulated in animal models of GIDD. This raises several important questions: to what extent is gut pathology a contributor to the altered neural physiology? What are the mechanisms by which dysregulation of the gut-brain axis can engender neural changes? Are the changes localized to specific brain structures, and are these sufficient to explain the predominant cognitive impairments and neuropsychiatric symptoms? In this article, we attempt to address these questions by means of a critical review of clinical and pre-clinical research. We present evidence that changes in brain and mentation are a result of GIDD-related physiological responses by the gut (including the organisms living in the gut), with a focus on the role of the immune system in remodeling key brain structures. Further, we propose a theory for how the remodeling affects information processing to produce the observed changes in mentation.

\section{Clinical Studies}

\subsection{Mood disorders and cognitive dysfunction are highly comorbid and correlative in GIDD}

GIDD are comorbid with a common set of cognitive impairments and neuropsychiatric illnesses (Table 1). We first review the widely studied links of GIDD to increased anxiety and depression, before describing their wider effect on cognition and other mental functions. A recent meta-analysis estimated the prevalence of depression and anxiety in patients with IBD to be $36 \%$ and $50 \%$, respectively (13). Similarly, it is widely accepted that patients with IBS display significantly greater levels of depression and anxiety than the general population (14), with reports of anxiety and depression ranging from $22 \%$ to $100 \%$ (15-18). Studies on the prevalence of depression and anxiety in $\mathrm{CeD}$ and FD are mixed. The reported rates of depression among patients with CeD varies widely, from $6-57 \%$, (19)(20), with anxiety levels being reported around $16 \%$ (19) Some reports indicate patients with FD do not express depressive comorbidity, while other studies report 2-times higher prevalence of depression and 3-times higher levels of anxiety, relative to the healthy population (21)(22). These discrepancies are likely due to differences in diagnostic criteria, population types, the type of GIDD, as well as internal factors such as genetics, stress-coping, etc. Regardless, these data highlight a strong comorbidity of GIDD with psychiatric illness. 
Evidence suggests a positive correlation between the severity of psychiatric conditions, and the severity of GIDD. Meta-analyses indicate that both anxiety and depression are significantly greater in IBD during periods of active disease $(75.6 \%$ and $40.7 \%$ ) than remission $(31.4 \%$ and $16.5 \%$; respectively) (13). Depression is associated with more severe IBD, and patients with depression or anxiety have an increased risk of relapse $(23,24)$. In fact, recent epidemiological evidence indicates that depression increases the risk of IBD (25). In patients with IBS, positive correlations between anxiety/depression and symptom severity have also been reported $(26,27)$. Among patients with $\mathrm{CeD}$, evidence suggests that poorer adherence to a gluten-free diet-a key driver of symptoms-is associated with higher levels of depression (28), and the presence of anxiety and depression increase speed of symptom onset when patients with $\mathrm{CeD}$ are exposed to gluten (29). These findings provide strong evidence for a link between pathology in the gut and anxiety/depression. This data is consistent with reports that link mood disorders with other types of chronic inflammatory diseases. For example, anxiety and depression are comorbid in patients with Rheumatoid arthritis $(13.5 \%$ and $41.5 \%$, respectively) (30), type 1 diabetes (anxiety 17\%-36\%; depression 15\%-30\%)(31, 32), and systemic lupus erythematosus (25\% anxiety, 32\% depression)(33). Furthermore, anti-inflammatory medications have been shown to possess anti-depressant properties in inflammatory diseases (34), suggesting a causal linkage.

\subsection{GIDD are associated with changes in cognition}

Executive functions refer to the mental transactions that require effort; inhibition and interference control (e.g. self-control, selective attention), working memory, and cognitive flexibility (e.g. mental flexibility) are generally agreed to represent the dominant cognitive processes that facilitate executive function (35). Although the bulk of research has focused on the anxiodepressive consequences of GIDD, several cognitive changes have been identified in patients with GIDD (Table 1). Most studies that assess memory in patients with GIDD have identified impairments in working memory, verbal memory, performance memory and visuospatial memory (36-41). Evidence suggests patients with GIDD possess an altered attentional bias, with increased sensitivity to negatively valenced words pertaining to gastrointestinal symptoms and sensations (42-46), social threats (42$45)$, and images associated with triggers of gastrointestinal symptoms (47,48). Attention and orientation appears to be biased towards threats. Female patients with IBS displayed increased performance in an attention network task, which corresponded with activation in brain regions associated with anxiety, hypervigilance, and visceral sensitivity, suggesting a heightened and selective attention to the visceral state (49).

The evidence on executive function, such as in GIDD is mixed. Some studies suggest impaired executive function associated with GIDD, (36, 50-52), whereas others do not (53,54). Some impairments in executive functioning (e.g. cognitive interference) are disease specific (36). Therefore, negative conclusions reached by studies that considered IBD as one group should be interpreted with caution $(53,54)$. Cognitive phenomena can intersect with mood regulation. In particular, the 'cognitive model' of depression/anxiety is built on the proposition that information processing plays a key role in the way that human experiences are interpreted, evaluated, and categorized, from which emerges a personal 'schema' of one's representation of the world (55). In this model, recurring patterns of attentional bias towards negative sensations can promote negative schemas that perpetuate a maladaptive emotional state, characterized by deficits in emotional and behavioral coping, promoting depression and anxiety $(56,57)$. Cognitive behavioural therapy has demonstrated long-lasting improvement of IBS symptoms $(58,59)$. We review later how 'top-down' modulation of visceral/enteric function may explain this effect.

Reports suggest level of cognitive impairments in GIDD are associated with severity of inflammation. Patients with $\mathrm{CeD}$ and other GIDD often present with mild cognitive impairments colloquially described as 'brain fog' (60). Adoption of a gluten free diet significantly improved processing speed, attention, cognitive flexibility, visuomotor speed, and visuospatial memory in patients with celiac disease; further, improved performance on several cognitive tests were 
significantly associated with reduced intestinal pathology and gluten/anti-transferglutamine (pathological) antibody concentrations (61). Patients with IBD-CD had reduced response times in a subtle cognitive impairment test that correlated with severity of inflammatory indices (62). The realtime intensity of inflammation is not the sole driver of cognitive impairments in GIDD. Eliminating inflammation does not ameliorate GIDD-related cognitive impairments (63). For example, Hu et al report only some patients with $\mathrm{CeD}$ demonstrate improvements in cognitive deficits after adopting a gluten free diet (64). Further, elderly patients with celiac disease had poorer cognitive function in a wide variety of domains relative to age-matched controls, despite adoption of a gluten free diet (39). One explanation for these results is that some changes in the brain can be ameliorated over the course of gluten free diet trials, whereas other changes are long-lasting or even permanent. Indeed, we review in subsequent sections data showing that some changes are neurochemical (that are likely reversed quickly), whereas others are involve extensive restructuring of neural morphology (which cannot be undone quickly/easily). Moreover, GIDD are risk factors for several age-related neurodegenerative diseases, including Parkinson's (65-67) and Alzheimer's (68). It is therefore possible that GIDD evokes brain changes that are less reversible in elderly people, as a consequence of the additive effects of inflammaging (69). Given the role of inflammation in anxiety and depression, it is not surprising that mood disorders also influence cognitive deficits in GIDD: anxiety and depression are associated with lower processing speed, verbal learning, and delayed recall memory among patients with IBD, as well as rheumatoid arthritis and multiple sclerosis (70). This suggests that the underlying pathophysiological processes are related.

Overall, evidence suggests GIDD are associated with an increased risk of impairment in some aspects of executive function, including attention and schema building. Despite evidence that cognitive impairments are widespread in GIDD, this feature of GIDD is frequently overlooked. Given these findings, it is not surprising that GIDD is accompanied by widespread changes to the brain. This does beg the question: what kind of neural changes are observed in patients with GIDD? Are changes in the brain of patients with GIDD disease-specific? Are certain regions more impacted than others? What are the consequences of these changes?

\subsection{GIDD drive structural, functional, and connective changes in the brain}

For nearly two decades, studies have employed various brain imaging techniques to identify neural differences in patients with GIDD, predominantly IBS. Identifying unifying neural changes among patients with GIDD poses a significant challenge because of the wide variety of paradigms employed by different studies, including the imaging modality employed (e.g. PET vs fMRI), the nature of stimulus (subliminal, non-painful, painful rectal distention; delivered versus anticipatory stimulus), the nature of the disease/disorder (CD versus UC, remission versus active disease, IBS subtype) and other factors that influence brain physiology and activity (gender, psychiatric conditions, stress). Nonetheless, the preponderance of data suggests GIDD drive a number of neural changes that may influence affective and cognitive processing (Table 2).

\section{Brain-Gut Neuroanatomy}

Several brain regions are involved in processing multiple sources of visceral information, which plays a key role in the pathobiology/neuropathology of GIDD (see review by (71)). Vagal and spinal afferents convey information regarding the physiological state of the gut, including signals from the immune system, endocrine systems, and the microbiota. These visceral signals are integrated and processed by the brain, which then regulates autonomic systems involved in gut function, including nutrient and water absorption and secretion, bowel motility, and blood flow. A consequence of this bi-directional communication between the gut and the brain is the potential for a feedback loop in which brain dysfunction can drive gut dysfunction, and vice versa. Indeed, several brain regions demonstrate structural, functional, and connectivity changes in patients with GIDD.

\section{GIDD impact neural processing of pain}


Unsurprisingly, brain regions involved in interpreting and processing visceral sensations, pain, and the cognitive and emotional responses to pain display altered structure and function in GIDD. Patients with GIDD generally report stronger perception of pain than healthy controls (hyperalgesia), and a reduced threshold to generate pain (allodynia); these perceptual phenomena are accompanied by increased activation of brain structures that process pain (e.g. ACC, insula, sensory cortex, thalamus), and reduced activity of the descending pain modulation pathway (e.g. PAG, rostral ventromedial medulla, dorsal horn of spinal cord).] REF. The vast majority of studies that explore visceral pain employ the use of rectal distention to measure pain responses. However, cutaneous heat pain delivered to the forearm also induces altered neural responses in patients with IBD, relative to controls (72). This suggests that modulation of pain processing in GIDD is not limited to visceral sensations. Furthermore, hypervigilance to gut sensations is frequently reported by patients with GIDD (73), which can additionally increase the perception of pain intensity (74).

\section{GIDD impact neural regions associated with cognition and mentation}

As reviewed above and outlined in Table 1, GIDD are associated with numerous cognitive and mental deficits involving executive function, memory, and attention. These processes are concomitant with changes in a number of neural structures (Table 2). We have identified the cingulate cortex, specifically the anterior aspect, as a region frequently reported as having pathological structural or functional changes in GIDD. The cingulate (meaning 'ring') cortex is a thin strip of neocortex that lies on the medial aspect of each cortical hemisphere, and is typically functionally divided into the anterior (ACC), middle (MCC), and posterior (PCC) regions. The cingulate cortex appears to be involved in many functions, including the encoding of negative (e.g. painful) and positive (rewarding) affective states, and the regulation of emotional and behavioural responses.

This review focuses on the ACC due to the abundance of clinical evidence that its structure, activity, and connectivity is altered in GIDD (Table 2). Further, dysfunction of this structure may account for many of the mental illnesses comorbid in GIDD. This region is involved in making decisions involving uncertainty and affective outcomes - both positive (e.g. rewards) and negative (e.g. pain)(75). Importantly, it is involved not only in the primary sensation of the outcomes, but also activates in anticipation of these outcomes evoked by stimuli or by spontaneous recall (76). As a consequence of its anticipation of negative outcomes, its activity is strongly associated with anxiety $(77,78)$. In addition, changes in ACC structure and function are strongly correlated with depression. It becomes hyperactive (79), loses gray matter volume (80), and has altered functional connectivity with other structures (81) in major depressive disorder. Further, lesions of ACC are a last line treatment for major depression and obsessive-compulsive disease, and are highly effective in eliminating intrusive/compulsive thoughts associated with negative affective states (82). These data suggest that ACC pathophysiology is an important component in the altered mental functions that manifest in GIDD. 
Table 1. Studies of Cognitive Function in Patients with Gastrointestinal Disease/Disorders.

\begin{tabular}{|c|c|c|c|}
\hline $\begin{array}{c}\text { Gastrointestinal } \\
\text { disease/disorder (n) }\end{array}$ & Cognitive Function (test) & Cognitive domain tested & Reference \\
\hline $\begin{array}{l}\text { IBS }(n=39) \\
\text { HC }(n=40)\end{array}$ & $\begin{array}{l}\text { - Patients with IBS had impaired visuospatial memory (PAL) relative to } \\
\text { HC } \\
\text { Patients with IBS similar selective attentional and response inhibition } \\
\text { (Stroop), reversal learning and attentional flexibility (IED), working memory } \\
\text { (SWM) relative to HC }\end{array}$ & $\begin{array}{l}\text { Spatial memory } \\
\text { Cognitive flexibility } \\
\text { Working memory }\end{array}$ & (36) \\
\hline $\begin{array}{l}\text { IBS }(n=30) \\
\text { HC }(n=30)\end{array}$ & $\begin{array}{l}\text { - } \quad \text { Patients with IBS had impaired cognitive flexibility relative to HC } \\
\text { (WCST) }\end{array}$ & Cognitive flexibility & (50) \\
\hline $\begin{array}{l}\text { IBS }(n=20) \\
\text { HC }(n=30)\end{array}$ & $\begin{array}{l}\text { Patients with IBS had stronger and quicker bias toward pain than } \\
\text { neutral words relative to HC }\end{array}$ & Inhibition and interference control/Attention & (46) \\
\hline $\begin{array}{l}\text { IBS }(\mathrm{n}=15) \\
\mathrm{HC}(\mathrm{n}=15)\end{array}$ & $\begin{array}{l}\text { Patients with IBS had reduced inhibition/interference control (Stroop), } \\
\text { and displayed attention bias towards gastrointestinal symptom-related words } \\
\text { relative to controls and relative to neural words, respecitvely }\end{array}$ & $\begin{array}{l}\text { Inhibition and interference control/Attention } \\
\text { Cognitive flexibility }\end{array}$ & (51) \\
\hline $\begin{array}{c}\text { IBS }(\mathrm{n}=40) \\
\operatorname{IBD}(\mathrm{n}=150 ; \mathrm{n}=96 \mathrm{UC}, \\
\mathrm{CD} \mathrm{n}-54) \\
\mathrm{HC}(\mathrm{n}=41)\end{array}$ & $\begin{array}{l}\text { IBD but not IBS groups had lower scores on intelligence tests, though } \\
\text { when depression was added as a covariate the significance was abrogated or } \\
\text { attenuated } \\
\text { Similar performance on interference, psychomotor, attention, and } \\
\text { memory tests among groups (Cardiff cognitive battery test) } \\
\text { - No significant differences between UC and CD groups }\end{array}$ & Attention, memory, interference, intelligence & (53) \\
\hline $\begin{array}{l}\text { IBS }(\mathrm{n}=16) \\
\text { Asthma }(\mathrm{n}=9) \\
\mathrm{HC}(\mathrm{n}=8)\end{array}$ & $\begin{array}{l}\text { - Patients with IBS recalled more phrases associated with gut sensations } \\
\text { and more gut-associated words relative to HC and asthma group; asthma group } \\
\text { recalled more respiratory phrases/sensations than IBS group and HC (Recall } \\
\text { task, word recognition memory task) }\end{array}$ & Inhibition and interference control/Attention & (43) \\
\hline $\begin{array}{l}\text { IBS }(n=100) \\
\text { HC }(n=100)\end{array}$ & $\begin{array}{l}\text { Patients with IBS had lower experiential-intelligence relative to HC } \\
\text { (CTI) } \\
\text { - } \quad \text { Patients with IBS and HC had a similar performance on IQ test (WAID- } \\
\text { III) }\end{array}$ & $\begin{array}{l}\text { Global constructive thinking } \\
\text { IQ }\end{array}$ & (57) \\
\hline
\end{tabular}




\begin{tabular}{|c|c|c|c|}
\hline $\begin{array}{l}\text { IBS }(\mathrm{n}=36) \\
\text { Disease Control }(\mathrm{n}=40 \text {; } \\
13 \mathrm{UC}, 9 \mathrm{CD}, 18 \mathrm{CeD})\end{array}$ & $\begin{array}{l}\text { - Patients with IBS recognized words representing GI symptoms and } \\
\text { negative affects faster than disease control group (word recognition test) } \\
\text { IBS patients trended towards recognizing more false GI-related words } \\
\text { relative to patients with GI disease (word recollection) } \\
\text { - } \quad \text { Similar performance on word association task between groups } \\
\end{array}$ & Inhibition and interference control/Attention & (44) \\
\hline $\begin{array}{c}\text { IBS/pFGID }(\mathrm{n}=33) \\
\mathrm{HC}(\mathrm{n}=33)\end{array}$ & $\begin{array}{l}\text { Patients with pFGID after rumination induction recalled words related } \\
\text { to social threat than pain (word recognition memory task) }\end{array}$ & $\begin{array}{l}\text { Cognitive Inhibition and interference } \\
\text { control/Attention }\end{array}$ & (45) \\
\hline $\begin{array}{c}\text { IBS }(\mathrm{n}=30) \\
\text { MDD }(\mathrm{n}=28) \\
\text { Disease control }(\mathrm{n}-28) \\
\text { HC }(\mathrm{n}=30)\end{array}$ & $\begin{array}{l}\text { Patients with IBS recalled more negative words relative to HC and } \\
\text { disease control but not MDD group } \\
\text { Patients with IBS had greater false-positive rate for emotionally negative } \\
\text { words (word recognition memory task) relative all other groups }\end{array}$ & $\begin{array}{l}\text { Cognitive Inhibition and interference } \\
\text { control/Attention }\end{array}$ & $(42)$ \\
\hline $\begin{array}{l}\text { IBS }(n=21) \\
\text { HC }(n=20)\end{array}$ & $\begin{array}{l}\text { Patients with IBS displayed impaired performance on cognitive } \\
\text { interference test (Stroop) for negative words relative to HC }\end{array}$ & $\begin{array}{l}\text { Cognitive Inhibition and interference } \\
\text { control/Attention }\end{array}$ & (83) \\
\hline $\begin{array}{l}\text { IBS }(\mathrm{n}=20) \\
\mathrm{HC}(\mathrm{n}=23)\end{array}$ & $\begin{array}{l}\text { - } \quad \text { Patients with IBS displayed impaired fear-based memory learning } \\
\text { relative to HC }\end{array}$ & Memory & $(84)$ \\
\hline $\begin{array}{l}\text { Patients with IBS } \\
\text { and depression }(\mathrm{n}=27) \\
\text { Controls with } \\
\text { depression }(\mathrm{n}=20)\end{array}$ & $\begin{array}{c}\text { - No differences between patients with IBS and depression, and } \\
\text { depressed controls in tasks for attention (TMT), fine motor control (grooved } \\
\text { pegboard test), visual memory (BVLT), verbal memory (HVLT), cognitive } \\
\text { interference (Stroop) and verbal fluency (COWAT). }\end{array}$ & & (85) \\
\hline $\begin{array}{l}\mathrm{UC}(\mathrm{n}=41) \\
\mathrm{HC}(\mathrm{n}=42)\end{array}$ & $\begin{array}{l}\text { Patients with UC displayed impaired attention (ANT), cognitive } \\
\text { interference (Stroop) and working memory }\end{array}$ & $\begin{array}{c}\text { Cognitive Inhibition and interference } \\
\text { control/Attention Attention, working } \\
\text { memory, cognitive flexibility }\end{array}$ & (37) \\
\hline $\begin{array}{l}\text { Adolescent IBD } \\
\text { (UC=16, } \mathrm{CD}=17 \text {, } \\
\text { unclassified }=1) \\
\text { Juvenile idiopathic } \\
\text { arthritis (n=23) }\end{array}$ & $\begin{array}{c}\text { Patients with IBD displayed impaired verbal memory (CVLT } \\
\text { perseverative errors) relative to JIA } \\
\text { Similar performance in attention (WMS-R, TMT:A), Executive } \\
\text { functioning (TMT:B, TMT:B-A, Stroop), Working memory (WMS-R digit span } \\
\text { backward \& visual span backward), Processing speed (WAIS-R digit symbol } \\
\text { basic ability), Basic ability (WAIS-R, vocabulary), Logical reasoning/social } \\
\text { insight (WAIS-III, picture arrangement), Verbal learning and memory (CVLT } \\
\text { total recall of trials, short delay free recall, long delay free recall, } \\
\text { discriminability, intrusion errors, semantic clustering, learning slope) between } \\
\text { groups }\end{array}$ & $\begin{array}{l}\text { Verbal memory } \\
\text { Attention } \\
\text { Executive functioning } \\
\text { Working memory } \\
\text { Processing speed }\end{array}$ & (38) \\
\hline
\end{tabular}




\begin{tabular}{|c|c|c|c|}
\hline $\begin{array}{l}\text { Pediatric IBD (mixed } \\
\quad \text { CD and } U C, 30 \\
\quad H C=30, C F=28)\end{array}$ & $\begin{array}{l}\text { Patients with IBD and CF displayed impaired Attention (d2 test of } \\
\text { attention by Brickenkamp) relative to HC } \\
\text { - } \quad \text { Patients with IBD had impaired memory performance (BVRT) relative } \\
\text { to controls, and patients with IBD and CF had lower scores than control (Trial } \\
\text { of } 10 \text { words), }\end{array}$ & $\begin{array}{l}\text { Attention } \\
\text { Memory }\end{array}$ & $(40)$ \\
\hline $\begin{array}{l}\text { Pediatric IBD (mixed } \\
\quad \mathrm{CD} \text { and } \mathrm{UC}, 30 ; \\
\mathrm{HC}=30, \mathrm{CF}=28)\end{array}$ & $\begin{array}{l}\text { - Similar levels of cognitive flexibility (WCST) between IBD and HC } \\
\text { groups, while patients with CF displayed significantly poorer performance }\end{array}$ & Cognitive flexibility & (54) \\
\hline $\begin{array}{l}\operatorname{IBD}(\mathrm{n}=20, \text { mixed } \mathrm{CD} \\
\text { and } \mathrm{UC}) \\
\mathrm{HC}(\mathrm{n}=24)\end{array}$ & $\begin{array}{l}\text { - Patients with IBD displayed cognitive flexibility impairments (response } \\
\text { selection for task switching) deficits in relative to HC } \\
\text { Similar attentional selection, perceptual categorization, and working } \\
\text { memory between groups }\end{array}$ & Cognitive flexibility & (52) \\
\hline $\begin{array}{l}\text { IBD }(n=29) \\
\text { IBS }(n=29) \\
\text { HC }(n=30)\end{array}$ & $\begin{array}{l}\text { - Patients with IBD, and to a lesser extent IBS, displayed lower VIQ } \\
\text { relative to HQ, and relative to pre-morbid IQ scores (WATR) } \\
\text { - TRQ }\end{array}$ & Intelligence & (86) \\
\hline $\begin{array}{c}\text { IBS }(\mathrm{n}=27) \\
\text { IBD }(\mathrm{n}=16) \\
\text { healthy controls } \\
(\mathrm{n}=27) ; \\
\text { IBD }(\mathrm{n}=29) \\
\text { IBS }(\mathrm{n}=29) \text { controls } \\
(\mathrm{n}=30)\end{array}$ & $\begin{array}{l}\text { - Patients with IBS and IBD had lower verbal IQ scores relative to healthy } \\
\text { controls, and relative to their own performance IQ scores (WAIS-III) } \\
\text { Patients with IBD performed worse on object recognition, better on } \\
\text { spatial recognition relative to IBS and HC groups } \\
\text { - Similar performance on cognitive flexibility (Stroop) between groups }\end{array}$ & $\begin{array}{l}\begin{array}{l}\text { Verbal and performance IQ, recognition } \\
\text { memory }\end{array}\end{array}$ & $(86,87)$ \\
\hline $\begin{array}{l}\text { IBD }(17 \mathrm{CD}, 9 \mathrm{UC}) \\
\text { Controls }(24) \\
\end{array}$ & $\begin{array}{l}\text { - } \quad \text { Patients with IBD displayed impaired short term memory function } \\
(\mathrm{MMT})\end{array}$ & Memory & (41) \\
\hline $\begin{array}{l}\text { Crohn's Disease } \\
\qquad \begin{array}{l}\text { CD n }=18 \\
\text { HC n }=40\end{array}\end{array}$ & $\begin{array}{l}\text { - Patients with CD has impaired selective attentional and response } \\
\text { inhibition (Stroop) relative to HC } \\
\text { - } \quad \text { Similar working memory (SWM), Reversal learning and attentional } \\
\text { flexibility (IED), Visuospatial episodic memory (PAL) between groups }\end{array}$ & $\begin{array}{l}\text { Executive functioning } \\
\text { Visual memory } \\
\text { Working memory }\end{array}$ & (36) \\
\hline $\begin{array}{l}\text { Crohn's Disease } \\
\quad(\mathrm{n}=105)\end{array}$ & $\begin{array}{c}\text { Patients with CD displayed processing speed, verbal skills } 1 \text { standard } \\
\text { deviation or greater below average }\end{array}$ & $\begin{array}{l}\text { Verbal skills } \\
\text { Global cognition }\end{array}$ & (88) \\
\hline
\end{tabular}




\begin{tabular}{|c|c|c|c|}
\hline & $\begin{array}{l}\text { Performance on global cognitive scores correlated with disease activity } \\
\text { index }\end{array}$ & & \\
\hline $\begin{array}{l}\text { Crohn's Disease } \\
\qquad \begin{array}{l}\text { CD }(n=49) \\
H C(n=31)\end{array}\end{array}$ & $\begin{array}{l}\text { - Patients with CD displayed impaired response time, but not error rate, } \\
\text { in a cognitive processing task (SCIT) } \\
\text { Performance on SCIT was negatively correlated with indices of } \\
\text { inflammation }\end{array}$ & Processing & $(62)$ \\
\hline $\begin{array}{l}\text { Celiac Disease } \\
(\mathrm{n}=11,8 \text { females })\end{array}$ & $\begin{array}{l}\text { - Improvement in speed of information processing (TMT A), efficacy of } \\
\text { memory (response time in SCIT), visuospatial ability and memory (both } 3 \text { and } \\
\text { - } 30 \text { minute delay in the ROCF) } 52 \text { weeks after adoption of GFD } \\
\text { No change in word fluency (COWAT), verbal learning \& memory } \\
\text { (RAVLT), manual dexterity (grooved pegboard task), or IQ (WTAR) upon } \\
\text { adoption of GFD } \\
\text { - performance on Trails A, COWAT, SCIT-RT, RAVLT correlated } \\
\text { negatively with disease activity scores and levels of pathological antibody } \\
\text { concentrations }\end{array}$ & Cognitive function & $(61)$ \\
\hline $\begin{array}{l}\text { Celiac Disease } \\
(\mathrm{n}=13)\end{array}$ & - $\quad$ moderate cognitive impairment (Short Test of Mental Status) & Cognitive function & $(64)$ \\
\hline $\begin{array}{l}\mathrm{CeD}(\mathrm{n}=20) \\
\mathrm{HC}(\mathrm{n}=20)\end{array}$ & - $\quad$ Similar performance on MMSE (test for dementia) among groups & General cognitive function & (89) \\
\hline $\begin{array}{l}\text { Celiac Disease } \\
(\mathrm{n}=18 \text { on GFD for } \\
5.5+/-3 \text { years }) \\
\text { HC }(\mathrm{n}=18)\end{array}$ & $\begin{array}{c}\text { - } \quad \text { elderly patients with celiac disease demonstrated global impairments } \\
\text { (MMSE), deficits in attention, abstract thinking, concentration (TMT A, TMT B), } \\
\text { verbal processing (Semantic Fluency test), visuospatial intelligence (Digit } \\
\text { Symbol Test) relative to HC } \\
\text { - Similar perceptual relations (Raven's Matrices), short-term and long } \\
\text { term memory (Rey List, Verbal Span and Short Story Test), procedural and } \\
\text { propositional memory between groups }\end{array}$ & $\begin{array}{l}\text { General cognition, visual-motor \& cognitive } \\
\text { flexibility, executive functioning, attention, } \\
\text { perceptual speed, motor speed, visual } \\
\text { scanning and memory, intentional gesture } \\
\text { execution }\end{array}$ & (39) \\
\hline $\begin{array}{l}\text { Celiac Disease }(\mathrm{n}=33) \\
\text { Disease control } \\
\text { (mostly IBS; } \mathrm{n}=17) \\
\end{array}$ & $\begin{array}{l}\text { - Patients with CeD had impaired executive function (IFS) relative to HC } \\
\text { Patients with CeD and disease control group displayed cognitive } \\
\text { impairment (ACE-R) relative to HC }\end{array}$ & $\begin{array}{c}\text { ACE-R: attention, orientation, concentration, } \\
\text { memory, fluency language, visuospatial } \\
\text { abilities }\end{array}$ & $(60)$ \\
\hline
\end{tabular}




\begin{tabular}{|c|c|c|c|}
\hline $\mathrm{HC}(\mathrm{n}=26)$ & & & \\
\hline $\begin{array}{l}\text { Celiac Disease } \\
\qquad \begin{array}{l}(\mathrm{n}=50) \\
\mathrm{HC}(\mathrm{n}=37) \\
\text { All female }\end{array}\end{array}$ & $\begin{array}{l}\text { - Patients with CeD impaired working memory, planning/organizing } \\
\text { (BRIEF-A) } \\
\text { No differences for general executive function problem solving, } \\
\text { behavioural regulation, inhibition, emotional control, self-monitoring, initiating, } \\
\text { and task monitoring between groups } \\
\text { Patients with CeD had lower GPA and higher measures of social anxiety } \\
\text { (SAQ-A30) relative to controls }\end{array}$ & Executive functioning, social anxiety & (90) \\
\hline $\begin{array}{l}\text { Functional Dyspepsia } \\
\text { FD }(\mathrm{n}=60) \\
\text { PU }(\mathrm{n}=60) \\
\text { HC }(\mathrm{n}=60)\end{array}$ & $\begin{array}{l}\text { neuroticism (Eysenck personality questionnaire) greater among patients } \\
\text { with FD; significantly correlated with anxiety }\end{array}$ & Neuroticism & (91) \\
\hline $\begin{array}{l}\text { FD }(n=15) \\
\text { HC }(n=17)\end{array}$ & $\begin{array}{l}\text { - Patients with FD had significantly lower pleasantness rating to images } \\
\text { of food relative to HC, and high-fat food images versus low fat food images } \\
\text { Patients with FD decreased visual attention to food images, especially } \\
\text { high fat food images (eve tracing) }\end{array}$ & Attention & $(47)$ \\
\hline
\end{tabular}

ACE-R, Addenbrooke Cognitive Examination-Revised; BRIEF-A, Behaviour Rating Inventory of Executive Function-Adult; BVLT, Brief Visual Memory Test; CD, Crohn's Disease; CeD, Celiac Disease; CF, Cystic Fibrosis; COWAT, Controlled Oral Word Association Task; CTI, constructive thinking inventory; CVLT, California Verbal Learning Test; GI, gastrointestinal; GFD, gluten free diet; HC, Healthy Controls; HVLT, Hopkins Verbal Learning Test; IBD, Inflammatory Bowel Disease; IBS, Irritable Bowel Syndrome; IED, Intra-Extra Dimensional Set Shift; IFS, INECO frontal screening; MMT, Minimal mental state test; PAL, Paired Associated Learning; pFGID, putative functional gastrointestinal disorder; PU, peptic ulcer; RAVLT, Rey Auditory Verbal Learning Task;ROCF, ReyOsterrieth Complex Figure; SAQ-30, Social Anxiety Questionnaire for Adults-Short Form; SCIT, subtle cognitive impairment task, SCIT, subtle cognitive impairment task;SWM, Spatial Working Memory; TMT, Trail Making Test; WAIS-III, Wechsler Adult Inteligence Scale-Third Edition; WCST, Wisconson Card Sorting Task, WTAR, Wechsler's test of adult reading; 
Table 2. Neural changes in Gastrointestinal Diseases \& Disorders (GIDD).

\begin{tabular}{|c|c|c|}
\hline $\begin{array}{c}\text { Subject } \\
\text { details }\end{array}$ & Modality; Neural changes & Reference \\
\hline $\begin{array}{l}\text { IBS }(n=6) \\
\text { HC }(n=6)\end{array}$ & $\begin{array}{l}\text { PET } \\
\text { - ACC activation occurred in response to anticipation of, or delivery of, painful stimulus in healthy controls, but not } \\
\text { patients with IBS } \\
\text {-In patients with IBS, significant activation of left prefrontal cortex during anticipated or delivered painful stimuli }\end{array}$ & (92) \\
\hline $\begin{array}{l}\text { IBS }(\mathrm{n}=13 ; 6 \\
\text { male, } 7 \\
\text { female) }\end{array}$ & $\begin{array}{l}\text { PET } \\
\text { rectal distention increased activity in ACC, insula, PFC, thalamus, and cerebellum; moreso for males than females }\end{array}$ & (93) \\
\hline $\begin{array}{l}\text { IBS }(\mathrm{n}=18) \\
\mathrm{HC}(\mathrm{n}=16)\end{array}$ & $\begin{array}{c}\text { fMRI } \\
\text { - } \quad \text { increased ACC activation in patients with IBS, but not controls, during painful vs non-painful stimuli }\end{array}$ & (94) \\
\hline $\begin{array}{l}\text { IBS }(n=12) \\
\text { HC }(n=12)\end{array}$ & $\begin{array}{c}\text { PET } \\
\text { reduced activation of pACC, temporal lobe, brainstem, and increased activation of rACC and PCC during anticipated and } \\
\text { delivered rectal stimuli in patients with IBS relative to controls }\end{array}$ & (95) \\
\hline $\begin{array}{l}\text { IBS }(n=6) \\
\text { IBD }(n=6) \\
\text { HC }(n=6)\end{array}$ & $\begin{array}{l}\text { fMRI } \\
\text {-greater activation of anterior cingulate gyrus under non-painful and painful rectal stimuli in controls relative to IBS patients, and } \\
\text { in IBS patients relative to IBD patients (activation: controls }>\text { IBS }>\text { IBD) } \\
\text {-deactivation of left somatosensory cortex greater in IBS vs IBD, and IBD vs control }\end{array}$ & (96). \\
\hline $\begin{array}{l}\text { IBS }(\mathrm{n}=12 ; 11 \\
\quad \text { female) }\end{array}$ & $\begin{array}{l}\text { fMRI } \\
\text {-significant deactivation of insular cortex (IC), amygdala, and striatum (putamen) during painful vs non-painful stimuli }\end{array}$ & (97) \\
\hline $\begin{array}{l}\text { IBS }(n=23 \\
\text { female, } 19 \\
\text { male) }\end{array}$ & $\begin{array}{l}\text { PET } \\
\text {-greater activation of vmPFC, raACC, left Amygdala in women than men in response to rectal distention } \\
\text {-greater activation of right dlPFC, insula, dorsal pons/periaqueductal gray. } \\
\text {-similar sex differences during anticipation of stimulus }\end{array}$ & (98) \\
\hline $\begin{array}{l}\text { IBS }(n=6) \\
\text { HC }(n=6)\end{array}$ & $\begin{array}{c}\text { PET } \\
\text {-Reduced ACC activity during rectal distention in IBS versus HC group }\end{array}$ & (99) \\
\hline
\end{tabular}




\begin{tabular}{|c|c|c|}
\hline \multicolumn{3}{|c|}{-increased thalamic activity in patients with IBS versus HC } \\
\hline $\begin{array}{l}\text { IBS }(n=9) \\
\operatorname{HC}(n=9)\end{array}$ & $\begin{array}{l}\text { fMRI } \\
\text {-greater activation of thalamus, somatosensory cortex, insula, ACC, PCC, PFC in patients with IBS in response to rectal distention } \\
\text { and cutaneous heat stimuli, relative to healthy controls }\end{array}$ & $(100)$ \\
\hline $\begin{array}{l}\text { IBS }(n=26) \\
\text { HC }(n=11)\end{array}$ & $\begin{array}{l}\text { fMRI } \\
\text {-rectal distention generally increased activity in the ACC, insular cortex, and prefrontal cortex, and thalamus for both IBS and HC } \\
\text {-Significantly increased area of activation in the PFC as rectal distention increased in patients with IBS } \\
\text {-During rectal distention, IBS patients had greater area and greater activity in the IC, PFC, and thalamus relative to controls }\end{array}$ & $(101)$ \\
\hline $\begin{array}{l}\text { IBS (5 IBS-C, } \\
5 \text { IBS-D, } 10 \\
\text { HC, all } \\
\text { females) }\end{array}$ & $\begin{array}{c}\text { fMRI } \\
\text {-HC, but not IBS subjects, displayed activation of anterior perigenual cingulate, many prefrontal and SI cortices, posterior insula at } \\
\text { baseline } \\
\text {-IBS-D increased thalamic nuclei activation, lack of activation of most other region relative to baseline, controls, and IBS-C } \\
\text {-IBS-D had deactivation in anterior right insula relative to HC and IBS-C during distention. } \\
\text {-Increase activation of amygdala, hippocampus, in IBS-C during distention } \\
\text {-deactivation in PAG in HC, but not IBS subjects, during distention }\end{array}$ & $(102)$ \\
\hline $\begin{array}{l}\text { IBS }(n=8) \\
\text { HC }(n-8)\end{array}$ & $\begin{array}{l}\text { fMRI } \\
\text {-reduced PFC and ACC activation in subliminal and supraliminal rectal stimulation relative to controls } \\
\text {-increased HPC activation in response to supraliminal rectal stimulation relative to controls } \\
\text {-increased ACC and HPC activation in response to auditory stimulation relative to controls }\end{array}$ & $(103)$ \\
\hline $\begin{array}{l}\text { IBS }(n=9) \\
\mathrm{HC}(\mathrm{n}=11)\end{array}$ & $\begin{array}{l}\text { fMRI } \\
\text {-increased activity in primary sensory cortex in patients with IBS versus controls, during non-painful rectal distention } \\
\text {-increased activity in medial thalamus and hippocampus in patients with IBS versus controls, during painful rectal distention } \\
\text {-non-painful and painful rectal stimulation increased activation of right anterior insula and right anterior cingulate cortex in } \\
\text { control, but not IBS group }\end{array}$ & $(104)$ \\
\hline $\begin{array}{l}\text { IBS }(\mathrm{n}=7) \\
\mathrm{UC}(\mathrm{n}=8) \\
\mathrm{HC}(\mathrm{n}=7)\end{array}$ & $\begin{array}{l}\text { PET } \\
\text {-during anticipated and delivered rectal distention, IBS patients had greater activation of amygdala, rostroventral ACC, and } \\
\text { dorsomedial frontal cortical regions compared to controls and UC patients }\end{array}$ & $(105)$ \\
\hline $\begin{array}{l}\text { IBS }(\mathrm{n}=20 ; 14 \\
\text { female) }\end{array}$ & $\begin{array}{c}\text { PET } \\
\text { Activation of iACC and sACC during anticipation of visceral stimulus, and iACC activation during stimulus itself }\end{array}$ & $(106)$ \\
\hline $\begin{array}{l}\text { IBS }(\mathrm{n}=14 \\
\text { female) } \\
\mathrm{HC}(\mathrm{n}=12)\end{array}$ & $\begin{array}{l}\text { fMRI } \\
\text {-patients with IBS had reduced activation in the right posterior insula and bilateral DBS in response to cued anticipatory rectal } \\
\text { distention relative to controls } \\
\text {-Increased activity in DBS and dACC in patients with IBS relative to controls during painful rectal distention }\end{array}$ & $(107)$ \\
\hline
\end{tabular}




\begin{tabular}{|c|c|c|}
\hline \multicolumn{3}{|c|}{-during anticipation of painful stimulus, controls, but not patients with IBS, had deactivated thalamus } \\
\hline $\begin{array}{l}\text { IBS }(\mathrm{n}=9 ; 6 \\
\text { females) } \\
\text { HC (n-11, } 7 \\
\text { females) }\end{array}$ & $\begin{array}{c}\text { Modality } \\
\text {-reduced CT in the aMCC of IBS relative to controls }\end{array}$ & $(108)$ \\
\hline $\begin{array}{l}\text { IBS ( } \mathrm{n}=10 ; 5 \\
\text { with history } \\
\text { of abuse) } \\
\text { HC ( } \mathrm{n}=10 ; 5 \\
\text { with history } \\
\text { of abuse) }\end{array}$ & $\begin{array}{c}\text {-fMRI } \\
\text {-patients with IBS and history of abuse reported greatest pain during painful rectal distention } \\
\text {-greater activation of the MCC, PCC among subjects with history of abuse } \\
\text {-patients with IBS and a history of abuse had greater activation in MCC and PCC relative to all other groups, and less activation in } \\
\text { the SACC }\end{array}$ & $(109)$ \\
\hline $\begin{array}{l}\text { IBS }(n=11) \\
\text { HC }(n=16)\end{array}$ & $\begin{array}{c}\text { MRI } \\
\text {-reduced CT in the aMCC relative to controls } \\
\text {-negative correlation between dIPFC CT and pain catastrophizing scale (PCS) } \\
\text {-increased size (VBM) of hypothalamus in patients with IBS } \\
\text {-positive correlation between CT of anterior insula and pain duration in patients with IBS; no correlation of MCC/ACC }\end{array}$ & $(110)$ \\
\hline $\begin{array}{l}\text { IBS }(\mathrm{n}=15, \\
\text { female) } \\
\text { HC (n=12, } \\
\text { female) }\end{array}$ & $\begin{array}{l}\text { fMRI } \\
\text {-anxiety symptoms in patients with IBS correlated with increased activity in the anterior midcingulate cortex, and pregenual } \\
\text { anterior cingulate cortex in response to painful rectal distention } \\
\text {-increased activation in the insula, MCC, and vlPFC during rectal distention versus controls }\end{array}$ & $(111,112)$ \\
\hline $\begin{array}{l}\text { IBS }(7 \\
\text { females) } \\
\text { HC (n=6 } \\
\text { females) }\end{array}$ & $\begin{array}{l}\text { fMRI } \\
\text {-increased activity in the ACC, insula and superior/vm prefrontal regions during ramp-tonic rectal distention relative to controls } \\
\text {-reduced activity in thalamus, striatal regions, dlPFC relative to controls }\end{array}$ & $(113)$ \\
\hline $\begin{array}{l}\text { IBS }(n=55) \\
\text { HC }(n=45)\end{array}$ & $\begin{array}{l}\text { MRI } \\
\text {-decreased GM in mPFC, vlPFC, ventral striatum, posterior parietal cortex, thalamus versus HC } \\
\text {-increased GM in pgACC, orbitofrontal cortex }\end{array}$ & $(114)$ \\
\hline $\begin{array}{l}\text { IBS (n=10 } \\
\text { females) } \\
\text { HC ( } n=16 \\
\text { females) }\end{array}$ & $\begin{array}{l}\text { MRI DTI } \\
\text {-increased fractional anisotropy (marker of WM integrity) in the fornix and external capsule beside the right posterior insula; FA } \\
\text { of WM beside insula and traversing the VPL nucleus of the thalamus positively correlated with pain severity }\end{array}$ & (115) \\
\hline
\end{tabular}




\section{fMRI}

IBS $(\mathrm{n}=30) \quad$-reduced activity in rDLPFC and rHPC, and increased activity in left posterior insula at time of error feedback during WCST

$\mathrm{HC}(\mathrm{n}=30)$

relative to controls

-reduced connectivity between DLPFC and pre-supplementary motor areas in patients with IBS versus healthy controls

\section{DTI MRI}

-lower FA in globus pallidus, putamen, medial thalamus and substantia nigra relative to controls

IBS ( $\mathrm{n}=33) \quad$-higher FA in pre-frontal white matter regions, and regions within the corpus callosum relative to controls

$\mathrm{HC}(\mathrm{n}=93) \quad$-reduced mean diffusivity (MD) in the globus pallidus, higher MD in the thalamus, internal capsule, and coronal radiate relative

to controls

\begin{tabular}{|c|c|c|}
\hline $\begin{array}{c}\text { IBS (n=11 } \\
\text { females) } \\
\text { HC (n=15 } \\
\text { females) }\end{array}$ & $\begin{array}{c}\text {-reduced activity in the mPFC, pons, aINS, and hippocampus in patients with IBS, but not controls, when administered CRF-R1 } \\
\text { antagonist during extinction of conditioned fear to visceral pain }\end{array}$ & $(117)$ \\
\hline $\begin{array}{l}\text { IBS }(n=66) \\
\text { HC }(n=23)\end{array}$ & $\begin{array}{c}\text { MRI, DTI } \\
\text {-more FA of white matter bundles in S1 patients with IBS than controls }\end{array}$ & $(118)$ \\
\hline $\begin{array}{l}\text { IBS }(\mathrm{n}=82) \\
\mathrm{HC}(\mathrm{n}=119)\end{array}$ & $\begin{array}{c}\text { MRI } \\
\text {-lower GM volume in the superior frontal gyrus, insula, amygdala, hippocampus, orbital frontal gyrus cingulate, putamen relative } \\
\text { to controls } \\
\text {-increased GM volume in } \mathrm{S1} \text { relative to controls } \\
\text {-cingulate gyrus and thalamus displayed greater measure of connectedness (controlling information) than controls }\end{array}$ & $(119)$ \\
\hline $\begin{array}{l}\text { IBS }(n=31) \\
\text { HC }(n=32)\end{array}$ & $\begin{array}{c}\text { rsMRI } \\
\text {-increased ReHo values in postecentral gyri, calcarine, vermis, thalams parietal lobe and reduced ReHo in aMCC pgACC, sACC, } \\
\text { vmPFC dIPFC, and vlPFC caudate and angular gyrus relative to controls during resting state } \\
\text {-disease duration positively correlated with ReHo in postcentral gyruis, negatively correlated with Reho in aMCC supplementary } \\
\text { motor area, and insula } \\
\text {-SSS scores positively correlated with ReHo in the thalamus, negatively correlated with ReHo values in the vmPFC and MFG } \\
\text {-pain intensity levels positively correlated with ReHo values in the postcentral gyrus and negatively correlated with with mPFC } \\
\text { and LFG }\end{array}$ & $(120)$ \\
\hline IBS $(n=21)$ & Rs-fMRI & (121) \\
\hline
\end{tabular}




\begin{tabular}{|c|c|c|}
\hline $\mathrm{HC}(\mathrm{n}=21)$ & $\begin{array}{l}\text {-Reduced ALFF in the left superior frontal gyrus, right hippocampus, right middle frontal gyrus, bilateral postcentral right } \\
\text { superior temporal pole in patients with IBS relative to controls } \\
\text {-Increased ALFF in left media cingulate and left calcarine in patients with IBS relative to controls } \\
\text {-significant correlation between } \\
\text {-increased functional connectivity between cingulate and frontal cortex }\end{array}$ & \\
\hline $\begin{array}{l}\text { IBS }(n=37) \\
\text { HC }(n=37)\end{array}$ & $\begin{array}{l}\text { fMRI } \\
\text {-increased activity in the amygdala, ventral anterior INS, medial frontal gyrus, inferior occipital cortex, thalamus, PCC and } \\
\text { precuneus during uncued versus safe cued pain expectation relative to controls } \\
\text {-increased activation of inferior occipital cortex during cued threat versus cued safe condition versus controls }\end{array}$ & (122) \\
\hline $\begin{array}{l}\text { IBS }(9 \\
\text { adolescents) } \\
\text { HC ( }(n=8 \\
\text { adolescents) }\end{array}$ & $\begin{array}{c}\text { fMRI } \\
\text { increased activity in the AI, aMCC, pACC, sgACC, inferior and middle frontal gyrus, and clustered regions within the cerebellum, } \\
\text { and reduced activity in the precuneus, temporal-occipital conjunction, and parahippocampal gyrus in patients with IBS versus } \\
\text { controls during subliminal rectal stimulation } \\
\text {-increased activity in the AI, posterior insula, aMCC, pACC, sgACC, IFC, PCC, vmPFC, dmPFC and reduced acitivyt in the } \\
\text { parietal lobe and cerebellum relative to controls during liminal stimulation } \\
\text {-increased functional connections in the dmPFC, vmPFC, dlPFC, and PCC (when seed placed in insula and ACC) relative to } \\
\text { controls }\end{array}$ & (123) \\
\hline $\begin{array}{l}\text { IBS }(n=30 \\
\text { females) } \\
\text { HC (n=39 } \\
\text { females) }\end{array}$ & $\begin{array}{c}\text { MRI } \\
\text {-reduced CT in cuneus, rostral middle frontal cortex, supramarginal cortex, caudal anterior cingulate cortex, insula relative to } \\
\text { controls }\end{array}$ & (124) \\
\hline $\begin{array}{l}\text { IBS }(n=19) \\
\text { HC }(n=20)\end{array}$ & $\begin{array}{c}\text { DTI } \\
\text {-reduced FA in splenium of corpus callosum, retrolenticular area of internal capsule, superior corona radiate relative to controls } \\
\text {-increased MD in splenium and body of corpus callosum, retrolenticular area of internal capsule, superior corona radiate, } \\
\text { posterior limb of internal capsule }\end{array}$ & (125) \\
\hline $\begin{array}{l}\text { IBS }(\mathrm{n}=20 \\
\text { male) } \\
\mathrm{HC}(\mathrm{n}=10 \\
\text { male })\end{array}$ & $\begin{array}{c}\text { fMRI } \\
\text {-increased activity in insula, middle temporal gyrus, cerebellum, inferior orbitofrontal cortex versus controls during rectal } \\
\text { distention } \\
\text {-reduced activity in precuneus and superior parietal lobe relative to controls during rectal distention }\end{array}$ & (126) \\
\hline $\begin{array}{l}\text { IBS }(n=26) \\
\text { HC }(n=29)\end{array}$ & (2: & (127) \\
\hline & & 10 \\
\hline
\end{tabular}

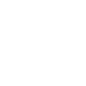

.

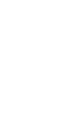

列


-uncertain anticipation of rectal distention drove increased activity in the aMCC, thalamus, and visual processing regions in patients with IBS versus controls

-after uncertain rectal distention cue, patients with IBS had greater activity in the posterior and midcingulate cortices and precuneus relative to controls, while controls demonstrated insular activation

\section{fMRI}

IBS $(\mathrm{n}=28)$

$\mathrm{HC}(\mathrm{n}=34)$

-increased activity of mPFC and pACC in patients with IBS relative to controls during rectal distention(128)

-Activity of mPFC and pgACC in controls, but not patients with IBS, were negatively correlated with ACTH levels during rectal

distention

IBS $(\mathrm{n}=16$

females)

HC (n=16

females)

females)

HC ( $n=21)$
DTI

-Adolescents with IBS displayed reduced fractional anisotropy (a marker of changes in white matter structure) in the right dorsal cingulum bundle relative to healthy controls

MRI

-increased positive FC in the aMCC in patients with IBS versus healthy controls -increased positive FC in the mid-insula of patients with hypersensitive vs normosensitive IBS

-increased positive FC of pgACC and thalamus in the salience network, the posterior insula in the sensorimotor network, and increased positive FC of right amygdala and increased negative FC in left dorsal anterior insula in the DMN in patients with

hypersensitive vs normosensitive IBS

-increased positive FC of right amygdala and increased negative FC in left dorsal anterior insula in controls relative to normosensitive patients with IBS

-negative correlations between FC of amygdala and dorsal anterior insula within the DMN and visceral sensation -negative correlation between FC of posterior insula and visceral sensation

-FC of posterior insula significantly correlated with symptom severity

\begin{tabular}{c}
\hline IBS $(n=19)$ \\
HC $(n=26)$ \\
\hline IBS ( $n=39$ \\
females)
\end{tabular}

females)

\section{Quantitative MRS}

-lower levels of glutamate+glutamine in the anterior insula relative to controls -no differences in GABA concentrations in anterior insula between groups 


\begin{tabular}{|c|c|c|}
\hline $\begin{array}{c}\mathrm{HC}(\mathrm{n}=21 \\
\text { females })\end{array}$ & & \\
\hline $\begin{array}{l}\text { IBS }(\mathrm{n}=32 \\
\text { girls }) \\
\text { HC }(\mathrm{n}=26 \\
\text { girls })\end{array}$ & $\begin{array}{l}\text { MRI } \\
\text {-lower GM volume in the thalamus, caudate nucleus, nucleus accumbens, aMCC, and dlPFC relative to controls } \\
\text {-reduced functional connectivity between aMCC and precuneus, increased functional connectivity between caudate nucleus and } \\
\text { precentral gyrus than controls }\end{array}$ & (133) \\
\hline $\begin{array}{l}\text { IBS }(n=65) \\
\text { HC }(n=21)\end{array}$ & $\begin{array}{l}\text { fMRI } \\
\begin{array}{l}\text { Reduced association between S1 activation, and increased association between S2 activation, with the gut microbe Lachnispiracea } \\
\text { incertae sedis and rectal pain threshold in patients with IBS versus controls } \\
\text {-both Clostridium XIVa and Coprococcus demonstrate several indirect associations between visceral sensation and connectivity in } \\
\text { subcortical regions in controls, but not patients with IBS }\end{array}\end{array}$ & (134) \\
\hline $\begin{array}{l}\text { IBS }(n=46) \\
\text { HC }(n=60)\end{array}$ & $\begin{array}{c}\text { MRI } \\
\text {-increased ReHo in postecentral gyrus relative to controls } \\
\text {-increased functional connectivity of the poCC and the insula, precentral cortex, and supplementary motor area } \\
\text {-global differences in neural organization; higher clustering coefficient, characteristic path length, and local and global efficiency } \\
\text { relative to controls }\end{array}$ & (135) \\
\hline $\begin{array}{c}\mathrm{CD}(\mathrm{n}=54) \\
\mathrm{HC}(\mathrm{n}=100)\end{array}$ & $\begin{array}{c}\text { MRI } \\
\text {-Significantly more patients with CD had cerebral T2 white matter hyper intensities relative to controls; patients with lesions were } \\
\text { older than those without }\end{array}$ & (136) \\
\hline $\begin{array}{l}\mathrm{CD}(\mathrm{n}=43 \\
\text { remission) } \\
\mathrm{HC}(\mathrm{n}=37)\end{array}$ & $\begin{array}{l}\text { rs-fMRI } \\
\text {-patients with CD displayed disruption and dysfunction in subcortical, sensorimotor, cognitive control, and default-mode neural } \\
\text { networks } \\
\text {-patients with CD had reduced superior temporal gyrus-precuneus connectivity, supplementary motor area-superior frontal gyrus } \\
\text { connectivity, and connectivity between the putamen and insula, superior temporal gyrus, precuneus, supramarginal and aMCC, } \\
\text { in addition to reduced connectivity between the aMCC-insula, supplementary motor area, thalamus, and precuneus } \\
\text {-Those patients with CD with higher levels of depression and/or anxiety displayed altered topographical patterns associated with } \\
\text { the ACC, mPFC, and PCC relative to other patients with CD }\end{array}$ & (137) \\
\hline $\begin{array}{l}\mathrm{CD}(\mathrm{n}=18) \\
\mathrm{HC}(\mathrm{n}=18)\end{array}$ & $\begin{array}{l}\text { RSFC } \\
\text {-patients with CD displayed significantly increased functional connectivity between the right middle frontal gyrus and right } \\
\text { inferior parietal lobe in the executeive control network, and increased functional connectivity between the right precuneus and } \\
\text { right posterior cingulate cortex in the default mode network, relative to HS }\end{array}$ & (138) \\
\hline
\end{tabular}




\begin{tabular}{|c|c|c|}
\hline $\begin{array}{l}\mathrm{CD}(\mathrm{n}=30 \text { in } \\
\text { remission) } \\
\mathrm{HC}(\mathrm{n}=30)\end{array}$ & $\begin{array}{l}\text { MRI } \\
\text {-reduced global network segregation in patients with CD relative to HC } \\
\text {-reduced nodal betweenness centrality in the right insula/left cuneus/left superior frontal cortex, and reduced nodal degree within } \\
\text { the left hemisphere of the cingulate/left lateral/right medial orbitofrontal cortex. }\end{array}$ & (139) \\
\hline $\begin{array}{l}\mathrm{UC}(\mathrm{n}=10, \\
\text { remission) } \\
\mathrm{HC}(\mathrm{n}=10)\end{array}$ & $\begin{array}{l}\text { fMRI } \\
\text {-Reduced BOLD signal in amygdala, hippocampus, thalamic and cerebellar areas in UC patients when presented with positive } \\
\text { visual emotional stimuli versus rest contrast, relative to HC }\end{array}$ & (140) \\
\hline $\begin{array}{l}\text { UC }(n=41) \\
\text { HC }(n=42)\end{array}$ & $\begin{array}{c}\text { rs-fMRI } \\
\text {-lower ALFF in HPC and paraHPC relative to controls } \\
\text {-higher ALFF in PCC, middle frontal gyrus } \\
\text {-increased FC between HPC/paraHPC and middle frontal gyrus, ACC, and caudate nucleus relative to controls } \\
\text {-increased FC between PCC and MCC and angular gyrus, reduced FC between PCC and inferior occipital gyrus } \\
\text {-increased FC between middle frontal gyrus and brainstem, inferior parietal lobe, and superior frontal gyrus relative to controls } \\
\text {-working memory test negatively correlated with reduced ALFF of HPC/paraHPC, and increased FC between HPP/paraHPC and } \\
\text { caudate nucleus in UC patients } \\
\text {-Stroop test RT positively correlated with increased ALFF of PCC, and negatively correlated with increased FC between } \\
\text { HPC/paraHPC and ACC in UC patients } \\
\text {-alerting effect of attention network task positively correlated with ALLF of PCC, negatively correlated with increased FC between } \\
\text { PCC, negatively correlated with increased FC strength between PCC and AUG (?)in UC patients } \\
\text {-PSS positively correlated with increased FC strength between PCC and MCC in UC patients } \\
\text {-SDS and SAS scores negatively correlated with increased FC strength between MFG and IPL in UC patients }\end{array}$ & (37) \\
\hline $\begin{array}{l}\mathrm{CD}(\mathrm{n}=18, \text { in } \\
\text { remission) } \\
\mathrm{HC}(\mathrm{n}=18)\end{array}$ & $\begin{array}{l}\text { sMRI } \\
\text {-decreased GM volumes in frontal cortex and anterior midcingulate cortex relative to controls } \\
\text {-disease duration negatively correlated with GM volumes in various regions (left precentral gyrus, bilateral middle and superior } \\
\text { frontal gyrus, sACC, pMCC, PCC, parahippocampal gyrus, right superior temporal gyrus, left inferior temporal gyrus) }\end{array}$ & (141) \\
\hline $\begin{array}{l}\text { IBS }(n=11) \\
\text { UC }(n=16) \\
\text { HC }(n=41)\end{array}$ & $\begin{array}{l}\text { MRI } \\
\text {-patients with UC had greater cortical thickness in the ACC, MCC, and somatosensory cortex; lower cortical thickness in } \\
\text { orbitofrontal cortex, mid, and posterior insula compared to IBS and HC } \\
\text {-IBS patients had lower cortical thickness in anterior insula vs HC } \\
\text {-among UC patients lower CT orbitofrontal cortex, mid and posterior insula relative to HC } \\
\text {-correlation between symptom duration and thickness of orbitofrontal cortex and post central gyrus in UC patients }\end{array}$ & (142) \\
\hline
\end{tabular}




\begin{tabular}{|c|c|c|}
\hline $\begin{array}{l}\text { Dyspepsia } \\
\quad(n=40) \\
H C(n=20)\end{array}$ & $\begin{array}{l}\text { fMRI } \\
\text {-increased ReHo values in the ACC left orbital-frontal gyrus, left fusiform gyrus, right superior parietal gyrus; decreases in left } \\
\text { hescel gyrus, left supplementary motor area, right thalamus } \\
\text {-ReHo significantly correlated with dyspepsia symptoms score in the ACC (positive) and thalamus (negative) }\end{array}$ & (143) \\
\hline $\begin{array}{l}\text { IBD }(n=18) \\
\text { HC }(n=20)\end{array}$ & $\begin{array}{c}\text { MRI } \\
\text {-GM volume in patients with IBD decreased in the fusiform, inferior temporal gyrus, precentral gyrus, SMA, middle frontal gyrus, } \\
\text { superior parietal gyrus } \\
\text {-decreased axial diffusivity (AD) in corticospinal trant and superior longitudinal fasciculus relative to controls } \\
\text {-more white matter hyperintensities in patients with IBD (66.6\%) than controls }(45 \%) \text {. } \\
\text {-large }\end{array}$ & (144) \\
\hline \multirow[t]{2}{*}{$\begin{array}{l}\mathrm{CD}(\mathrm{n}=45) \\
\mathrm{HC}(\mathrm{n}=33)\end{array}$} & $\begin{array}{l}\text { MRI } \\
\text {-increased GM volume in PAG, putamen, left pallidum, HIPP, thalamus, precuneus, PPC, right amygdala, and cerebellum of CD } \\
\text { patients relative to controls } \\
\text {-decreased GM volume in bilateral ACC, SMA, insula, postcentral gyrus, precentral gyrus, superior frontal cortex, dmPFC, middle } \\
\text { frontal cortex, superior temporal cortex, right MCC, left middle OFC, inferior frontal cortex, middle temporal cortex, inferior } \\
\text { temporal cortex, inferior parietal cortex of patients with CD relative to controls } \\
\text {-CT of OFC, superior frontal cortex, inferior parietal cortex, superior temporal cortex, left insula, rACC, caudal middle frontal } \\
\text { cortex, pars triangularis, postcentral gyrus, middle temporal cortex, paraHIPP, right PCC, precentral gyrus, fusiform gyrus } \\
\text { reduced in CD versus controls } \\
\text {-GM volumes of rACC, dmPFC, and left insula, and CT of left insula and orbitofrontal cortex negatively correlated with CD } \\
\text { disease duration }\end{array}$ & (145) \\
\hline & & (120) \\
\hline $\begin{array}{l}\text { IBS }(n=21) \\
\text { HC }(n=21)\end{array}$ & $\begin{array}{l}\text { Rs-fMRI } \\
\text {-Reduced ALFF in the left superior frontal gyrus, right hippocampus, right middle frontal gyrus, bilateral postcentral right } \\
\text { superior temporal pole in patients with IBS relative to controls } \\
\text {-Increased ALFF in left media cingulate and left calcarine in patients with IBS relative to controls } \\
\text {-significant correlation between } \\
\text {-increased functional connectivity between cingulate and frontal cortex }\end{array}$ & (121) \\
\hline $\begin{array}{l}\mathrm{CD}(\mathrm{n}=52) \\
\mathrm{HC}(\mathrm{n}=36)\end{array}$ & $\begin{array}{l}\text { Rs-fMRI } \\
\text {-ReHo values higher in bilateral ACC, superior frontal medial cortex, middle frontal cortex, superior temporal pole, precuneus, } \\
\text { right superior frontal cortex, inferior temporal cortex, angular gyrus, left middle temporal cortex, superior parietal cortex, middle } \\
\text { occipital cortex relative to controls }\end{array}$ & (146) \\
\hline
\end{tabular}




\begin{tabular}{|c|c|c|}
\hline & $\begin{array}{l}\text {-ReHo values lower in bilateral thalamus, insula, MCC, PCC, lingual gyrus, cerebellum, PAG, brainstem HPC, SMA postcentral } \\
\text { gyrus, inferior frontal operculum cortex, right amygdala, and superior temporal cortex relative to controls }\end{array}$ & \\
\hline $\begin{array}{l}\text { IBS and IBD } \\
(\mathrm{n}=20 \text { young } \\
\text { adults) } \\
\text { HC }(\mathrm{n}=10 \\
\text { from } \\
\text { different } \\
\text { study })\end{array}$ & $\begin{array}{l}\text {-increased activity of ACC and anterior insula in patients with IBS relative to controls, and increased ACC, thalamus and right } \\
\text { anterior insula activation relative to IBD group during anticipation of heat pain } \\
\text {-reduced activation of cerebellum, right IPL, and higher activation of left medial frontal gyrus versus IBD during heat pain } \\
\text { condition } \\
\text {-reduced activation in STG, left cerebellum, left lentiform nucleus, right PCC right dIPFC versus control during heat pain } \\
\text { condition } \\
\text {-higher activation of right IPL and reduced activation of PCC and vmPFC in patients with IBD versus controls during heat pain } \\
\text { condition }\end{array}$ & (72) \\
\hline $\begin{array}{l}\text { IBS }(n=30) \\
\text { HC }(n=31)\end{array}$ & $\begin{array}{c}\text { Rs-fMRI } \\
\text {-reduced ALFF in MPFC, PCC, bilateral IPC, middle frontal cortex, ORBsup, dACC, vACC in IBS versus HC } \\
\text {-increased ALFF in bilateral insula and cuneus in IBS versus HC } \\
\text {-decreased positive FC between MPFC and right ROBsup, vACC and PCC, decreased negative FC between MPFC and left } \\
\text { posterior insula in IBS versus HC } \\
\text {-increased negative FC between MPFC and cuneus in IBS versus HC }\end{array}$ & (147) \\
\hline & & (148) \\
\hline $\begin{array}{l}\mathrm{CD}(\mathrm{n}=9 \text { in } \\
\text { remission }) \\
\mathrm{HC}(\mathrm{n}=9)\end{array}$ & $\begin{array}{l}\text { fMRI } \\
\text {-significant increase of activation in cingulate cortex, amygdala, and thalamus, and an increasing trend of activation in the } \\
\text { hippocampus, PFC and somatosensory cortex--regions of the brain associated with sensory, cognitive, and emotional aspects of } \\
\text { pain and threat appraisal }\end{array}$ & (149) \\
\hline $\begin{array}{l}\mathrm{CD}(\mathrm{n}=15, \text { in } \\
\text { remission, } \\
\text { subgrouped } \\
\text { according to } \\
\quad \text { EIM) } \\
\mathrm{HC}(\mathrm{n}=15)\end{array}$ & $\begin{array}{c}\text { MRI } \\
\text {-no differences in cortical thickness between } \mathrm{CD} \text { and } \mathrm{HC} \text {, or } \mathrm{CD} \text { wityh EIM and } \mathrm{CD} \text { without EIM (extraintestinal manifestations) } \\
\text {-no differences in cortical folding or surface area between patietns with } \mathrm{CD} \text { and HC } \\
\text {-patients with CD and EIM had more surface area in left rostral middle frontal gyrus, and more gyrification in the left lingual } \\
\text { gyrus relative to HC } \\
\text {-CD with EIM had hypogyrification in the right insular cortex, and hypergyrification of the right rostral ACC compared to CD } \\
\text { without EIM }\end{array}$ & (150) \\
\hline
\end{tabular}




\begin{tabular}{|c|c|c|}
\hline $\begin{array}{l}\mathrm{CD}(\mathrm{n}=21 \\
\text { with } \\
\text { abdominal } \\
\text { pain, } \mathrm{n}=26 \\
\text { without } \\
\text { abdominal } \\
\text { pain) } \\
\mathrm{HC}(\mathrm{n}=30)\end{array}$ & $\begin{array}{c}\text { MRI } \\
\text {-Patients with CD with abdominal pain had lower GM volume in the ACC and insula relative to patients without abdominal pain } \\
\text { and controls } \\
\text {-GM volume of ACC and insula significantly negatively correlated with daily pain scores among patients with CD with } \\
\text { abdominal pain } \\
\text {-patients without abdominal pain had greater GM volumes in hippocampal and parahippocampal cortex relative to patients with } \\
\text { pain and controls }\end{array}$ & $(151)$ \\
\hline $\begin{array}{l}\text { IBS }(\mathrm{n}=20 ; 10 \\
\text { IBS-D, } 10 \\
\text { IBS-C) } \\
\text { HC }(n=20)\end{array}$ & $\begin{array}{l}\text { fMRI } \\
\text {-Patients with IBS had greater activation in insula, middle temporal gyrus, cverebellum than HC during rectal distention } \\
\text {-HC, but not patients with IBS, had activation in precuneus, superior parietal lobules } \\
\text {-IBS-C subgroup had activation of mid-cingulate cortex, whereas in the IBS-D subgroup the inferior orbito-frontal cortex, } \\
\text { calcarine, and fusiform gyri were activated during rectal distention }\end{array}$ & $(152)$ \\
\hline $\begin{array}{l}\text { IBS }(n=28) \\
\text { HC }(n=34)\end{array}$ & $\begin{array}{c}\text { fMRI } \\
\text {-Healthy controls, but not patients with IBS, displayed negative association between ACTH response to CRH and pregenual ACC } \\
\text { activity in response to rectal distention }\end{array}$ & $(128)$ \\
\hline \multirow[t]{2}{*}{$\begin{array}{l}\text { IBS }(n=19,13 \\
\text { females) } \\
\text { HC ( }(n=26)\end{array}$} & $\begin{array}{c}\text { Rs-fMRI } \\
\text {-no differences in GM volume } \\
\text {-positive correlation between Self Awareness Questionnaire (SAQ) and FC between left ventral anterior insular cortex and } \\
\text { supramarginal gyrus bilaterally } \\
\text {-negative correlation between Illness Attitude Scale (IAS) score and connectivity between PCC, and left supramarginal gyrus and } \\
\text { superior temporal gyrus }\end{array}$ & $(153)$ \\
\hline & TMS & $(154)$ \\
\hline $\begin{array}{l}\mathrm{CD}(\mathrm{n}=15 \text { in } \\
\text { remission }) \\
\mathrm{HC}(\mathrm{n}=14)\end{array}$ & $\begin{array}{c}\text { rs-fMRI } \\
\text {-increased connectivity in ACC and left superior medial frontal gyrus, and middle cingulate cortex } \\
\text {-significant association between middle cingulate activity and anxiety scores }\end{array}$ & $(155)$ \\
\hline $\begin{array}{l}\text { IBS }(n=31) \\
\text { HC }(n=20)\end{array}$ & $\begin{array}{l}\text { fMRI } \\
\text {-strongest activation in patietns with IBS in the parietal region, PFC, cerebellum; activation of occipital lobe, temporal lobe, ACC, } \\
\text { IC, THAL increased as rectal distention increased }\end{array}$ & (156) \\
\hline $\begin{array}{l}\mathrm{CD}(\mathrm{n}=60 \\
\text { remission) } \\
\mathrm{HC}(\mathrm{n}=40)\end{array}$ & $\begin{array}{c}\text { rs-fMRI } \\
\text {-higher ALFF values in the bilateral hippocampus and parahippocampus, left ACC, right insula, and superior frontal cortex } \\
\text { relative to controls }\end{array}$ & $(157)$ \\
\hline
\end{tabular}


-lower ALFF in right secondary somatosensory cortex, precentral gyrus, left medial PFC compared to controls

-functional connectivity was lower in patients with CD between left hippocampus and left inferior temporal cortex, right MCC,

hippocampus, and fusiform; right hippocampus had lower FC with right inferior orbitofrontal cortex and left hippocampus than controls

\begin{tabular}{|c|c|c|}
\hline & $\begin{array}{l}\text {-lower ALFF in right secondary somatosensory cortex, precentral gyrus, left medial PFC compared to controls } \\
\text {-functional connectivity was lower in patients with CD between left hippocampus and left inferior temporal cortex, right MCC, } \\
\text { hippocampus, and fusiform; right hippocampus had lower FC with right inferior orbitofrontal cortex and left hippocampus than } \\
\text { controls }\end{array}$ & \\
\hline $\begin{array}{c}\mathrm{CD}(\mathrm{n}=16 \\
\text { with } \\
\text { abdominal } \\
\text { pain, } 13 \\
\text { without } \\
\text { abdominal } \\
\text { pain) } \\
\mathrm{HC}(\mathrm{n}=20)\end{array}$ & $\begin{array}{l}\text { MRS } \\
\text {-CD patients with abdominal pain have higher Glu/tCr that CD patients without abdominal pain and HC, in the bilateral ACC } \\
\text {-Glu/tCr levels positively correlated with pain (categorized by VAS) }\end{array}$ & (158) \\
\hline $\begin{array}{l}\mathrm{CD}(\mathrm{n}=18) \\
\mathrm{HC}(\mathrm{n}=18)\end{array}$ & $\begin{array}{l}\text { Rs MRI } \\
\text {-increased resting state functional connectivity between middle frontal gyrus and inferior parietal lobe in the executive control } \\
\text { network and between precuneus and posterior cingulate cortex in the default mode network }\end{array}$ & (138) \\
\hline $\begin{array}{l}\mathrm{CD}(\mathrm{n}=30) \\
\mathrm{HC}(\mathrm{n}=30)\end{array}$ & $\begin{array}{l}\text { MRI } \\
\text {-global transivity (measure/function of network density) reduced in patients with CD versus controls } \\
\text {-reduced betweenness centrality in insule and cuneus, and the superior frontal cortex, and reduced nodal degree within the } \\
\text { cingulum, lateral orbitofrontal, and medial orbitofrontal relative to controls }\end{array}$ & (139) \\
\hline $\begin{array}{c}\text { Newly } \\
\text { diagnosed } \\
\text { CeD not on a } \\
\text { GFD (n=20 - } \\
\text { Patients with } \\
\text { CeD on a } \\
\text { GFD for } \\
\text { about } 16 \\
\text { months } \\
(n=20) \\
\text { HC }(n=20) \\
\end{array}$ & $\begin{array}{l}\text { TMS } \\
\text {-Adoption of a GFD restored motor cortex excitability and cortical silent period among CeD patients to a level similar to controls } \\
\text {-relative to controls, patients displayed decreased average short-latency intra-cortical inhibition and enhancement of intra-cortical } \\
\text { facilitation }\end{array}$ & (154) \\
\hline $\begin{array}{l}\mathrm{CeD}(\mathrm{n}=33) \\
\mathrm{HC}(\mathrm{n}=33)\end{array}$ & $\begin{array}{l}\text { MRI } \\
\text {-patients with CeD had less cerebellar volume, and less grey matter density in multiple areas of the brain (superior cerebellar } \\
\text { hemispheres, and supratentorial cortical and subcortical regions) relative to controls }\end{array}$ & (159) \\
\hline
\end{tabular}




\begin{tabular}{|c|c|c|}
\hline $\begin{array}{l}\text { CeD }(\mathrm{n}=17 \\
\text { females on } \\
\text { GFD without } \\
\text { neurological } \\
\text { involvement) } \\
\text { HC ( } \mathrm{n}=17,13 \\
\text { females) }\end{array}$ & $\begin{array}{l}\text {-reduced GM volume in cerebral cortex, caudate nucleus relative to controls } \\
\text {-more white matter hyperintensities in frontal, parietal-occipital lobes and basal ganglia }\end{array}$ & (160) \\
\hline $\begin{array}{r}(\mathrm{FD}) \\
30 \mathrm{FD} \\
30 \mathrm{HC}\end{array}$ & $\begin{array}{c}\text { Resting State fMRI / ReHo Analysis. } \\
\text {-The study included a self-rating for both depression and anxiety. } \\
\text { - Differences included the dorsomedial prefrontal cortex (dmPFC), left ventromedial prefrontal cortex (vmPFC), left orbitofrontal } \\
\text { cortex (OFC), right supplementary motor area (SMA), right temporal pole (TP), bilateral insula, right pregenual ACC (pACC), left } \\
\text { subgenual ACC (sACC), right MCC, left thalamus, left HIPP/ParaHIPP and right cerebellum. } \\
\text { ReHo } \\
\text {-Increased ReHo value when compared with the disease index (Severity of disease) in the ACC }\end{array}$ & (161) \\
\hline
\end{tabular}

\begin{tabular}{|c|c|c|}
\hline $\begin{array}{c}\text { FD PDS } \\
\text { FD post- } \\
\text { prandial } \\
\text { distress } \\
\text { syndrome. } \\
18 \text { FD-PDS } \\
18 \text { HC } \\
\text { All female }\end{array}$ & $\begin{array}{l}\text {-Magnetic Resonance Spectroscopy } \\
\text { Anxiety and Depressive Scores correlated strongly with severity of disease } \\
\text { Increased Glutamate in the somatosensory cortex in FD patients. } \\
\text { Increased glutamate in the somatosensory cortex also correlated with severity of disease / chronicity of disease. }\end{array}$ & (162) \\
\hline $\begin{array}{l}\mathrm{FD} \\
\mathrm{FD}=24 \\
\mathrm{HC}=20\end{array}$ & $\begin{array}{c}\text { Mucosal electrical impedance (MI) } \\
\text { The duodenal MI of FD group was significantly lower than the HC group. } \\
\text { The expression of zonula occludens was significantly lower in the FD group. } \\
\text { Increased IL-1 } \beta \text { was higher in the FD group. }\end{array}$ & (10) \\
\hline $\begin{array}{l}\mathrm{FD} \\
\mathrm{Fd}=12 \\
\mathrm{HC}=12\end{array}$ & $\begin{array}{c}\text { PET } \\
\text { Increased } \mathrm{CB}_{1} \text { receptor density in FD patients in the following brain areas: Brainstem, } \mathrm{ACC} \text {, and insula. }\end{array}$ & (163) \\
\hline $\mathrm{FD}(\mathrm{n}=40)$ & PET & (164) \\
\hline
\end{tabular}


HC $(n=20) \quad$ Increased glycometabolism in insula, ACC, MCC, cerebellum, PFC, precentral gyrus, postcentral gyrus, middle temporal gyrus, superior temporal gyrus, putamen, parahippocampal gyrus, claustrum, precuneus of the resting brain of patients with FD relative

to $\mathrm{HC}$

-hypermetabolism in the ACC, insula, thalamus, MCC and cerebellum correlated with symptom severity of FD

PET + efficacy of acupuncture treatment in 2 different acupuncture regions.

FD

$\mathrm{FD}=20$

(divided into

2 groups)

FD

$\mathrm{FD}=100$

All of the patients, no matter the location of acupuncture, reported an increase in the quality of life and had a decrease in symptoms related to dyspepsia.

Decreased glycometabolism in the brainstem, ACC, superior frontal temporal gyrus, thalamus. (These were the areas consistent between the 2 different groups)

Also, an increase in cerebral glucometabolism in the middle cingulate cortex.

$$
\text { fMRI }
$$

Patients with FD showed increased functional connectivity in the BLA (basolateral amygdala) and the bilateral supplementary motor cortex (SMC)/middle cingulate cortex, central/parietal operculum, left precentral gyrus (PrG), post- central gyrus (PoG),

supramarginal gyrus (SMG), right anterior insula (INS), planum temporale (PT), and superior temporal gyrus (STG)

Also, decreased functional connectivity was reported in multiple areas.

Sexual Differences accounted for different brain functional connectivity in some brain regions.

FD
FD $=43 \quad$ Descriptive observational study analysing the cognitive emotion regulation strategies of individuals
$\mathrm{HC}=43 \quad$ This had no information about brain areas or connectivity.

$\mathrm{FD}$
$\mathrm{FD}=15$
$\mathrm{HC}=17$

FD

$\mathrm{N}=$ ? Could

not get full

access.
FD $(n=25)$

$\mathrm{HC}(\mathrm{n}=25)$
Attentional and physiological processing of food.

After fasting, FD patients ate significantly less fat, carbs, and protein than the HC group. Pleasantness ratings of food images was significantly less than the HC group.

Biopsy of duodenal ganglion, indication neural and structural changes in these ganglion.

Decreased neural functioning in FD patients. (decreased calcium responses to depolarization and electrical stimulation)

Eosinophils and mast cells infiltrated the mucous layer to a much larger extent in FD patients.

Also different ganglionic architecture and neural abnormalities.

-higher clustering coefficient relative to $\mathrm{HC}$

-higher local efficiency relative to $\mathrm{HC}$, (suggests reduced information transfer, as path lengths remained similar) -nodal centralities in the FD group were observed in the OFC, ACG, and HPC 
-nodal centralities in ACG positively correlates with symptom severity -decrease in nodal centralities in the PCG, putamen, cuneus, MOG, and IOG (168)

PET

FD $(n=40) \quad$-patients with FC displayed increased glucose metabolism in insula, ACC, MCC, midFC relative to controls; among FD patients,

$\mathrm{HC}(\mathrm{n}=20)$

greater metabolism when comorbid with anxiety and depression

MRI

$\mathrm{FD}(\mathrm{n}=69)$

$\mathrm{HC}(\mathrm{n}=49)$

-reduced CT in dIPFC, vlPFC, mPFC, aCC, PCC, insula, SPC, supramarginal gyrus, lingual gyrus in patients with FD relative to $\mathrm{HC}$

-negative correlations between symptom severity and CT in the MPFC, Sii, ACC, and paraHIPP

-negative correlation between disease duration and CT in the vlPFC, SI, and insula

ACC, anterior cingulate cortex; CT, cortical thickness; FD, functional dyspepsia; MRI, magnetic resonance imaging; PET, xxx; 


\subsection{GIDD drive functional, structural, and connective changes in the Anterior Cingulate Cortex}

The ACC is predominantly activated in situations with a strong affective component - either appetitive (e.g. food) or aversive (e.g. visceral pain) (171). The ACC also plays a key role in integrating the way that emotional and attentional processes impact pain perception (172). Moreover, the ACC activates in anticipation of affective outcomes, or even by imagining them. This is consistent with its key role in 'prospection', which is the ability to shift thoughts to different places and times (173). It also plays a role in arousal and sympathetic activation (fight or flight)(174). Hence, the ACC is ideally suited to use associations between stimuli and affective outcomes to promote activation of sympathetic or 'executive' systems to guide behavior in anticipation of potential future outcomes. This computation can be engaged by pain-related cues, anticipation of pain, or simply thinking about pain, and is dependent on psychological factors (emotional state, attentional processes). This is especially relevant to GIDD, which are characterized by sudden acute onset of symptoms, and flare-ups that are often unpredictable and uncontrollable. This leads to anticipatory anxiety, stress, and psychological distress during both flares, and periods of quiescence $(175,176)$, and contribute to the enhanced perception of pain $(177,178)$. Indeed, neuroimaging studies reveal increased activity in the ACC of patients with GIDD both during painful stimuli, and during the anticipation of painful stimuli (179).

\section{GIDD is associated with increased Anterior Cingulate Cortex activity}

Quantitative meta-analyses of studies using a variety of rectal distention paradigms revealed that activation of the ACC was among the most consistent differences between patients with IBS and healthy controls (180). Disparate observations from earlier studies $(92,99,103)$ likely resulted from less sensitive methods and study designs (180). Less attention has been paid to ACC activity during rectal distention in patients with $\mathrm{IBD}, \mathrm{CeD}$, and $\mathrm{FD}$. One small study reported reduced ACC activity among patients with IBD relative to controls during non-painful and painful rectal distention (96); however, both patients with IBD-ulcerative colitis and IBD-Crohn's were considered as a single group in this study, and more recent evidence suggests differences in rectal sensitivity between these groups. Interestingly, enhanced ACC activity in response to non-visceral stimuli has been demonstrated in patients with IBS relative to controls, including auditory stimuli $(103,181,182)$ and cutaneous heat application (100). This suggests that GIDD-related changes in ACC function generalize to other sensory domains, and support the overall hypothesis that the ACC is involved in perceptions and emotion synthesized as a 'gestalt' from all modalities.

\section{GIDD are associated with an increase in ACC metabolism}

Consistent with the functional MRI data summarized above, analysis of metabolites also reveals hyperactivity in the ACC as a consequence of gut dysfunction and pain. Patients with IBD-Crohn's with abdominal pain had significantly greater levels of glutamate, the primary excitatory neurotransmitter in mammalian brains, in ACC than patients with IBD-Crohn's without abdominal pain, and healthy controls (158). Further, levels of glutamine and glutamate metabolites were positively correlated with pain scores among patients with IBD-Crohn's experiencing pain (158). Levels of GABA, the main inhibitory neurotransmitter in the CNS, were reduced in the ACC of patients with IBD-Crohn's relative to healthy controls. These data indicate increased activity of the primary excitatory neurons in the ACC, without a compensatory increase in the inhibitory neurons that normally regulate their overall firing rates (183). A similar pattern has been reported in depression. Reduced GABA (184) and increased glucose and lactate levels (markers of neural metabolism) are observed in the ACC of patients with depression (185). Several studies report higher levels of glucose metabolism in the ACC in patients with FD relative to controls, with positive correlations between hypermetabolism in the ACC and symptom severity (164), and this relationship is greatest when FD is comorbid with anxiety and/or depression (169). 


\section{GIDD are associated with structural changes in the ACC}

The structure of the ACC often changes in mood disorders. Two common metrics are cortical thickness (CT) and gray matter (GM) density, which are affected by the size of neuron cell bodies, the density of neurons, dendrites, and synapses (186). Although functional measures indicate excessive activity of ACC in mood disorders, structural assays typically show reduction of CT and GM, suggesting loss of neurons, or their processes; human studies the support the latter (187). This pattern appears to generally hold in GIDD. Several reports indicate reduced CT in GIDD, including in FD (170) and IBD-Crohn's (145). Evidence in other GIDD is mixed. For instance, a study of IBS revealed similar levels of ACC cortical thickness, but increased GM density, relative to healthy controls (114). These data suggest that additional factors play a role in structural changes in ACC, and the variance of these factors among specific GIDD may explain the inconsistency of structural changes detected by MRI. Indeed, the relationship between ACC structure and mental function becomes more consistent across specific GIDD when factors such as pain are taken into account.

Several studies highlight a relationship between structural changes in the ACC, GI symptom severity, and disease duration. For example, patients with IBD-Crohn's and FD had a negative correlation between CT of the ACC and symptom severity and disease duration (170). Gray matter volume in the ACC of patients with IBD-Crohn's (in remission) was negatively correlated with disease duration $(141,145)$. When subjects with IBD-Crohn's were analyzed as subgroups with and without the presence of abdominal pain, those with abdominal pain had reduced GM in the ACC compared to those without abdominal pain, and the GM volume of the ACC was negatively correlated with daily pain scores among IBD-Crohn's subjects (151). These results suggest that reduced GM volume of the ACC is associated with chronic pain, a finding supported by studies on other diseases characterized by chronic pain including osteoarthritis (188), neuropathic pain (189), and fibromyalgia (190).

Structural changes in the ACC are observed in other inflammatory diseases, such as diabetes (191). This appears to be driven by inflammatory signaling, as markers of immunometabolic dysfunction (IL-6, TNF $\alpha, \mathrm{CRP}$, and triglyceride levels) were correlated with rostral ACC (but not HPC, amygdala, or caudal ACC) thinning (192). Furthermore, depression is now considered to be primarily an inflammatory disease: inflammatory markers increase the risk of depression and antiinflammatories possess anti-depressive properties (193). Recent meta-analysis revealed that reduced GM volume of the ACC is observed in patients with Major Depressive Disorder and Bipolar Disorder, relative to healthy controls (194).

These data suggest that chronic inflammation helps drive atrophy of neurons or their processes in the ACC, which then promotes depression/anxiety. In GIDD, pain appears to be an additional factor promoting ACC shrinkage. The combination of these factors, pain and inflammation, may contribute to the high prevalence of mood disorders in GIDD.

\section{GIDD is associated with altered connectivity of the ACC}

There is no question that GIDD are associated with dysregulation of neural pathways (Table 2, Figure 2), with the ACC emerging as a key region impacted by GIDD. Several key questions emerge: how does the structure and/or physiology of ACC become altered in GIDD, and how does this impact information encoding? How do functional and structural changes of the ACC impact larger-scale neural networks? This is particularly important to understand mental dysfunction in GIDD because ACC function is foundational for many of the predominant mental alterations: anxiety, depression, negative rumination, attention, threat assessment, and pain processing. Of course, the ACC does not do this in insolation, but it part of larger brain networks. It is therefore important to critically evaluate evidence of 'functional connectivity' between ACC and other regions, which quantifies the relative amount of co-activation among distinct brain regions.

Increased functional connectivity between the ACC and a variety of different regions has been observed in patients with IBS (123, 147), IBD-Crohn's (155), and IBD-ulcerative colitis (37). Elucidating the relevance of changes in functional connectivity of the ACC and other regions of the 
brain is challenging because it depends on behavior and brain state. For example, increased functional connectivity was observed between the ACC, and the left superior medial frontal gyrus and MCC in patients with IBD-Crohn's. These regions are associated with emotional regulation and self-referential processing, which reflects the altered affective regulation and increased selfmonitoring (e.g. awareness of visceral symptoms, rumination) observed in patients with IBD (155). Further, it is well recognized that affective state plays a key role in the perception of pain (195). The increased functional connectivity between pgACC and thalamus, the posterior insula, and the amygdala in patients with hypersensitive IBS (who experience more pain than in normosensitive IBS), and reduced functional connectivity between pgACC and dorsal anterior insula relative to patients with normosensitive IBS (131) highlights the role these structures play in integrating the perception of pain. Decreased positive functional connectivity between the ventral region of the ACC and PCC in patients with IBS versus healthy controls suggest altered affective (e.g. emotional regulation) and cognitive processing (147). Conversely, increased functional connectivity between the ACC and hippocampal formation was observed in patients with IBD-colitis relative to controls, and was found to be negatively correlated with performance on a task measuring executive function, working memory, and attention (37). Combined these studies highlight several emergent properties that accompany altered functional connectivity with the ACC, namely affective processing, negative rumination, heightened perception of pain, and cognitive deficits (executive function).

\section{Conclusion}

Despite their idiosyncratic nature, similar mental comorbidities such as anxiety, depression, hyperalgesia, and cognitive impairment emerge in patients with GIDD. This suggests the involvement of common neural structures or pathways. The diversity of methodologies and subject groups employed in clinical studies pose a significant challenge in identifying unifying neural features of GIDD. However, our examination of the literature has led us to identify the ACC as a significant region of interest. Structural, functional, and connective changes in the ACC emerge in patients with GIDD relative to healthy controls. Increased activity and reduced cortical thickness of the ACC are the most prominent neural modifications (Figure 2). This suggests that the ACC may be particularly sensitive to disruption of the gut-brain axis. Further, hyperactivity in this structure is associated with chronic pain, anxiety, and major depressive disorder-common co-morbidities of GIDD. Thus, the involvement of this region may explain the high level of comorbidities in these gut diseases and disorders.

Many questions still remain: to what extent are observed neural changes the result of a particular aspect of gut pathology such as pain or inflammation? Are they mediated by similar neurological processes that drive depression and anxiety? Can they be reversed? Data from humans and animals (largely rodent) bear on these questions. Brain function in humans is largely restricted to behavioural testing and non-invasive imaging. This is important for identifying large-scale changes in the brain related to particular changes in function (depression, attention, etc.). Animal models allow us to address these questions using invasive methods, and therefore provide the basis of our present understanding the cellular/molecular mechanisms of gut-brain interactions. It is important to align data from both humans and animals to mechanistically understand the relationship of GIDD and altered brain function. Understanding how these neural changes come about (and why they evolved) is the domain of preclinical studies. Indeed, pre-clinical studies have identified mechanisms of peripherally-induced neuroinflammation, which have begun to elucidate the etiology of gut-brain dysfunction in GIDD.

\section{Preclinical Studies}

\subsection{Animal models of GIDD}

Many well-validated animal models have been developed to explore the etiology, mechanisms, pathology, symptoms and potential treatments for GIDD. It should be noted that no animal model 
fully recapitulates the complexity of GIDD in humans. However, animal models of GIDD exhibit changes to behaviour and the brain similar to that in humans. Although rodents lack the cognitive sophistication of humans, they do display reliable behaviours that share some fundamental components of human behavior (i.e. endophenotypes). Furthermore, they possess close homologues of many fundamental brain structures affected in GIDD, and are therefore an indispensable tool for understanding cellular/molecular changes in GIDD.

\subsection{Animal models of GIDD induce behavioral changes}

Several protocols have emerged to model specific GIDD. Chronic stress, colorectal distention, and colonic anaphylaxis are used to induce an IBS phenotype in rodents, which is characterized by visceral sensitivity, anxiety, and depressive-like behaviours, in addition to memory deficits and decision-making impairments (Table 3). Chemically-induced models of IBD are widely used due to their ease of induction, and high reproducibility. Oral exposure to the colitic agent dextran sodium sulfate (DSS) in the drinking water is frequently used to model ulcerative colitis in rodents. Because DSS-induced inflammation is self-resolving, multiple cycles of DSS exposure can be used to mirror the periods of active disease and remission that characterize ulcerative colitis in humans (196). The intra-rectal instillation of di/tri-nitrobenzene sulphonic acid (D/TNBS) generates an acute inflammation resembling Crohn's Disease in rodents that is similarly self-resolving (197). Other models employ the use of infectious agents like C. rodentium or T. suis, which colonize the intestinal tract and induce intestinal inflammation; they are also employed as a post-infectious model of IBS. Generally, these infectious and post-infectious models of GIDD reveal increased levels of anxiety, depressive-like behaviours, hyperalgesia, reduced locomotor activity, reduced grooming, reduced social interactions, impaired spatial and recognition memory, and altered responses to physiological stressors (Table 3).

These studies reveal that gut inflammation has an impact on a wide range of behaviours. More recently, studies have focused on identifying neural changes associated with GIDD. This fits with a wider body of work examining mechanisms of neuroinflammation, which has revealed a key role of glial cells, particularly microglia and astrocytes, in generating and sustaining inflammatory processes in the CNS. Although many of these studies examine the role of neuroinflammation in models of stroke or traumatic brain injury, evidence suggests that these treatments evoke similar processes as peripheral inflammation (198). We can therefore use these studies to infer processes likely to occur in GIDD.

\subsection{Mechanisms of neuroinflammation: glial cells}

Microglia are a tissue-resident population of immune cell in the brain that are exquisitely sensitive to perturbations in the CNS. These highly ramified cells use their motile processes to survey the extracellular environment in order to maintain brain homeostasis and enhance neuronal function (199). Emerging research paints microglia as neuronal sculptors: modulating neuronal wiring (200), eliminating and refining synaptic connections based on neuronal activity (201), and promoting learning-dependent formation of synapses (202)(see review by (203)). In addition to their extraordinarily important role in the healthy brain, microglia also serve as the first line of defense in the CNS (see review by (204)): in response to pathogens, damage signals, pro-inflammatory signals, or neuronal factors, microglia transition from surveillance mode, to a 'reactive' pro-inflammatory phenotype, characterized by retracted bushy processes, an enlarged soma, and the secretion of cytotoxic and inflammatory mediators including cytokines (e.g TNF- $\alpha$, IL-1 $\beta$, IL-6), chemokines, proteases (e.g., matrix metalloproteinase-9), nitric oxide, reactive oxygen species, and ATP (205).

Astrocytes are the most abundant glial cell type in the CNS; they perform a range of homeostatic functions including providing trophic support for neurons, driving the formation, function, and pruning of synapses, and formation and maintenance of the blood brain barrier via the astrocytic endfeet (206). (see review by (207)). Astrocytes also possess dynamic phenotypes: brain injury or disease (including trauma, ischemia, neurodegeneration, and infection) induce a response in 
astrocytes termed reactive astrogliosis, which can be characterized by a spectrum of dramatic changes in astrocyte morphology, increased expression of glial fibrillary astrocyte protein (GFAP), and an extensive shift in gene expression (208). Astrocytes further contribute to the neuroinflammatory landscape through their ability to regulate permeability of the blood brain barrier (BB. Interestingly, the reactive astroglial phenotype is dependent on the nature of the insult; while a core set of genetic changes emerge in astrocytes in response to different brain insults, there exists a clear phenotypic difference between "A1" reactive astrocytes induced by systemic LPS administration (a model of peripherally-induced neuroinflammation), and "A2" reactive astrocytes induced by ischemia (a model of stroke) (208). Using transgenic mice, it was revealed that activated microglia are a requirement for the development of $\mathrm{A} 1$ reactive astrocytes, through their secretion of the proinflammatory cytokines TNF-a, IL-1a, and C1q (209).

\subsection{Other players in neuroinflammation: mast cells, $T$ cells, monocytes}

It was formerly believed that the BBB restricted immune cells from entering the brain. However, the long-standing concept of the brain as an immuno-privileged organ has been revised. The recent discovery of the neural meningeal lymphatic system highlight a closer relationship between the brain and immune system than previously believed $(210,211)$. Other immune cells beyond microgliasuch as infiltrating monocytes, $\mathrm{T}$ cells, and mast cells-are important contributors to neuroinflammation processes. While outside the scope of this review, their potential role in driving neuroinflammatory events bears mentioning. Bone-marrow derived monocytes can be recruited into the brain from the circulatory system, where they augment the neuroinflammatory response. Once they breach the blood brain barrier and infiltrate neural tissue, these cells differentiate into macrophages (212). Because these monocytes and microglia stem from the same lineage of hematopoietic cells during development, these cells share several phenotypic (e.g. IBA1 expression) and functional (e.g anti and pro-inflammatory profiles) features with microglia (212). For these reasons, determining the relative roles of tissue-resident microglia and infiltrating monocytes has been a challenge.

Multiple populations of $\mathrm{T}$ cells, including effector $\mathrm{CD} 4^{+} \mathrm{T}$ cells (e.g. TH1, Th17), regulatory $\mathrm{T}$ cells, and CD8 ${ }^{+} \mathrm{T}$ cells have been identified in the brain under homeostatic (213) and in diseasespecific conditions $(214)(164,215,216)$. Mast cells are an innate immune cell characterized by the presence of intracellular granules that contain chemical mediators of inflammatory responses (217). They are most commonly associated with tissues lining the airways and gastrointestinal tract and best known for their role in allergic responses, although their location has been confirmed in the CNS - specifically the area postrema, choroid plexus, and parenchyma of the hypothalamic region (218). More specifically, these cells are associated with the abluminal side of blood vessels, where they can interact with glial cells and neurons. The overall number of mast cells in the brain in human brain is believed to be very small, although increased in response to infection (219). Some in vivo evidence suggests that neural mast cells may play an important role in neuroinflammation. Central administration of an agent that that prevents mast cell degranulation impaired peripheral LPSinduced sickness behaviours (motivation, locomotion, anxiety) in mice (220) and inhibited microglial activation and neuroinflammation in WT mice, but not mast cell deficient mice (221). These studies suggest a potentially important role of both innate and adaptive immune cells in driving neuroinflammatory responses.

\subsection{Resolution of neuroinflammation}

The dominant role glial cells play in regulating neuroinflammation extends to the resolution of inflammation, through their ability to shift towards anti-inflammatory/pro-resolution phenotypes. Anti-inflammatory mediators (e.g. cytokines TGF-b, IL-10) pro-resolving mediators (e.g. resolvins, prostaglandins, lipoxins) (222), and glucocorticoids (223) are all implicated in resolution processes. Anti-inflammatory microglia demonstrate neuroprotective properties via the production of antiinflammatory cytokines, restriction of neural damage, and promoting tissue repair $(224,225)$. Indeed, 
induction of microglia to anti-inflammatory phenotypes is being explored as a therapeutic intervention for stroke, traumatic brain injury, and neurodegenerative diseases (226-228). Temporal tracking studies of microglia indicate that microglia exist in heterogeneous states within the proinflammatory spectrum in mouse models of neurodegenerative diseases, with populations fluctuating as the disease state progresses (229). For example, microglia depletion, in which a colonystimulating factor 1 receptor (CSF1R) inhibitor is used to transiently deplete $95 \%$ of the microglial population (230), have been employed to assess the neurotoxic and neuroprotective roles of microglia in various contexts. Elimination of microglia attenuate the normal changes in pre- and post-synaptic markers, as well as reduced dendritic spine density induced by hippocampal lesions, whereas neuronal loss is enhanced (231). In a mouse model of cerebral ischemia/stroke, elimination of microglia exacerbated severity of brain injury, increased pro-inflammatory cytokine production, leukocyte infiltration, led to increased excitotoxicity, spreading depolarization, and neuronal cell death $(232,233)$. In mouse models of Alzheimer's Disease (AD), microglia form a protective barrier around $\beta$-amyloid plaques, which attenuates plaque expansion and axonal damage (234): however, elimination of microglia rescued dendritic spine loss, neuronal cell death, and led to improvements in contextual memory/fear conditioning (235). These data highlight the profound effect microglia exert on neural processes.

Astrocytes also possess pro-resolving capabilities. Inflammation-induced A1 astrocytes appear to possess cytotoxic properties; conversely, models of ischemia and spinal cord injury support a beneficial role of the 'A2' astrocyte phenotype, which promote neuronal survival, neuronal regeneration, and synaptic repair (236-239). It is believed that glial states of activation are not binary, but rather lie on a spectrum of polarization between pro-inflammatory/neurotoxic, and antiinflammatory/neuroprotective phenotypes. Thus, neuro-inflammatory events present with a dynamic spectrum of pro-inflammatory, anti-inflammatory, and intermediate phenotypes of microglia and astrocytes, with differential neuroprotective properties. In vitro and in vivo studies revealed IL-10, an anti-inflammatory cytokine, directs astrocytes to secrete TGF- $\beta$, which attenuated microglial IL- $\beta$ expression; inhibition of TGF- $\beta$ signaling in brain of mice challenged with LPS resulted in increased expression of pro-inflammatory cytokines, and prolonged sickness behaviour (240). Infiltrating monocytes have also been demonstrated to regulate microglial reactivity (241). Conversely, in certain contexts reactive microglia can drive neuroprotective astrocytes: via purinergic mechanisms, reactive microglia induced neuroprotective scar-forming astrocytes in a model of TBI (242).

These studies highlight the extreme plasticity of glial cells, and the key role they play in inflammation and resolution. Evidence presented below suggests at least some of these processes occur in response to gut inflammation.

\subsection{Animal models of GIDD drive neural changes}

Animal models of GIDD are associated with neuroinflammation, as evidenced by the induction of reactive phenotypes of glial cells, and increased expression of pro-inflammatory mediators in the CNS (Table 3). Increased neural expression of pro-inflammatory cytokines and enzymes and reactive glial phenotypes are reported in models of ulcerative colitis (243-249), Crohn's disease (250-253), and IBS $(254,255)$. Reports of reactive microglia and astrocytes are most commonly reported in the hippocampus. Other reported regions demonstrating gliosis include the entorhinal cortex in a model of $\mathrm{CD}-\mathrm{a}$ region which interfaces the hippocampus and neocortex and plays a role in memory and navigation (250), the median eminence in a model of UC - notable due to its role in the HPA axis, and its proximity to the blood brain barrier (246) and the ACC in a model of IBS (254).

The literature similarly reveals the hippocampus as a region with increased expression of inflammatory mediators (Table 3). Because reactive glial cells are a source of pro-inflammatory cytokines, this is not unexpected. These cytokines play an important role in modulating neuronal synapses (256), and pro-inflammatory cytokines are implicated in impairments in neuroplasticity (257). Indeed, reduced hippocampal spine density was reported in a model of IBS (258) and exposure 
to DSS impaired hippocampal neurogenesis (243). However, the presence of pro-inflammatory cytokines does not explicitly suggest reactive glial cells. For example, increased IL- $1 \beta$ mRNA in the hippocampus of mice exposed to DSS was not associated with reactive microglia, based on flow cytometry analysis (249) Further, DSS was associated with an increase in neutrophils and infiltrating monocytes - both of which are sources of inflammatory mediators - in the microcirculation within the PFC (249)

Our examination of the literature revealed reduced brain-derived neurotrophic factor (BDNF) levels as a commonly reported finding in the hippocampus in models of UC, CD, IBS, and infectioninduced intestinal inflammation (247) $(253,258-260)(261)$. BDNF is a key neurotrophic factor that plays a crucial role in neuronal survival, differentiation, and plasticity during development and into adulthood, influencing learning and memory processes. While BDNF has anti-depressant properties in the hippocampus and PFC (262), its expression in the ventral tegmental area-nucleus accumbens pathway plays an essential role in a model of depression (263). Evidence suggests peripheral proinflammatory cytokines can influence the expression of BDNF in the hippocampus (264), and hippocampal BDNF expression is modulated by gut microbiota $(265,266)$. This suggests that BDNF plays an important role in the gut-brain-microbiota axis, and may be an effective therapeutic target to combat the cognitive and psychiatric aspects of GIDD.

Although preclinical studies have focused on neural changes in the HPC, other regions are clearly affected. DSS-induced colitis is associated with altered permeability of the blood-brain barrier (244), which suggests that neuroinflammatory changes are likely more widespread than the literature indicates. The limitations of neuroimaging tools used in animal studies typically requires selecting a region of interest ex ante, which may favor the hippocampus. For example, sampling bias in favor of the hippocampus is evident in LPS-induced models of neuroinflammation (267), and thus future studies should explore the involvement of additional regions.

In addition to the inflammatory processes summarized above, models of GIDD also induce hyperactivity of neurons in some structures. Elevated expression of the immediate early gene c-Fos, used as a marker for neuronal activation, is reported in region(s) involved in pain processing (e.g. ACC, sensory neurons of the vagus, area postrema, thalamus, spinal cord etc.), stress responses (e.g. ACC, hypothalamus, amygdala), and learning and decision making (e.g. ACC, hippocampus) in various animal models of GIDD (Table 3). 
Table 3. Behavioural and neural changes in animal models of GIDD.

\begin{tabular}{|c|c|c|c|}
\hline Models of Ulcerative Colitis & Effect on Behaviour & Effect on Brain/CNS & Reference \\
\hline $\begin{array}{l}\text { DSS colitis ( } 1 \text { cycle) in C57Bl/6 } \\
\text { female mice }\end{array}$ & $\begin{array}{l}\text {-visceral hyperalgesia present } 49 \text { days post DSS } \\
\text { exposure (resolution of inflammation) }\end{array}$ & -increased c-fos expression in lamina $X$ of spinal cord & $(268)$ \\
\hline DSS ( 3 cycles) male mice & $\begin{array}{c}\text {-mice treated with B. longum displayed attenuated } \\
\text { anxiety, step down latency even faster than } \\
\text { controls } \\
\text {-B. longum didn't impact colitis inflammation } \\
\text {-anxiolytic effect of B. longum mediated by vagus } \\
\text { nerve }\end{array}$ & & $(269)$ \\
\hline $\begin{array}{l}\text { DSS (1 cycle) in WT, NPY KO, } \\
\text { PPY KO, and NPY/PPY DKO } \\
\text { male and female mice }\end{array}$ & $\begin{array}{c}\text {-Increased anxiety in male, not female mice (EPM) } \\
\text {-no effect on locomotion or anxiety in OFT } \\
\text {-depressive-like behaviours in female but not male } \\
\text { mice (FST) }\end{array}$ & $\begin{array}{c}\text {-NPY mediates severity of DSS colitis } \\
\text {-colitis-induced anxiety and depression-type } \\
\text { behaviours in a sex-dependent and NPY-dependent } \\
\text { manner }\end{array}$ & $(270)$ \\
\hline DSS ( 1 cycle) in C57Bl/6 mice & & $\begin{array}{c}\text {-DSS colitis inhibited stress-induced c-Fos expression } \\
\text { in CeA, CA1, ILC }\end{array}$ & $(271)$ \\
\hline $\begin{array}{l}\text { DSS ( } 1 \text { cycle) in C57Bl/ } 6 \text { male } \\
\text { mice (double check) }\end{array}$ & $\begin{array}{c}\text {-increased anxiety (Open field test) } \\
\text {-reduced social interaction behaviours } \\
\text {-DSS did not drive depressive-like behaviour } \\
\text { (TST) }\end{array}$ & $\begin{array}{c}\text { Reduced BDNF, NPY, and MR mRNA expression in } \\
\text { the hippocampus; increased COX-2 mRNA } \\
\text { expression in hypothalamus }\end{array}$ & (247); \\
\hline $\begin{array}{l}\text { DSS (1 cycle) in C } 57 \mathrm{Bl} / 6 \text { male } \\
\text { mice }\end{array}$ & $\begin{array}{l}\text {-increased mechanical and thermal } \\
\text { hyperalgesia/central sensitization relative to } \\
\text { controls } \\
\text {-no changes in short-term activity levels relative to } \\
\text { controls } \\
\text {-reduced locomotion and rearing behaviours post } \\
\text { spray test relative to controls }\end{array}$ & $\begin{array}{l}\text {-DSS-treated mice had increased expression of } \\
\text { phosphorylated MAPK in the spinal cord, and c-Fos } \\
\text { in the spinal cord, thalamus, hypothalamus, } \\
\text { amygdala, and PFC relative to controls }\end{array}$ & $(272)$ \\
\hline $\begin{array}{l}\text { DSS (1 cycle) in C57Bl/6 mice } \\
\text { (recovery phase) }\end{array}$ & $\begin{array}{l}\text {-mechanical and chemical-induced visceral } \\
\text { hypersensitivity } 5 \text { weeks post DSS exposure } \\
\text {-reduced distance travelling and climbing } \\
\text { behaviour (cage monitoring) during active }\end{array}$ & & (273) \\
\hline
\end{tabular}


disease, and recovery phase (5 weeks post DSS exposure)

DSS ( 1 cycle) C57Bl/6 male mice immobility than controls following psychological stressor (WAS) -increased levels of CXCl1 in the hypothalamus -increased levels of IL-6 in the hypothalamus, amygdala, and hippocampus, and CXCl1 in the hypothalamus and hippocampus of mice given a psychological stressor (WAS)

-altered expression of Npy, Npy1r, Crh, Crh1, Bdnf, $\mathrm{Nr} 3 \mathrm{C} 1$ mRNA in specific regions of the brain -increased expression of Iba1 (marker of microglia activation) in the hippocampus in acute, but not chronic colitis

-increased expression of protein kinase p21 in hippocampus during acute and chronic colitis -astrogliosis in hippocampus of chronic DSS-treated mice

-reduced expression of early progenitor cell markers in hippocampus of chronic DSS-treated mice
DSS (1 cycle) in C57Bl/6J male and female mice; disease and recovery phase -impaired memory (novel object recognition), anxiety (light box preference test) in disease phase, but not resolution phase of DSS-colitis; deficits attenuated by treatment with probiotics
-DSS treatment increased c-Fos expression in CA-1 region; restored by pre-treatment with probiotics
-Reduced BDNF mRNA in amygdala, increased BDNF in hypothalamus relative to controls -increased COX2 in the hippocampus and hypothalamus, reduced Cox-2 in amygdala -GFAP immunoreactivity increased in the hippocampus

Increased IBA1 immunoreactivity; increased IL-6, but not IL-1b or TNF-a in cortical tissue of DSS-treated DSS (1 cycle) to C57Bl/6 male
mice mice relative to controls 
-reduced tight junction protein (occludin and

claudin-5) mRNA in the hippocampus and cortex of

DSS-treated mice relative to controls; increased

cleaved caspase 3 (marker of apoptosis) mRNA in

cortex of DSS-treated mice relative to controls

DSS ( 1 cycle) in C57Bl/6 male
mice
DSS (1 cycle) in C57Bl/6J male
and female mice

DSS (1 cycle) in male Wistar rats,
during disease and
resolution/recovery phase

-increased markers of oxidative stress in the PFC and hippocampus

-increased anxiety and reduced locomotion in male and female mice (EPM, OFT)

-thermal and mechanism hypersensitivity in male

-increased CNS excitability (seizure onset time when exposed to KA seizing agent)

mice

-increased IL-6 and iNOS mRNA in the cerebral

-reduced locomotion and increased anxiety in active, but not recovery phase (open field test) -reduced sucrose consumption during active and recovery phase (sucrose preference test) -reduced marble burying in recovery phase -depression in recovery phase (FST) -increased anxiety in recovery phase (light/dark box, EPM)

cortex of rats during active disease and recovery phase

-increased iNOS, 3-NT, and IBA1 immunoreactivity in median eminence in active and recovery phase

-Increase in ventricular volume in active and recovery phase

-reduced T2 relaxation times in DSS-treated animals

in the cingulate, sensory, and motor cortices -increase in FosB immunoreactivity in DSS-treated mice

-increased volume, \# reactive microglia, reduced neurons in peri-lesion area $7 \mathrm{~d}$ after a stroke in DSStreated mice

DSS (4 cycles) in C57Bl/6 female mice

-reduced ratio of anti-inflammatory/proinflammatory microglia 3 and $7 \mathrm{~d}$ post stroke in DSS treated mice

-increased infiltration of gut-derived T-cells in meninges, and peripherally derived T cells in the peri-lesion area of DSS-treated mice 


\begin{tabular}{|c|c|c|c|}
\hline & & $\begin{array}{l}\text {-peripheral macrophage depletion suppressed T-cell } \\
\text { infiltration in the peri-lesion area }\end{array}$ & \\
\hline $\begin{array}{l}\text { DSS (1 cycle) in C57Bl/6 male } \\
\text { and female mice, at peak disease } \\
\text { and resolution of colitis }\end{array}$ & $\begin{array}{c}\text {-reduced latency to food interactions } \\
\text { (hyponeophagia) and reduced time spent } \\
\text { grooming } 2.5 \text { weeks post DSS exposure } \\
\text {-increased depressive-like behaviour (FST and } \\
\text { TST) during recovery phase } 3.5 \text { weeks post DSS } \\
\text { exposure }\end{array}$ & $\begin{array}{l}\text { Increased eIPSCs and lower eIPSC threshold in } \\
\text { pyramidal cells of the CA1 area of the hippocampus } \\
\text {-increased IL-1b mRNA in hippocampus } \\
\text {-increased trafficking of leukocytes in PFC }\end{array}$ & (249) \\
\hline $\begin{array}{l}\text { DSS (1 cycle) in male kunming } \\
\text { mice }\end{array}$ & -increased anxiety (EPM, OFT) & $\begin{array}{l}\text {-reduced protein expression of CRH in the } \\
\text { hypothalamus }\end{array}$ & $(278)$ \\
\hline Models of Crohn's Disease & Effect on Behaviour & Effect on Brain/CNS & Reference \\
\hline $\begin{array}{c}\text { TNBS colitis in Sprague-Dawley } \\
\text { rats }\end{array}$ & & $\begin{array}{c}\text {-increased mRNA of CRF in mPVN and SON of } \\
\text { TNBS-treated rats }\end{array}$ & $(279)$ \\
\hline $\begin{array}{l}\text { TNBS colitis in Sprague-Dawley } \\
\text { adult male rats }\end{array}$ & & $\begin{array}{l}\text { Increased c-fos expression in the CeA, thalamus, } \\
\text { habeluna, and PIR cortex of coltic rats }\end{array}$ & $(280)$ \\
\hline $\begin{array}{l}\text { TNBS ( } 1 \text { administration) in adult } \\
\text { male Sprague-Dawley rats }\end{array}$ & & $\begin{array}{c}\text {-rats with colitis had reduced threshold to PTZ- } \\
\text { induced seizures; positive correlation with seizure } \\
\text { susceptibility and severity of disease } \\
\text {-significant increase in microglial activation in the } \\
\text { CA1, CA3, EC (entorhinal cortex), and DG of rats } \\
\text { exposed to TNBS at peak of disease, but not upon } \\
\text { resolution of colitis } \\
\text {-increased level of TNF-a in hippocampus at peak } \\
\text { and resolution of TNBS colitis } \\
\text {-TNBS-induced seizure susceptibility dependent on } \\
\text { microglial activation and TNF-a }\end{array}$ & $(250)$ \\
\hline DNBS in male NMRI mice & $\begin{array}{c}\text {-impaired spatial memory (Y-maze); iNOS } \\
\text { dependent mechanism }\end{array}$ & & $(281)$ \\
\hline TNBS in male NMRI mice & $\begin{array}{l}\text { Increased mobility time (FST); partially dependent } \\
\text { on iNOS }\end{array}$ & $\begin{array}{c}\text {-increased expression of iNOS, nitrite, and TNF-a in } \\
\text { hippocampus }\end{array}$ & $(251)$ \\
\hline
\end{tabular}


-no changes in locomotor activity (OFT)

-no impairment in associative memory (step down

latency test)

\begin{tabular}{|c|c|c|c|}
\hline DNBS in male NMRI mice & $\begin{array}{l}\text {-increased immobility time in FST and TST } \\
\text {-reduced sucrose preference } \\
\text {-reduced grooming behaviour } \\
\text {-increased anxiety (HBT, EPM) }\end{array}$ & $\begin{array}{c}\text {-increased mRNA expression of inflammatory genes } \\
\text { in hippocampus (IL-6, Tnf-a, Tlr2, Tlr4, Myd88, } \\
\text { Hmgb1) and reduced BDNF } \\
\text {-evidence of mitochondrial changes in the } \\
\text { hippocampus: reduced GSH and ATP, and increased } \\
\text { nitrite and ROS production }\end{array}$ & (252) \\
\hline TNBS colitis in male ICR mice & $\begin{array}{l}\text {-impaired memory (Y-maze, passive avoidance } \\
\text { task); attenuated by oral administration of } \\
\text { Lactobacillus johnsonii }\end{array}$ & $\begin{array}{c}\text {-increased NFk-B activation and TNFa expression } \\
\text { hippocampus of TNBS-treated mice } \\
\text {-reduced BDNF in hippocampus of TNBS treated } \\
\text { mice } \\
\end{array}$ & (253) \\
\hline TNBS in C57Bl/6 male mice & $\begin{array}{l}\text { Memory impairment (Y-maze, novel object } \\
\text { recognition) }\end{array}$ & $\begin{array}{l}\text {-reduced BDNF protein expression and increased } \\
\text { NFkB expression in hippocampus; restored by oral } \\
\text { administration of lactobacillus pantarum }\end{array}$ & (259) \\
\hline $\begin{array}{c}\text { Models } \\
\text { Irritable Bowel } \\
\text { Syndrome/Visceral } \\
\text { Hypersensitivity } \\
\end{array}$ & Effect on Behaviour & Effect on Brain/CNS & Reference \\
\hline $\begin{array}{l}\text { Stress-induced visceral } \\
\text { hyperalgesia in Female Wistar } \\
\text { rats }\end{array}$ & & $\begin{array}{l}\text {-colorectal distention in VH rats drove increased c- } \\
\text { fos expression in sacral spinal cord, PVN, and MeA } \\
\text { relative to controls; effect abated by treatment with } \\
\text { Lactobacillus farciminis }\end{array}$ & $(282)$ \\
\hline $\begin{array}{l}\text { Male Sprague-Dawley (control) } \\
\text { and Wistar-Kyoto (predisposed } \\
\text { to IBS phenotype) rats }\end{array}$ & & $\begin{array}{l}\text {-increased expression of c-Fos in the prelimibic } \\
\text { coertex, infra limbic cortex, and rACC in Wistar rats } \\
\text { given colorectal distention }\end{array}$ & (283) \\
\hline $\begin{array}{l}\text { Zymosan-induced colitis/IBS in } \\
\text { adult male C57B1/6 mice }\end{array}$ & $\begin{array}{l}\text {-increased persistent pain-related behaviours and } \\
\text { reduced locomotion and activity (OFT) }\end{array}$ & $\begin{array}{c}\text {-Increased expression of AMPA receptors in the ACC } \\
\text {-increased AMPA receptor-mediated synaptic } \\
\text { transmission in ACC }\end{array}$ & $(284)$ \\
\hline
\end{tabular}


-AMPA receptor inhibitor into ACC blocked zymosan-induced pain behaviours

\begin{tabular}{|c|c|c|c|}
\hline $\begin{array}{l}\text { Colonic anaphylaxis (model of } \\
\text { IBS) in adult male Sprague- } \\
\text { Dawley rats }\end{array}$ & & -altered synaptic plasticity in the ACC & (285) \\
\hline $\begin{array}{l}\text { Colonic anaphylaxis (model of } \\
\text { VH/IBS) in adult male Sprague- } \\
\text { Dawley rats }\end{array}$ & $\begin{array}{c}\text {-impaired decision making (rat gambling task) in } \\
\text { VH rats }\end{array}$ & $\begin{array}{l}\text {-VH impaired synaptic plasticity in the BLA-ACC } \\
\text { pathway } \\
\text {-reduced functional coupling between BLA and ACC } \\
\text { in rats with VH }\end{array}$ & (286) \\
\hline $\begin{array}{l}\text { Neonatal colorectal distention- } \\
\text { induced VH in Sprague-Dawley } \\
\text { male rats }\end{array}$ & $\begin{array}{l}\text {-reduced locomotion, rearing behaviour (open } \\
\text { field test), sucrose consumption (sucrose } \\
\text { preference test), and impaired spatial memory } \\
\text { (Morris Water Maze Task) of rats re-exposed to } \\
\text { colorectal distention relative to controls }\end{array}$ & $\begin{array}{l}\text {-increased IBA1 staining, TNFa and IL-b protein } \\
\text { levels, and reduced glucocorticoid receptor protein } \\
\text { expression in hippocampus of rats with neonatal and } \\
\text { adult colorectal distention; GR expression restored } \\
\text { by hippocampal minocycline administration }\end{array}$ & (255) \\
\hline $\begin{array}{l}\text { Colonic anaphylaxis (model of } \\
\text { IBS) in adult male Sprague- } \\
\text { Dawley rats }\end{array}$ & & $\begin{array}{l}\text {-VH induced reactive astrocytes in the ACC, } \\
\text { impaired their secretion of lactate } \\
\text {-lactate infusion restored VH-impaired decision } \\
\text { making (rat gambling task) }\end{array}$ & (254) \\
\hline $\begin{array}{l}\text { Neonatal colorectal distention in } \\
\text { male Sprague-Dawley rats }\end{array}$ & $\begin{array}{l}\text {-increased pain behaviour (AWR abdominal } \\
\text { withdfrawl reflex) mediated by CRH }\end{array}$ & $\begin{array}{l}\text {-increased expression of Tyrosine hydroxylase in the } \\
\text { VTA of VH rats } \\
\text {-increased expression of CRH in the PVN }\end{array}$ & (287) \\
\hline Chronic Stress-induced IBS & $\begin{array}{l}\text { reduced sucrose consumption( sucrose preference } \\
\text { test), increased immobility (FST), reduced } \\
\text { locomotion (OFT), increased anxiety (OFT, EPM) }\end{array}$ & $\begin{array}{l}\text {-reduced number of dendrites, reduced dendritic } \\
\text { length, and reduced spine density in the } \\
\text { hippocampus } \\
\text {-increased PDE4A levels and reduced pCREB and } \\
\text { BDNF protein expression in the hippocampus }\end{array}$ & (258) \\
\hline $\begin{array}{c}\text { Other models of Intestinal } \\
\text { Inflammation }\end{array}$ & Effect on Behaviour & Effect on Brain/CNS & Reference \\
\hline $\begin{array}{l}\text { Mustard oil-induced colonic } \\
\text { inflammation in Sprague- } \\
\text { Dawley rats }\end{array}$ & & $\begin{array}{l}\text {-increased qualitative c-Fos expression in the nucleus } \\
\text { solitary tract, area postrema, parabrachial nucleus, } \\
\text { locus coeruleus }\end{array}$ & (288) \\
\hline
\end{tabular}




\begin{tabular}{|c|c|c|c|}
\hline $\begin{array}{l}\text { Trichuris suis induced chronic } \\
\text { gut inflammation in AKR mice }\end{array}$ & $\begin{array}{l}\text { - increased anxiety (light/dark preference test, } \\
\text { step-down test) }\end{array}$ & $\begin{array}{c}\text {-reduced BDNF mRNA in hippocampus (Ca1) of } \\
\text { T.muris infected mice; normalized by treatment with } \\
\text { B. longum }\end{array}$ & (260) \\
\hline $\begin{array}{l}\text { C. rodentium-induced colitis in } \\
\text { CF-1 male mice }\end{array}$ & $\begin{array}{l}\text {-increased anxiety, reduced risk-taking behaviour } \\
(\text { (OFT, HBT) }\end{array}$ & $\begin{array}{l}\text {-increased c-fos expression in sensory neuron cells of } \\
\text { the vagus nerve }\end{array}$ & (289) \\
\hline $\begin{array}{l}\text { Citrobacter rodentium-induced } \\
\text { colitis in C57B1/6 female SPF } \\
\text { mice and swiss webster germ } \\
\text { free female mice }\end{array}$ & $\begin{array}{c}\text {-no anxiety (light/dark box) } \\
\text {-reduced spatial memory (NOR and T-maze), only } \\
\text { when subjected to psychological stressor (WAS) } \\
\text {-memory impairments restored by treatment with } \\
\text { probiotics } \\
\end{array}$ & $\begin{array}{c}\text {-reduced BDNF and c-Fos expression in CA1 of } \\
\text { hippocampus in C.rodentium-exposed mice } \\
\text { subjected to a psychological stressor (WAS); restored } \\
\text { by probiotic treatment }\end{array}$ & (261) \\
\hline $\begin{array}{l}\text { Dietary emulsifier-induced } \\
\text { intestinal inflammation in } \\
\text { C57B1/6 male and female mice }\end{array}$ & $\begin{array}{c}\text {-no change in measures of anxiety in EPM, } \\
\text { light/dark box; increased measures of anxiety in } \\
\text { OFT } \\
\text {-no change in number of marbles buried, or } \\
\text { latency to bury first marble } \\
\text {-reduced social novelty behaviour in female mice } \\
\text { (three chambers test) } \\
\text {-no change in immobility (FST) }\end{array}$ & $\begin{array}{c}\text {-increased AgRP immunoreactivity in the PVT of } \\
\text { male mice, and reduced a-melanocyte stimulating } \\
\text { hormone immunoreactivity in the PVT of male and } \\
\text { female mice. }\end{array}$ & (290) \\
\hline
\end{tabular}




\subsection{Animal models of GIDD: Role of the ACC}

Evidence from preclinical studies strongly supports the ACC as a region of considerable interest in GIDD pathobiology, which is consistent with the overwhelming clinical evidence indicating pathology in this structure [section 2.4]. Animal models of IBS are accompanied by increased central sensitization (a key feature of hyperalgesia/enhanced visceral pain) (291), upregulation of NMDA receptor subunits (292), and altered synaptic plasticity (285) in the ACC. Wang and colleagues elegantly revealed a role of ACC astrocytes in decision making deficits using a model of IBS. They showed that the release of lactate by ACC astrocytes ceases when astrocytes become reactive, leading to deficits in decision-making; administration of exogenous lactate into the ACC, or increased endogenous lactate via optogenetic stimulation of ACC astrocytes, rescued the decision making deficit (254). Lactate is a key energy source for neurons, and is essential for long-term memory formation (293). These results demonstrate that pro-inflammatory glial cells in the ACC can affect cognitive function. These findings warrant further exploration in other models of GIDD, where the role of the ACC is understudied.

\subsection{Acute versus chronic models of GIDD}

A key feature of GIDD is their chronic, relapsing nature. However, preclinical studies focus almost exclusively on peak disease states in acute models, characterized by a single gastrointestinal insult, or a single cycle of a colitic agent, which does not accurately model the cycles of flare-ups and remissiont prevalent in most GIDD. Several studies highlight key differences in peripheral immune responses, neural changes, and behavioural changes during acute, chronic, and recovery phases [cites?]. Furthermore, the first and second cycles of exposure to DSS and the subsequent recovery periods possess unique cellular and inflammatory response profiles, suggesting some adaptation after the first exposure (294). Such immune tolerance evolved as a means to limit immunopathology caused by repeated or chronic exposure to endotoxin/LPS/inflammatory stimuli. Repeated or chronic exposure to LPS has been shown to drive a global transcriptional shift in macrophages with distinct anti-inflammatory features (295). Similarly, multiple systemic exposures to LPS reduces the inflammatory phenotype of microglia (296), astrocytes (297), and is associated with a unique neurogenesis profile (298) relative to a single dose, suggesting neuroinflammatory tolerance. This is supported by several studies using animal models of colitis. A single exposure to DSS evoked increased expression of IBA1 (a marker of microglial reactivity) in the hippocampus, while multiple exposures to DSS were not (243). Immune tolerance is reflected behaviorally as well. Acute exposure to DSS was associated with memory impairments and altered stress-coping strategies, while these behavioural changes were absent when chronically exposed to DSS during the active phase of disease (299).

Several studies report that some behaviours altered in GIDD-induced are normalized upon resolution of inflammation. Other behaviours, however, persist well after resolution. For instance, colitis-induced memory recognition deficits and anxiety at the peak of disease were normalized 9 days post discontinuation of DSS, but animals exhibited anhedonia, reduced grooming, and other depressive-like behaviours for several weeks after discontinuation of DSS (249). Further, several biochemical and electrophysiological changes persisted at least one month after discontinuation. These include increased expression of pro-inflammatory cytokines and enzymes in the HPC, hypothalamus, cortex, colon, spleen, and liver, and hippocampal neurons exhibited altered electrophysiological properties (249). Long-lasting changes have also been reported in other studies. Mice exhibited visceral hypersensitivity and reduced locomotive behaviours (travel distance, climbing) both at peak disease and recovery phases of colitis 5 weeks post DSS exposure (273). These data suggest that recovery phases, even in the absence of clinical signs of disease, such as altered bowel motility, diarrhea, fecal blood and sickness behaviours, may still bear altered neural changes, and thereby induce cognitive dysfunction. It is important to note that differences in study outcomes-even when employing the same model of disease--is likely a consequence of many factors. 
Differences in host species, microbiota, and institution are recognized to influence GIDD severity. Additionally, differences in brain sampling and behavioural assays employed may yield conflicting results. Clinical studies similarly demonstrate a heterogeneous array of cognitive deficits and neural changes during periods of remission, highlighting the need to understand the how and why these changes persist in in the absence of overt inflammation.

\subsection{Conclusions}

Rodent models of GIDD exhibit changes in specific behaviors (. endophenotypes) with some level of analogy to those observed in the clinic. These models have revealed multiple interacting processes involved in neuroinflammation and its long-lasting impact on brain structure and behaviour. The impact of these molecular/structural changes on information processing in the brain are virtually unknown at present. This functional linkage is essential for understanding how neuroinflammation causes changes in mental function supporting depression, anxiety, and other mental health problems prevalent in GIDD. In the next section, we synthesize a working hypotheses of this process by integrating knowledge gained from studies of function in key neural structures affected in GIDD, with a focus on the ACC, in addition to the hippocampus and prefrontal cortexkey neural systems related to ACC function.

\section{Adaptive and maladaptive consequences of ACC inflammation}

We have so far provided evidence that GIDD and animal models of gut inflammation/disorders are associated with an array of behavioral changes, including memory impairments, depression, anxiety, and altered stress coping. Further, our review of the literature has identified the ACC as an important component of the neural networks impacted in GIDD. The final section of this review aims to integrate this data with the wealth of studies investigating the function of ACC in healthy subjects so as to synthesize a hypotheses for mechanisms by which gut dysfunction could lead to anxiety/depression. We propose here that GIDD-triggered neuroinflammation causes remodeling of synapses in ACC and associated structures in a manner that biases the network toward processing signals related to negative affective states, such as pain, and existential threats such as predators. This influences perception, emotions, and cognition because the ACC network provides a context (or 'schema') in which to interpret stimuli and to generate physiological, behavioural, and emotional responses in anticipation of expected future events. Although a temporary shift to negative schemas is adaptive in dealing with acute illness or injuries, long-lasting or excessive shifts become maladaptive because perceptions and physiological responses are geared toward non-existent threats. This leads to an imbalance between parasympathetic and sympathetic nervous system responses, which in turn perpetuates and exacerbates intestinal inflammation. [AG: love this paragraph - nailed it!]

\subsection{Adaptive function of depression and anxiety}

The emergence of depression and anxiety in patients with GIDD seems intuitive. The unpredictability of symptoms is a source of anxiety, and chronic pain is strongly correlated with depression. It has become clear, however, that these mood disorders are not merely a by-product of the 'psychological burden of disease', but rather a physiological response to inflammation and other mechanisms involved in the disease. To understand the relationship between GIDD and psychiatric comorbidities, it is important to recognize that depressive-like behaviours (e.g. low-motivation) and anxiety (e.g. altered threat assessment) have an adaptive function in some contexts. Depressive states can help to conserve energy and allocate energetic resources for an immune response (e.g. fever). Anxiety increases sensitivity to predatory and social threats, which compensates for increased vulnerability that occurs during a bout of illness. However, when these behaviors fail to return to some level of homeostasis, and begin to interfere with meeting basic needs (e.g. grooming/hygiene, eating, foraging, sleeping, etc.), they are no longer adaptive. The ACC plays a key role in guiding 
these behaviours. To better understand the function of the ACC in these responses, we next present a brief examination of the ethological origin of this system.

\subsection{Ethological origin of limbic brain systems-function of the ACC}

Murray and colleagues' excellent exposition on the evolution of learning and memory systems reveals that the first vertebrates 525 million years ago possessed a network linking the HPC with a precursor of the ACC, and other structures such as amygdala. This network, which we refer to as ACC-HPC as short-hand, persists today in all vertebrates, suggesting that its function is adaptive in a wide range of environments. This network projects to hypothalamus and other midbrain structures that provide enteric and motoric control over fundamental behaviours such as feeding, reproduction, energy regulation, and coping with threats passively (freezing) and actively (fighting, fleeing). The ACC-HPC does not encode these behaviours directly, but provides governance by promoting or suppressing the component systems that do. The ACC-HPC uses episodes of experience to form a mental model/representation, or 'schema', of environments. This process is typically called memory consolidation (300). The schemas provide a 'top down' signal to interpret and respond to the environment and/or events in the context of the organisms needs. Wise \& Passingham have proposed that the distinguishing feature of the ACC is that it can guide actions by inferring affective outcomes (appetitive or aversive) (301). We have shown that the rat ACC encodes inference of potential outcomes (302), which is consistent with recordings in monkeys (303) and fMRI imaging in humans [cite - look in Mashhoori eLife 2018 paper] Moreover, the ACC activates in response to pain or the expectation of pain (304). Thus, the ACC appears to be important for generating and applying a schema to link environmental cues to possible future positive or negative outcomes. This can provide a fitness advantage by allowing animals to rapidly change behaviours faster than trial-and-error learning would allow. For example, the early vertebrate might be attacked one day by a type of predator that tends to dwell in caves formed by piles of rocks. The ACC plays a key role in linking the environmental cue (pile of rocks) to a negative outcome (predatory attack). Laboratory studies have clearly shown that ACC-HPC are involved in fear to context. Thus, the ACC plays an important role in anticipating outcomes based on complex configurations of stimuli. This complements other brain systems, such as regions of the amygdala, which develop associations between outcomes and specific stimuli [cite fear to cue paper].

\subsection{Hypothesis for the functional aetiology of depression/anxiety}

The ACC projects to several brain structures in the midbrain and pons that are responsible for engaging threat-coping responses. These include the lateral hypothalamus (sympathetic activation \& triggers adrenaline release), periaqueductal gray (pain inhibition and autonomic responses), and locus coeruleus (norepinephrine production). The ACC has indirect routes to structures involved in mood/depression (lateral habenula) and anxiety (medial habenula). Further, the ACC inputs to goaldirected behavior via the medial striatum, and is thought to suppress reflexive 'habitual' responses. What does ACC do with so many connections?

We propose that the ACC evaluates abstract features of the environment and internal physiological state to calculate overall risk present in a given scenario/context. The degree of threat and vulnerability as assessed by the ACC determine the appropriate schema to be selected, and promote activation of relevant sub-cortical systems. Note that the ACC does not encode specific behaviours, but rather adjudicates competition among several other systems for control of behavioural output (e.g. forage or fight) and physiological responses (e.g. sympathetic vs parasympathetic activation). This can be conceptualized as a see-saw (see figure X): in a context assessed as safe, the ACC promotes goal-directed or habit control systems to collect resources and engage in other behaviours for survival and reproduction. When under threat, the ACC engages a negative schema that inhibits these behaviours, instead promoting activity of threat-coping systems (e.g. sympathetic systems). We postulate that acute inflammation is indicative of increased threat, and promotes the engagement of negative schemas as an adaptive mechanism to offset the increased 
vulnerability that accompanies inflammatory states (e.g. fatigue, pain, etc.). In other words, in the face of inflammation, the ACC guides towards a high threat assessment behavioural response. Upon resolution of inflammation, reassessment of threat status causes negative schemas to abate, and behaviour returns to a baseline.

Under chronic inflammatory states, the stimulus that drives increased threat assessments does not abate. AS a consequence, the neural processes that promote engagement of negative schemas and high threat assessment behaviours are prolonged. Over time, ACC neurons promoting threat coping become dominant over those ACC neurons promoting behaviours appropriate in 'safe' conditions, such as feeding, exploring, socializing, etc. The dominance comes about as an emergent property of the neural dynamics. Because only one schema activates at a time, they 'compete' with one another. The negative schemas dominate this competition, which may come from strengthening synapses \& promoting excitability of neurons projecting to threat-coping structures, and/or by weakening neurons in non-threat pathways.

In this section, we have attempted to integrate theories on the ethological role of the ACC with evidence highlighting the role of the ACC in mood disorders, and data that suggests the ACC is involved in the course of GIDD. We further propose that the role of the ACC in GIDD is mediated primarily through the role the ACC plays in facilitating context dependent arousal states. Arousal states are largely mediated by the autonomic nervous system. Aligning with our proposed framework of the ACC in GIDD, functional neuroimaging has revealed an important role of the ACC in regulating autonomic activity to generate contextually appropriate motor, emotional, and cognitive responses $(305,306)$. Thus, a key function of the ACC is to calibrate bodily states of arousal based on past and present contextual information, which can engender dysfunction in ANS, manifesting as inappropriate threat assessment/stress responses/mood disorders. This accounts for multiple features of information processing that are altered in GIDD: hypervigilance, hyperalgesia, and negative schemas. As presented below, dysregulation of the ANS can have dramatic effects on gut immune status via neuroendocrine and neuroimmune pathways.

\subsection{Top down: Effects of the brain (ANS) on the gut}

The gut is home to intrinsic neural plexuses, more neurons than the spinal cord, and over 30 gutgenerated neurotransmitters (307). This enables the enteric nervous system a degree of autonomy over gastrointestinal functions, such as digestion, nutrient absorption, secretion, and motility. The CNS provides additional extrinsic neural inputs to regulate these functions via the parasympathetic and sympathetic arms of the autonomic nervous system. The parasympathetic and sympathetic nervous system work together to regulate autonomic functions and maintain homeostasis by acting in opposition to each other (308). Under homeostatic conditions, the parasympathetic nervous promotes 'feed and breed, rest and digest' responses via its dominant neurotransmitter, acetylcholine. When the body faces a stressor - any physical, psychological, or immunological event that disrupts homeostasis-- the parasympathetic nervous system withdraws its inhibitory effects, which promotes activation of the sympathetic nervous system. The release of the catecholamines epinephrine (a.k.a adrenaline) from adrenal medulla in the adrenal glands, and norepinephrine from the locus coeruleus in the brainstem of the CNS, drive the canonical 'fight or flight' response. This is followed by the endocrine facet of the stress response: activation of the hypothalamus-pituitaryadrenal (HPA) axis. Corticotrophin-releasing hormone is released from cells in the periventricular nucleus of the hypothalamus, in turn prompting the release of ACTH from the pituitary gland, which enters the peripheral blood circulation to stimulate the adrenal gland. Here, glucocorticoids (GCs) secreted by the adrenal gland serve as the effector hormone. The basal effects of CORT are mediated through binding of high-affinity mineralocorticoid receptors; when these receptors become saturated, the binding of GCs to lower-affinity glucocorticoid receptors (GR) promotes negative feedback that regulates activity of the HPA axis (309). Both receptors are widely distributed throughout the body, including the gut and the CNS. Below we describe the relationship between both arms of the ANS and gut inflammation. 


\subsubsection{Sympathetic Nervous System effects on the gut and brain}

There is no question that stress response and GIDD are connected. The weight of evidence supports an association between psychosocial stress and clinical relapse in IBD (310) and exacerbation of IBS $(311,312)$. Animal studies reveal that stress can induce dysfunction in the epithelial barrier, (313-316), alter gastrointestinal motility $(317,318)$, influence visceral pain $(319)$ and aggravate colitic disease $(313,320-330)$. For instance, colitis alters stress responses $(248,271,279)$, and both stress and depression can reactivate colitis $(331,332)$. Stress also influences the gut-brain axis via the microbiome $(333,334)$. This can occur remarkably quickly. As little as 2 hours of social stress is capable of exerting an impact on microbial communities (335). These changes can be mediated indirectly, by the actions of the autonomic nervous system, or directly, through luminal release of neurotransmitters, which bind to receptors on gut bacteria. (336). This can have life-long effects. For instance, animal models of IBS induced through early life stress, evoke visceral sensitivity, alterations in bowel motility and intestinal permeability, low grade inflammation, and anxiety/depression-like behaviours later in life (337).

The stress response is mediated by the sympathetic nervous system (SNS) which densely innervates the serosal side of the gastrointestinal tract. Here it communicates with the enteric plexuses: a network of sensory, motor, and interneurons that are embedded between the longitudinal and circular muscles (myenteric plexus) or within the submucosal layer (submucosa plexus) that constitute the enteric nervous system. This communication enables sympathetic regulation over motility, secretion/absorption, and vasodilation (see (338) for review). In addition, sympathetic innervation of gut-associated lymphoid tissue enables regulation over the gut immune response, via sympathetic neurotransmitters that act on immune cells (339). The SNS has been demonstrated to impact migration of immune cells (340), modulate apoptosis of intestinal immune cells (341), and can modulate the function of both innate and adaptive immune cells towards pro or anti-inflammatory phenotypes $(342,343)$. Gut inflammation is linked to loss of sympathetic nerve fibers, changes in levels of sympathetic neurotransmitters, and their receptors (338). Thus, gut inflammation may impede the ability of the SNS to regulate immune responses, exacerbating or prolonging gut inflammation; conversely, changes in SNS activity may drive gut inflammation. Regardless of which process occurs first, both processes promote gut dysregulation and dysfunction

The SNS plays an important role in restoring homeostasis, including the resolution of inflammation systemically, and centrally. Stress research indicates GCs play a potent role in this regard: indeed, the immunosuppressive and anti-inflammatory properties of GC have been studied for decades, and synthetic versions of cortisol (e.g. prednisone) are routinely used to manage chronic inflammatory and autoimmune disease (344). However, it is becoming increasingly clear that glucocorticoids are not uniformly anti-inflammatory, particularly in chronic contexts. Prolonged or excessive production of GCs can enhance neuroinflammation in a region, dose, and timingdependent manner (345). For example, in LPS-induced neuroinflammation was increased in the frontal cortex and hippocampus, and decreased in the hypothalamus of chronically stressed rats (346) [The mechanisms of these opposing effects are not fully known, though the different affinities and heterogenous distribution of MR and GR are believed to play a role. Microglial cells are a target of GCs, and have been implicated in mediating stress-induced neuroinflammatory changes (347-349). Exposure to stress and GCs can exacerbate neuronal injury (cite). Glucocorticoids regulate hippocampus neurogenesis (350), which has been implicated as a mechanism of stress-induced depression (351), and antidepressants increase hippocampal neurogenesis via activation of the GR (352). There is extensive literature illustrating how GCs drive structural remodeling in the hippocampus, amygdala, and the MPFC; moreover, these structural changes persist for weeks after exogenous administration of GCs is completed, highlighting the chronic/longterm nature of neural remodeling (353). [are you going to talk about antidepressants \& GRs in the mPFC later - perhaps in the context of top-down control \& treatment? Sounds really cool]

\subsubsection{Parasympathetic nervous system and the Vagus Nerve}


The parasympathetic nervous system is supplied by cranial nerves, pelvic splanchnic nerves, and the vagus nerve, the latter of which innervates the gastrointestinal tract. The vagus nerve contains approximately $80 \%$ afferent sensory fibers that originate in the mucosal and muscular layers of the digestive tract and project to the brain. Information regarding the environment within the GI tract (e.g. inflammation, nutrient composition, microbial community etc.) is directly and indirectly conveyed to the brain via activation of receptors on vagal afferents. Some bacterial metabolites (e.g. short-chain fatty acids), bacterial products (LPS) and cytokines (e.g. IL-1b) can directly activate vagal fibers $(354,355)$. Other sensory information is relayed to the vagal nerve by enteroendocrine cells located along the gut epithelial barrier that secrete substances, such as serotonin, in response to luminal contents (gut nutrients, microbial products and metabolites, etc.). This sensory information is transmitted to the spinal cord (nodose ganglia) and subsequently relayed to the dorsal vagal complex, which is comprised of the nucleus tractus solitarus (NTS), area postrema, and dorsal motor nucleus of the vagus. The remaining $20 \%$ of vagal fibers serve as the effector for the parasympathetic nervous system, and provide efferent signals from the dorsal motor nucleus in the brain to the gut to modulate physiological functions (e.g. secretion/absorption, motility)(356).

The vagus nerve can exert immunomodulating effects through afferent and efferent pathways. Vagal afferents that detect inflammatory responses relay this information to the nucleus tractus solitarus, activating noradrenergic neurons, which in turn project to the PVN of the hypothalamus and engage the HPA axis $(357,358)$. In the vago-sympathetic pathway/reflex, descending neurons from regions of the central autonomic network communicate with vagal fibers in the DMNV that may modulate efferent sympathetic fibers to induce anti-inflammatory activity (359). Activated vagal afferents also communicate with efferent vagal fibers in the dorsal vagal complex. These fibers release acetylcholine, the dominant parasympathetic neurotransmitter, in turn stimulating Ach release from enteric neurons which act on macrophages via the $\alpha 7$-nicotinic receptors to suppresses cytokine production (360). Vagal efferents also communicate with sympathetic nerves in the celiac ganglion that project to the spleen, an organ critically involved in systemic inflammation. Stimulation of the splenic sympathetic nerve prompts the release of NE-the dominant neurotransmitter of the SNSwhich activates splenic lymphocytes via $\beta 2$ adrenergic receptors. These activated cells are a source of acetylcholine that attenuate production of the pro-inflammatory cytokines in macrophages(360).

Chronic stress--immunological, physiological or physical--can drive dysfunction in the ANS. An imbalance between the SNS and PNS can influence the gut environment via endocrine and neuroimmunomodulating mechanisms, and has been postulated to play an important role in the etiopathology of $\operatorname{GIDD}(359,361)$. Research suggests that dysregulation of the autonomic nervous system and the HPA axis plays a role in the pathogenesis of IBD (362), IBS (363), FD (364), in addition to anxiety and depression(365, 366). Vagal dysfunction is a proposed mechanism by which depression can influence intestinal inflammation (367). Conversely, vagal nerve stimulation is used to treat a variety of chronic pain conditions and depression, and has demonstrated therapeutic potential in preclinical and pilot clinical studies for IBD (368-370). Stimulation of the vagus nerve is believed to attenuate inflammation via activation of the HPA axis and the cholinergic antiinflammatory pathway.

\subsubsection{Relationship between the ACC and the ANS}

We have described in previous sections of this review how the ACC is involved in regulating the ANS, and the immunoregulatory capacity of the ACC via neuroendocrine mechanisms. In this section, we present evidence indicating that ACC dysfunction is a common denominator in disruption of both arms of the ANS, mood disorders, and GIDD. Preclinical and clinical evidence overwhelmingly indicate a linkage between functional and structural changes in the ACC and altered sympathetic responses. Activity of the HPA axis and its downstream effects are modulated by multiple brain circuits, including the ACC, which can have a stimulatory or inhibitory role on the HPA axis depending on the subregions involved, or the nature of stressor (371). Control of the ACC/PFC over the HPA axis is a suggested mechanism for depression; for example, depressed 
patients display an increased ratio of GR:MR expression in the ACC versus matched controls (372). Studies have identified a negative correlation between ACC volume and basal ACTH levels (373), and reveal that reduced ACC volume is associated with impaired negative feedback of the HPA axis (374). Structural alterations in the ACC induced by pain, mood disorders, or stress are also associated with sympathetic changes: chronic pain in rats is associated with altered ACC volume and sympathetic regulation of renal blood flow (375); depressed youths with high levels of activity in the ACC bore higher cortisol levels upon waking (376); and ACC activity was only correlated with appropriate negative feedback of the HPA axis in healthy controls, not patients with IBS (377). Combined, these studies suggest hyperactivity and structural changes in the ACC are indicative of unregulated sympathetic responses.

The efficacy of neuromstimulation treatments for depression (e.g. deep brain stimulation, transcranial brain stimulation, and vagal nerve stimulation) have led researchers to theorize the existence of frontal-vagal pathways $(378,379)$ that include an anatomical and functional link between the ACC and the parasympathetic nervous system (vagus nerve). A clinical study revealed transcutaneous stimulation of the auricular vagus nerve induced significant activity in the anterior cingulate cortex (380). Animal studies indicate that vagal signals can modulate the functional connectivity of the ACC network (381) and modulate phase synchrony in the ACC of and facilitates decision-making in rats (382). Furthermore, changes in the gut microbiota modulate GABAergic signaling in the cingulate cortex through a vagal-dependent mechanism (383).

The ACC maintains homeostatic functions through its mediation of context-dependent arousal states, and regulation of the HPA axis (305). As we have presented, gut inflammation-induced neuroinflammation mediates behavioural changes (e.g. cognition, anxiety, and depression) that involve ACC. The observed hyperactivity of the ACC in GIDD may therefore reflect a loss of of sympathetic-parasympathetic balance. The role of PNS/SNS balance in the etiology of GIDD is not new: in 1928 Bockus et al. first suggested ANS dysfunction played a role in IBS (384). Since then, many distinguished researchers have contributed to our understanding of the importance of ANS in the context of GIDD $(361,385-387)$. We propose to extend upon this framework/school of thought/ by introducing the ACC as a key neural correlate in the etiology of GIDD. In short, we submit hyperactivity of the ACC contributes to and promotes gut dysfunction/GIDD through dysregulation of the ANS. ACC hyperactivity may be a symptom of GIDD, a cause of GIDD, or a means by which GIDD are promoted, exacerbated, and/or maintained in some populations. This proposition reconciles the key role of environmental stressors (threats?), negative schema, ANS imbalance, and strong comorbidity with mood disorders that are observed in patients with GIDD. This framework additionally suggests that the ACC is a likely useful biomarker for GIDD treatments, and may be a useful target for therapy.

\section{Remediation of gut-brain dysfunction}

In the final section of this review, we summarize GIDD treatments that modulate gut-brain dysfunction through a bottom-up, or top-down approach. Further, we will offer how our proposed model may 1) explain how some of these treatments are effective, which may aid towards identifying treatment-responsive populations, and 2) propose additional therapeutic strategies.

\subsection{Pharmacological therapies}

\section{Gut inflammation}

Pharmacological disease management of patients with IBD is primarily directed towards controlling gut inflammation, while the management of the 'functional' gastrointestinal disorders (e.g. IBS, FD) is focused on treating dominant symptoms (e.g. diarrhea, constipation, pain). However, patients with IBD frequently display IBS-type symptoms during disease remission, and thus management of IBD and IBS possess considerable overlap. Pharmacological management of IBD is dependent upon the type of disease (ulcerative colitis, Crohn's disease, or unclassified), the 
classification of disease severity (mild, moderate, or severe), the disease state (flare versus remission), and how patients respond to treatments (e.g. side effects, refractory versus response). Mild to moderate disease is initially managed with non-steroidal anti-inflammatory drugs (e.g. ASA-5). As disease severity increases, treatments are escalated to include corticosteroids (e.g. budesonide), and finally biologics (cell-generated antibodies that target and neutralize aspects of the inflammatory response) (388). Pharmacological treatment of IBS is targeted towards management of the most dominant symptoms of a patient, which are classified according to type of motility dysfunction (diarrhea, constipation, or mixed) and include drugs that modulate gastrointestinal transit (e.g. smooth muscle relaxers/antispasmodics, secretagogues, laxatives, anti-diarrheals) (389). Similarly, FD is managed pharmacologically based on subtype (post-prandial syndrome, epigastric pain syndrome, and mixed), through drugs that relax the fundus (stomach), promote gastric emptying, and attenuate gastric acid secretion (390). Many studies provide evidence that drugs used to attenuate gut inflammation also improve co-morbid mood disorders (193), and is discussed in greater detail below/in section x.x. No direct studies on the effects of gut-specific treatments for FD or IBS on the brain were identified, although drugs that attenuate gastric acid section (e.g. proton pump inhibitors) were associated with cognitive impairments (391). The absence of studies on the effects of drugs frequently used to manage 'functional' gut diseases/disorders on cognition and mood disorders highlights a knowledge gap that warrants attention.

\section{Neuromodulators}

Some treatments improve outcomes of GIDD through top-down (i.e. brain->gut) effects. Neuromodulating drugs such as antidepressants are used to treat the psychological symptoms of GIDD. It is well-established that treating depression/anxiety improves clinical outcomes in IBD, IBS, and FD (392-395). Preclinical studies similarly report that antidepressants attenuate severity of colitis in rodents (396-398); further, depression can reactivate gut inflammation during remission (331).

Consistent with the emerging view that depression is an inflammatory illness, antiinflammatory drugs possess anti-depressant properties (193). Many compounds can attenuate inflammation, and can do so through a variety of pathways. For example, the antibiotic minocycline, which readily crosses the $\mathrm{BBB}$, suppresses pro-inflammatory mediators in the brain, as well as engaging neuroprotective processes and increasing neurogenesis (399). Both immune and stress responses can influence serotonin availability, which has long been thought to affect mood (400). Proinflammatory mediators and glucocorticoids increase the activity of the enzymes that shunt the synthesis of tryptophan from serotonin into kynurenine, a glutamate receptor antagonist. Further, kynurenine metabolites can possess neurotoxic properties (401), and pro-inflammatory cytokines can influence the activity and expression of serotonin transporters (402). Selective serotonin reuptake inhibitors (SSRI) are one of the most commonly prescribed classes of neuromodulators for the treatment of depression, which function by increasing serotonin availability through preventing the uptake and degradation of this neurotransmitter. Clinical studies suggest efficacy of SSRIs is linked to their ability to attenuate pro-inflammatory mediators: patients that responded positively to SSRIs also demonstrated reduced levels of inflammatory markers, while those patients that did not exhibit reduction in markers of inflammatory processes were refractive to SSRIs (403). It is noteworthy that SSRIs demonstrate potential to improve IBS symptoms even in the absence of depression (404-406). This is likely in part due to the relative abundance of serotonin that exists in the gut, which houses more than $95 \%$ of the body's serotonin reserves, produced by gut-resident enterochromaffin cells and serotonergic neurons on the myenteric plexus (407). Serotonin signaling plays a role in intrinsic physiological processes within the gut including motility, secretion and absorption, and also has extrinsic effects, such as generating sensations of nausea (407). Therefore, the effects of inhibiting serotonin reuptake via oral SSRI administration on the gut is expected. However, remarkably few studies have been published on the effects of SSRIs on the gut: a PUBMED search for gut AND SSRI yields only 106 journal articles in the last 3 decades, 75 of which are original research. Increase in small intestinal motility — but not gastric and colonic motility—have been reported (408). Recent 
laboratory studies have revealed potential mechanisms by which SSRIs may improve outcomes of GIDD: exposure to the SSRI fluoxetine modulates gut microbial communities, via impairing the colonization of serotonin-importing gut microbes (409), and additional lab studies indicate SSRIs activate vagal fibers (410). Other classes of neuromodulators include the SNRIs, which increase serotonin and norepinephrine availability, highlighting the role of the sympathetic nervous system in psychiatric illness. Inflammation itself plays an important role in the way that anti-depressants function, as inflammatory mediators alter the metabolism and drug transport dynamics of antidepressants (411). The diverse mechanisms by which anti-depressants and neuromodulators function likely contribute to potential synergistic benefits of combined anti-depressants and antiinflammatory treatments observed in clinical trials (412).

The ACC is associated with clinical outcomes and antidepressant treatment response in MDD. There is a consistent body of evidence indicating that increased activity in the ACC-regardless of modality used to assess activity (e.g. PET, fMRI, EEC) - is predictive of positive treatment response to depression, including pharmacological strategies, transcranial magnetic stimulations, and CBT $(413,414)$. This suggests that ACC hyperactivity, a key feature of many patients with GIDD, is a marker of dysfunction that is amenable to treatment.

Antidepressants are often ineffective in depression. Interestingly, SSRI administration reduced depressive-like behaviours in mice when they were exposed to favourable/enriched environments, but they exacerbated depressive-like phenotypes in stressful environments. SSRIs may therefore have positive or negative outcomes, based on the quality of the environment (415), which may explain the population of patients with depression that do not respond to SSRIs. The fact that increasing serotonin availability does not immediately increase mood, and is only sometimes effective, present challenges to the longstanding theory that depression is a consequence of insufficient serotonin (400). The mechanisms of antidepressant action are not clear at present. It has been proposed that it is the property of antidepressants to promote the regrowth of neural processes and synapses that ameliorates depression $(416,417)$. Indeed, a randomly controlled trial using a non-human primate model of depression revealed reduced ACC volume among depressed, but not healthy animals, and long-term exposure to the SSRI antidepressant sertraline significantly increased the volume of the ACC in depressed animals (418). This potentially explains why other compounds that do not primarily target serotonin transmission have long-lasting antidepressant effects. For example, clinical evidence suggests that ketamine modulates plasticity in the ACC to induce anti-depressant effects $(419,420)$. Laboratory studies reveal ketamine attenuates ACC activity (421), can induce neuroregulatory effects $(422,423)$, and promote synaptogenesis (424). Interestingly, the 5HT2a receptor is required for ketamine's synaptogenic effects [cite]. This receptor is similarly responsible for the hallucinogenic effects of psychedelics, such as psilocybin (magic mushrooms), Ayuasca, Peyote, and LSD. A recent study has shown that these psychedelics do cause robust increase in the dendrites and spines of cortical neurons (425), which may explain why resurgent clinical work with this class of compounds shows excellent outcomes in treating depression and anxiety (426-428). Moreover, psychedelics possess potent anti-inflammatory properties(429). It is tempting to speculate that this class of drug may improve the outcome of GIDD among some cohort of patients.

\subsection{The gut-microbiome and diet}

Evidence increasingly supports a facilitating [right word? Some bugs are bad, so don't facilitate. I'll insert the word 'healthy' to fix ] role of healthy gut microbiota in the gut-brain axis. The microbiome synthesizes a wide variety of neuromodulators (e.g. acetylcholine, catecholamines, gamma-amino butyric acid, melatonin, serotonin) $(430,431)$, and produces key short-chain fatty acids (acetate, prionate, butyrate) that cross the BBB and exert immunomodulating effects on microglia $(432,433)$. Elevated levels of some pathogenic gut microbes were significantly correlated with increased levels of choline --a neural metabolite that serves as a proxy for neural activity-- in the ACC of some clinical populations with mood dysregulation (434). Microbial dysbiosis is a key feature of GIDD, and several interventions involve direct (e.g. fecal microbial transplant) or indirect (e.g. diet) manipulation of the 
gut microbiome. Fecal microbial transplants (FMT) induce long-lasting changes in the composition of the gut microbiota $(435,436)$, and clinical testing reveals a high level of efficacy in pathogenic infections (437) as well benefit in UC (438), and potentially CeD (439). Although the psychiatric effects of FMT have not been widely studied in the clinic, data from animal models suggests that it has the potential for significant benefits. The microbiota in the gut affect measures of depression, anxiety, and neurometabolism. Fecal transplant from depressed patients induced anhedonia, anxiety, and modulated tryptophan metabolism in rats (440), while FT from alcoholic patients induced alcohol dependence, anxiety and depressive-like behaviours, and molecular changes in the brain of mice (441). Further, microbiota regulate visceral pain in mouse (442) and genes involved in glucocorticoid signaling in the hippocampus (443). Positive correlation between [missing something?] Although FMT was found to reduce anxiety in patients with IBS (444) and anxiety, depression, and obsession in patients with IBD (445), several limitations of these clinical studies- small sample sizes and lack of a proper controlindicate more research is needed. Nonetheless, these data are consistent with the larger theme that microbiota composition affect neural signaling related to mood disorders. Indeed, practitioners frequently recommend some level of dietary intervention as part of a treatment paradigm for GIDD. Probiotics (living organisms that confer a health benefit to the host) are frequently recommended for patients with GIDD. The mechanisms by which benefit occurs is likely multifactorial: probiotics promote the establishment of certain beneficial microbial communities, which in turn limits pathogenic bacterial overgrowth (cite). There is also evidence that probiotics improve epithelial barrier integrity (cite).-Nutrition can play an important role in brain health and cognition. For example, several studies have revealed omega-3 Poly unsaturated fatty acids supplementation can alter brain activity and improve cognitive performance $(446,447)$. Some research indicates the ACC volume may serve as a mediating variable between O3-PUFA levels of cognitive function (448). While more research is needed, these findings suggest that nutritional therapy may offer benefits through ACC involvement.

\subsection{Stress reduction techniques}

Managing the psychological aspects of GIDD may also involve the use of stress-reduction techniques/psychotherapy. Multiple studies reveal significant benefits of meditation-based therapy, hypnotherapy and cognitive behavioral therapy in FD, IBS, and IBD (449-457) (458). The most commonly reported benefits of psychotherapy are improvements in mood disorders and overall quality of life. However, there is evidence of reduced inflammatory markers and reduced disease activity in some $(456,459)$, but not all $(460,461)$ studies, suggesting the potential for immunomodulation. Beneficial effects mediated by stress-reduction techniques (e.g. hypnotherapy, CBT, yoga) are facilitated through modulation of vagal tone (462-464). Indeed, devices that deliver stimulation to the vagus nerve are used to treat refractive depression (465), and attenuate inflammation $(466,467)$. There is evidence that modulating vagal tone has direct effects on the anterior cingulate cortex. Vagal nerve stimulation reduced ACC activity in response to a noxious thermal stimulus (468), cardiac vagal tone correlated with ACC activity and was altered in patients with depression (469), and treatment with anti-depressants improved correlation between vagal tone and ACC activity (470). Long-term meditation is associated with neuroplasticity of key brain structures including the ACC (471): indeed, zen practitioners had significantly increased CT in the ACC relative to controls, which corresponded with the number of years of meditation experience (472). In addition, CBT and hypnosis has been shown to attenuate activity of the ACC $(473,474)$. Combined, these studies align with our proposed model of ACC atrophy and hyperactivity as a key neural feature that promotes and perpetuates neural and gut pathology related to GIDD.

\subsection{Conclusion}

Humans are beginning to understand how gut dysfunction remodels the brain, and how this feeds back to promote further gut dysfunction. We propose here that one important mechanism is via gut-related inflammation, which engages neuroinflammation to drive atrophy and hyperactivity 
in ACC. This promotes activation of threat responses at inappropriate times, which affects not only mental function, but also digestive, immune, and cardiovascular systems. In particular, the ACC is part of a network that influences midbrain structures mediating mood (e.g. LHb, dorsal raphe), anxiety (e.g. $\mathrm{MHb}$, Lat hypothalamus), and threat-related behaviours (periaqueductal grey, parabrachial nucleus). This provides a parsimonious explanation for reduced neurites and hyperactivity in the ACC, greater likelihood of negative schemas, and increased threat-coping behaviours. It also shifts the balance of sympathetic/parasympathetic systems to prepare for threat, which disrupts the enteric system. This forms a 'positive' feedback loop. Treating ACC dysfunction can break the positive feedback of gut-brain dysfunction. Our proposal predicts that the ACC neurons in ensembles with at least some member neurons projecting to threat-related structures will become hyperactive. Key outstanding questions include the relative contributions of the stress response (e.g. glucocorticoids) and the immune system (e.g. inflammatory mediators).

Our proposal can likely be applied to diseases and disorders beyond those involving the gut. Chronic inflammation presents in a wide array of illnesses, including multiple sclerosis, rheumatoid arthritis, and diabetes. Moreover, inflammation is a hallmark of aging (69), and chronic inflammation is a risk factor for neurodegenerative illnesses, particularly Parkinson's and Alzheimer's/dementia $(475,476)$. These all present with cognitive impairments and dysregulation of mood $(477,478)$ although the etiologies of the specific immune trigger are at least partially dissociated. Finally, depression is now considered an inflammatory disease. These data suggest that many sources of inflammation may recruit a set of common neuro-immune functions that become pathological when activated chronically, and lead to depression, anxiety, and other forms of mood dysregulation. Thus mood disorders and GIDD appear to be different facets of multi-system responses linked by immune function.

\section{REFERENCES}

1. D'Mello C, Swain MG. Immune-to-Brain Communication Pathways in Inflammation-Associated Sickness and Depression. Current topics in behavioral neurosciences. 2017;31:73-94.

2. D'Mello C, Le T, Swain MG. Cerebral microglia recruit monocytes into the brain in response to tumor necrosis factoralpha signaling during peripheral organ inflammation. The Journal of neuroscience : the official journal of the Society for Neuroscience. 2009;29(7):2089-102.

3. Valles-Colomer M, Falony G, Darzi Y, Tigchelaar EF, Wang J, Tito RY, et al. The neuroactive potential of the human gut microbiota in quality of life and depression. Nature Microbiology. 2019;4(4):623-32.

4. Dinan TG, Cryan JF. The Microbiome-Gut-Brain Axis in Health and Disease. Gastroenterol Clin North Am. 2017;46(1):77-89.

5. Felger JC. Imaging the Role of Inflammation in Mood and Anxiety-related Disorders. Curr Neuropharmacol. 2018;16(5):533-58.

6. Dantzer R, O'Connor JC, Freund GG, Johnson RW, Kelley KW. From inflammation to sickness and depression: when the immune system subjugates the brain. Nature Reviews Neuroscience. 2008;9:46.

7. Ondicova K, Tillinger A, Pecenak J, Mravec B. The vagus nerve role in antidepressants action: Efferent vagal pathways participate in peripheral anti-inflammatory effect of fluoxetine. Neurochemistry international. 2019;125:47-56.

8. Bednarska O, Walter SA, Casado-Bedmar M, Ström M, Salvo-Romero E, Vicario M, et al. Vasoactive Intestinal Polypeptide and Mast Cells Regulate Increased Passage of Colonic Bacteria in Patients With Irritable Bowel Syndrome. Gastroenterology. 2017;153(4):948-60.e3.

9. Cirillo C, Bessissow T, Desmet AS, Vanheel H, Tack J, Vanden Berghe P. Evidence for neuronal and structural changes in submucous ganglia of patients with functional dyspepsia. Am J Gastroenterol. 2015;110(8):1205-15.

10. Komori K, Thara E, Minoda Y, Ogino H, Sasaki T, Fujiwara M, et al. The Altered Mucosal Barrier Function in the Duodenum Plays a Role in the Pathogenesis of Functional Dyspepsia. Digestive diseases and sciences. 2019.

11. Walker MM, Talley NJ. The Role of Duodenal Inflammation in Functional Dyspepsia. Journal of clinical gastroenterology. 2017;51(1):12-8. 
12. Witt ST, Bednarska O, Keita AV, Icenhour A, Jones MP, Elsenbruch S, et al. Interactions between gut permeability and brain structure and function in health and irritable bowel syndrome. NeuroImage Clinical. 2018.

13. Neuendorf R, Harding A, Stello N, Hanes D, Wahbeh H. Depression and anxiety in patients with Inflammatory Bowel Disease: A systematic review. Journal of psychosomatic research. 2016;87:70-80.

14. Fond G, Loundou A, Hamdani N, Boukouaci W, Dargel A, Oliveira J, et al. Anxiety and depression comorbidities in irritable bowel syndrome (IBS): a systematic review and meta-analysis. European Archives of Psychiatry and Clinical Neuroscience. 2014;264(8):651-60.

15. Elsaied H, Sherra K, Mahmoud E-H, Ebrahim M. A study of sociodemographic factors and anxiety: depressive disorders among irritable bowel syndrome patients. Egyptian Journal of Psychiatry. 2017;38(2):97104.

16. Hausteiner-Wiehle C, Henningsen P. Irritable bowel syndrome: relations with functional, mental, and somatoform disorders. World J Gastroenterol. 2014;20(20):6024-30.

17. Roohafza H, Bidaki EZ, Hasanzadeh-Keshteli A, Daghaghzade H, Afshar H, Adibi P. Anxiety, depression and distress among irritable bowel syndrome and their subtypes: An epidemiological population based study. Advanced biomedical research. 2016;5:183-.

18. Tosic-Golubovic S, Miljkovic S, Nagorni A, Lazarevic D, Nikolic G. Irritable bowel syndrome, anxiety, depression and personality characteristics. Psychiatria Danubina. 2010;22(3):418-24.

19. Hauser W, Janke KH, Klump B, Gregor M, Hinz A. Anxiety and depression in adult patients with celiac disease on a gluten-free diet. World J Gastroenterol. 2010;16(22):2780-7.

20. Zylberberg HM, Ludvigsson JF, Green PHR, Lebwohl B. Psychotropic medication use among patients with celiac disease. BMC psychiatry. 2018;18(1):76-.

21. Lin S, Gao T, Sun C, Jia M, Liu C, Ma A. The association between functional dyspepsia and depression: a meta-analysis of observational studies. Eur J Gastroenterol Hepatol. 2019;31(8):911-8.

22. Aro P, Talley NJ, Ronkainen J, Storskrubb T, Vieth M, Johansson SE, et al. Anxiety is associated with uninvestigated and functional dyspepsia (Rome III criteria) in a Swedish population-based study. Gastroenterology. 2009;137(1):94-100.

23. Gracie DJ, Guthrie EA, Hamlin PJ, Ford AC. Bi-directionality of Brain-Gut Interactions in Patients With Inflammatory Bowel Disease. Gastroenterology. 2018;154(6):1635-46.e3.

24. Kochar B, Barnes EL, Long MD, Cushing KC, Galanko J, Martin CF, et al. Depression Is Associated With More Aggressive Inflammatory Bowel Disease. Am J Gastroenterol. 2018;113(1):80-5.

25. Frolkis AD, Vallerand IA, Shaheen AA, Lowerison MW, Swain MG, Barnabe C, et al. Depression increases the risk of inflammatory bowel disease, which may be mitigated by the use of antidepressants in the treatment of depression. Gut. 2019;68(9):1606-12.

26. Mykletun A, Jacka F, Williams L, Pasco J, Henry M, Nicholson GC, et al. Prevalence of mood and anxiety disorder in self reported irritable bowel syndrome (IBS). An epidemiological population based study of women. BMC gastroenterology. 2010;10:88-

27. Phillips K, Wright BJ, Kent S. Psychosocial predictors of irritable bowel syndrome diagnosis and symptom severity. Journal of psychosomatic research. 2013;75(5):467-74.

28. Sainsbury K, Marques MM. The relationship between gluten free diet adherence and depressive symptoms in adults with coeliac disease: A systematic review with meta-analysis. Appetite. 2018;120:578-88.

29. Barratt SM, Leeds JS, Sanders DS. Factors influencing the type, timing and severity of symptomatic responses to dietary gluten in patients with biopsy-proven coeliac disease. Journal of gastrointestinal and liver diseases : JGLD. 2013;22(4):391-6.

30. Isik A, Koca SS, Ozturk A, Mermi O. Anxiety and depression in patients with rheumatoid arthritis. Clinical rheumatology. 2007;26(6):872-8.

31. Buchberger B, Huppertz H, Krabbe L, Lux B, Mattivi JT, Siafarikas A. Symptoms of depression and anxiety in youth with type 1 diabetes: A systematic review and meta-analysis. Psychoneuroendocrinology. 2016;70:70-84.

32. Castellano-Guerrero AM, Guerrero R, Relimpio F, Losada F, Mangas MA, Pumar A, et al. Prevalence and predictors of depression and anxiety in adult patients with type 1 diabetes in tertiary care setting. Acta diabetologica. 2018;55(9):943-53.

33. Zhang L, Fu T, Yin R, Zhang Q, Shen B. Prevalence of depression and anxiety in systemic lupus erythematosus: a systematic review and meta-analysis. BMC Psychiatry. 2017;17(1):70.

34. Sun Y, Wang D, Salvadore G, Hsu B, Curran M, Casper C, et al. The effects of interleukin-6 neutralizing antibodies on symptoms of depressed mood and anhedonia in patients with rheumatoid arthritis and multicentric Castleman's disease. Brain Behav Immun. 2017;66:156-64. 
35. Diamond A. Executive functions. Annu Rev Psychol. 2013;64:135-68.

36. Kennedy PJ, Clarke G, O'Neill A, Groeger JA, Quigley EMM, Shanahan F, et al. Cognitive performance in irritable bowel syndrome: evidence of a stress-related impairment in visuospatial memory. Psychological medicine. 2014;44(7):1553-66.

37. Fan W, Zhang S, Hu J, Liu B, Wen L, Gong M, et al. Aberrant Brain Function in Active-Stage Ulcerative Colitis Patients: A Resting-State Functional MRI Study. Frontiers in human neuroscience. 2019;13:107.

38. Castaneda AE, Tuulio-Henriksson A, Aronen ET, Marttunen M, Kolho K-L. Cognitive functioning and depressive symptoms in adolescents with inflammatory bowel disease. World journal of gastroenterology. 2013;19(10):1611-7.

39. Casella S, Zanini B, Lanzarotto F, Ricci C, Marengoni A, Romanelli G, et al. Cognitive performance is impaired in coeliac patients on gluten free diet: a case-control study in patients older than 65 years of age. Digestive and liver disease : official journal of the Italian Society of Gastroenterology and the Italian Association for the Study of the Liver. 2012;44(9):729-35.

40. Piasecki B, Stanislawska-Kubiak M, Strzelecki W, Mojs E. Attention and memory impairments in pediatric patients with cystic fibrosis and inflammatory bowel disease in comparison to healthy controls. Journal of investigative medicine : the official publication of the American Federation for Clinical Research. 2017;65(7):1062-7.

41. Hollerbach SH, Kullmann F, Geissler A, Schoelmerich J, Andus T. Impairment of short-term memory function and morphologic brain abnormalities in inflammatory bowel disease (IBD). Gastroenterology. 2000;118(4):A313.

42. Gomborone JE, Dewsnap PA, Libby GW, Farthing MJ. Selective affective biasing in recognition memory in the irritable bowel syndrome. Gut. 1993;34(9):1230-3.

43. Gibbs-Gallagher N, Palsson OS, Levy RL, Meyer K, Drossman DA, Whitehead WE. Selective recall of gastrointestinal-sensation words: evidence for a cognitive-behavioral contribution to irritable bowel syndrome. Am J Gastroenterol. 2001;96(4):1133-8.

44. Posserud I, Svedlund J, Wallin J, Simren M. Hypervigilance in irritable bowel syndrome compared with organic gastrointestinal disease. Journal of psychosomatic research. 2009;66(5):399-405.

45. Martin M, Chapman SC. Cognitive processing in putative functional gastrointestinal disorder: rumination yields orientation to social threat not pain. European journal of pain (London, England). 2010;14(2):207-13.

46. Chapman S, Martin M. Attention to pain words in irritable bowel syndrome: increased orienting and speeded engagement. Br J Health Psychol. 2011;16(Pt 1):47-60.

47. Lee IS, Preissl H, Giel K, Schag K, Enck P. Attentional and physiological processing of food images in functional dyspepsia patients: A pilot study. Sci Rep. 2018;8(1):1388.

48. Higgs S. Cognitive processing of food rewards. Appetite. 2016;104:10-7.

49. Hubbard CS, Hong J, Jiang Z, Ebrat B, Suyenobu B, Smith S, et al. Increased attentional network functioning related to symptom severity measures in females with irritable bowel syndrome. Neurogastroenterology and motility : the official journal of the European Gastrointestinal Motility Society. 2015;27(9):1282-94.

50. Aizawa E, Sato Y, Kochiyama T, Saito N, Izumiyama M, Morishita J, et al. Altered cognitive function of prefrontal cortex during error feedback in patients with irritable bowel syndrome, based on FMRI and dynamic causal modeling. Gastroenterology. 2012;143(5):1188-98.

51. Afzal M, Potokar JP, Probert CS, Munafo MR. Selective processing of gastrointestinal symptom-related stimuli in irritable bowel syndrome. Psychosom Med. 2006;68(5):758-61.

52. Petruo VA, Zeissig S, Schmelz R, Hampe J, Beste C. Specific neurophysiological mechanisms underlie cognitive inflexibility in inflammatory bowel disease. Sci Rep. 2017;7(1):13943.

53. Berrill JW, Gallacher J, Hood K, Green JT, Matthews SB, Campbell AK, et al. An observational study of cognitive function in patients with irritable bowel syndrome and inflammatory bowel disease. Neurogastroenterology \& Motility. 2013;25(11):918-e704.

54. Piasecki B, Turska-Malinska R, Matthews-Brzozowska T, Mojs E. Executive function in pediatric patients with cystic fibrosis, inflammatory bowel disease and in healthy controls. European review for medical and pharmacological sciences. 2016;20(20):4299-304.

55. Beck AT, Haigh EAP. Advances in Cognitive Theory and Therapy: The Generic Cognitive Model. Annual Review of Clinical Psychology. 2014;10(1):1-24.

56. Clark DA, Beck AT. Cognitive theory and therapy of anxiety and depression: Convergence with neurobiological findings. Trends in Cognitive Sciences. 2010;14(9):418-24. 
57. Rey E, Moreno Ortega M, Garcia Alonso MO, Diaz-Rubio M. Constructive thinking, rational intelligence and irritable bowel syndrome. World J Gastroenterol. 2009;15(25):3106-13.

58. Lackner JM, Jaccard J, Keefer L, Brenner DM, Firth RS, Gudleski GD, et al. Improvement in Gastrointestinal Symptoms After Cognitive Behavior Therapy for Refractory Irritable Bowel Syndrome. Gastroenterology. 2018;155(1):47-57.

59. Lackner JM, Jaccard J, Radziwon CD, Firth RS, Gudleski GD, Hamilton F, et al. Durability and Decay of Treatment Benefit of Cognitive Behavioral Therapy for Irritable Bowel Syndrome: 12-Month Follow-Up. Am J Gastroenterol. 2019;114(2):330-8.

60. Longarini G, Richly P, Temprano MP, Costa AF, Vazquez H, Moreno ML, et al. A Prospective Study on Cognitive Impairment in Middle-aged Adults With Newly Diagnosed Celiac Disease. Journal of clinical gastroenterology. 2018.

61. Lichtwark IT, Newnham ED, Robinson SR, Shepherd SJ, Hosking P, Gibson PR, et al. Cognitive impairment in coeliac disease improves on a gluten-free diet and correlates with histological and serological indices of disease severity. Alimentary pharmacology \& therapeutics. 2014;40(2):160-70.

62. van Langenberg DR, Yelland GW, Robinson SR, Gibson PR. Cognitive impairment in Crohn's disease is associated with systemic inflammation, symptom burden and sleep disturbance. United European gastroenterology journal. 2017;5(4):579-87.

63. Pennisi M, Bramanti A, Cantone M, Pennisi G, Bella R, Lanza G. Neurophysiology of the "Celiac Brain": Disentangling Gut-Brain Connections. Front Neurosci. 2017;11:498.

64. $\mathrm{Hu}$ WT, Murray JA, Greenaway MC, Parisi JE, Josephs KA. Cognitive impairment and celiac disease. Archives of neurology. 2006;63(10):1440-6.

65. Lai SW, Liao KF, Lin CL, Sung FC. Irritable bowel syndrome correlates with increased risk of Parkinson's disease in Taiwan. European journal of epidemiology. 2014;29(1):57-62.

66. Clairembault T, Leclair-Visonneau L, Coron E, Bourreille A, Le Dily S, Vavasseur F, et al. Structural alterations of the intestinal epithelial barrier in Parkinson's disease. Acta neuropathologica communications. 2015;3:12-.

67. Brudek T. Inflammatory Bowel Diseases and Parkinson's Disease. Journal of Parkinson's disease. 2019;9(s2):S331-S44.

68. Kowalski K, Mulak A. Brain-Gut-Microbiota Axis in Alzheimer's Disease. Journal of neurogastroenterology and motility. 2019;25(1):48-60.

69. Zuo L, Prather ER, Stetskiv M, Garrison DE, Meade JR, Peace TI, et al. Inflammaging and Oxidative Stress in Human Diseases: From Molecular Mechanisms to Novel Treatments. International journal of molecular sciences. 2019;20(18):4472.

70. Whitehouse CE, Fisk JD, Bernstein CN, Berrigan LI, Bolton JM, Graff LA, et al. Comorbid anxiety, depression, and cognition in MS and other immune-mediated disorders. Neurology. 2019.

71. Kano M, Dupont P, Aziz Q, Fukudo S. Understanding Neurogastroenterology From Neuroimaging Perspective: A Comprehensive Review of Functional and Structural Brain Imaging in Functional Gastrointestinal Disorders. J Neurogastroenterol Motil. 2018;24(4):512-27.

72. Huang JS, Terrones L, Simmons AN, Kaye W, Strigo I. Pilot Study of Functional Magnetic Resonance Imaging Responses to Somatic Pain Stimuli in Youth With Functional and Inflammatory Gastrointestinal Disease. J Pediatr Gastroenterol Nutr. 2016;63(5):500-7.

73. Jones MP, Dilley JB, Drossman D, Crowell MD. Brain-gut connections in functional GI disorders: anatomic and physiologic relationships. Neurogastroenterol Motil. 2006;18(2):91-103.

74. Bantick SJ, Wise RG, Ploghaus A, Clare S, Smith SM, Tracey I. Imaging how attention modulates pain in humans using functional MRI. Brain. 2002;125(Pt 2):310-9.

75. Yu R, Zhou W, Zhou X. Rapid processing of both reward probability and reward uncertainty in the human anterior cingulate cortex. PLoS One. 2011;6(12):e29633.

76. Nitschke JB, Sarinopoulos I, Mackiewicz KL, Schaefer HS, Davidson RJ. Functional neuroanatomy of aversion and its anticipation. NeuroImage. 2006;29(1):106-16.

77. Modi S, Rana P, Kaur P, Rani N, Khushu S. Glutamate level in anterior cingulate predicts anxiety in healthy humans: a magnetic resonance spectroscopy study. Psychiatry research. 2014;224(1):34-41.

78. Chua P, Krams M, Toni I, Passingham R, Dolan R. A functional anatomy of anticipatory anxiety. NeuroImage. 1999;9(6 Pt 1):563-71.

79. Kuhn S, Gallinat J. Resting-state brain activity in schizophrenia and major depression: a quantitative meta-analysis. Schizophrenia bulletin. 2013;39(2):358-65. 
80. Spati J, Hanggi J, Doerig N, Ernst J, Sambataro F, Brakowski J, et al. Prefrontal thinning affects functional connectivity and regional homogeneity of the anterior cingulate cortex in depression. Neuropsychopharmacology. 2015;40(7):1640-8.

81. Rolls ET, Cheng W, Gong W, Qiu J, Zhou C, Zhang J, et al. Functional Connectivity of the Anterior Cingulate Cortex in Depression and in Health. Cerebral cortex (New York, NY : 1991). 2019;29(8):3617-30.

82. Tolomeo S, Christmas D, Jentzsch I, Johnston B, Sprengelmeyer R, Matthews K, et al. A causal role for the anterior mid-cingulate cortex in negative affect and cognitive control. Brain. 2016;139(Pt 6):1844-54.

83. Phillips K, Wright BJ, Kent S. Irritable bowel syndrome and symptom severity: evidence of negative attention bias, diminished vigour, and autonomic dysregulation. Journal of psychosomatic research. 2014;77(1):13-9.

84. Icenhour A, Langhorst J, Benson S, Schlamann M, Hampel S, Engler H, et al. Neural circuitry of abdominal pain-related fear learning and reinstatement in irritable bowel syndrome. Neurogastroenterol Motil. 2015;27(1):114-27.

85. Farup PG, Hestad K. Cognitive Functions and Depression in Patients with Irritable Bowel Syndrome. Gastroenterology research and practice. 2015;2015:438329-.

86. Dancey CP, Attree EA, Stuart G, Wilson C, Sonnet A. Words fail me: the verbal IQ deficit in inflammatory bowel disease and irritable bowel syndrome. Inflamm Bowel Dis. 2009;15(6):852-7.

87. Attree EA, Dancey CP, Keeling D, Wilson C. Cognitive function in people with chronic illness: inflammatory bowel disease and irritable bowel syndrome. Applied neuropsychology. 2003;10(2):96-104.

88. Golan D, Gross B, Miller A, Klil-Drori S, Lavi I, Shiller M, et al. Cognitive Function of Patients with Crohn's Disease is Associated with Intestinal Disease Activity. Inflammatory Bowel Diseases. 2016;22(2):364-71. 89. Pennisi G, Lanza G, Giuffrida S, Vinciguerra L, Puglisi V, Cantone M, et al. Excitability of the motor cortex in de novo patients with celiac disease. PLoS One. 2014;9(7):e102790.

90. Arnone JM, Rizzolo D, Conti RP. Examination of Executive Function and Social Phobia Among Female College-Aged Students With Celiac Disease. Journal of psychosocial nursing and mental health services. 2018:110.

91. Filipovic BF, Randjelovic T, Ille T, Markovic O, Milovanovic B, Kovacevic N, et al. Anxiety, personality traits and quality of life in functional dyspepsia-suffering patients. European journal of internal medicine. 2013;24(1):83-6.

92. Silverman DH, Munakata JA, Ennes H, Mandelkern MA, Hoh CK, Mayer EA. Regional cerebral activity in normal and pathological perception of visceral pain. Gastroenterology. 1997;112(1):64-72.

93. Berman S, Munakata J, Naliboff BD, Chang L, Mandelkern M, Silverman D, et al. Gender differences in regional brain response to visceral pressure in IBS patients. European journal of pain (London, England). 2000;4(2):157-72.

94. Mertz H, Morgan $\ddagger$, Tanner* G, Pickensł D, Priceł R, Shyr§ Y, et al. Regional cerebral activation in irritable bowel syndrome and control subjects with painful and nonpainful rectal distention. Gastroenterology. 2000;118(5):842-8.

95. Naliboff BD, Derbyshire SWG, Munakata J, Berman S, Mandelkern M, Chang L, et al. Cerebral Activation in Patients With Irritable Bowel Syndrome and Control Subjects During Rectosigmoid Stimulation. Psychosomatic Medicine. 2001;63(3):365-75.

96. Bernstein CN, Frankenstein UN, Rawsthorne P, Pitz M, Summers R, McIntyre MC. Cortical mapping of visceral pain in patients with GI disorders using functional magnetic resonance imaging. American Journal Of Gastroenterology. 2002;97:319.

97. Bonaz B, Baciu M, Papillon E, Bost R, Gueddah N, Le Bas JF, et al. Central processing of rectal pain in patients with irritable bowel syndrome: an fMRI study. Am J Gastroenterol. 2002;97(3):654-61.

98. Naliboff BD, Berman S, Chang L, Derbyshire SW, Suyenobu B, Vogt BA, et al. Sex-related differences in IBS patients: central processing of visceral stimuli. Gastroenterology. 2003;124(7):1738-47.

99. Ringel Y, Drossman DA, Turkington TG, Bradshaw B, Hawk TC, Bangdiwala S, et al. Regional brain activation in response to rectal distension in patients with irritable bowel syndrome and the effect of a history of abuse. Digestive diseases and sciences. 2003;48(9):1774-81.

100. Verne GN, Himes NC, Robinson ME, Gopinath KS, Briggs RW, Crosson B, et al. Central representation of visceral and cutaneous hypersensitivity in the irritable bowel syndrome. Pain. 2003;103(1-2):99-110.

101. Yuan Y-Z, Tao R-J, Xu B, Sun J, Chen K-M, Miao F, et al. Functional brain imaging in irritable bowel syndrome with rectal balloon-distention by using fMRI. World Journal of Gastroenterology : WJG. 2003;9(6):1356-60. 
102. Wilder-Smith CH, Schindler D, Lovblad K, Redmond SM, Nirkko A. Brain functional magnetic resonance imaging of rectal pain and activation of endogenous inhibitory mechanisms in irritable bowel syndrome patient subgroups and healthy controls. Gut. 2004;53(11):1595-601.

103. Andresen V, Bach DR, Poellinger A, Tsrouya C, Stroh A, Foerschler A, et al. Brain activation responses to subliminal or supraliminal rectal stimuli and to auditory stimuli in irritable bowel syndrome. Neurogastroenterol Motil. 2005;17(6):827-37.

104. Kwan CL, Diamant NE, Pope G, Mikula K, Mikulis DJ, Davis KD. Abnormal forebrain activity in functional bowel disorder patients with chronic pain. Neurology. 2005;65(8):1268.

105. Mayer EA, Berman S, Suyenobu B, Labus J, Mandelkern MA, Naliboff BD, et al. Differences in brain responses to visceral pain between patients with irritable bowel syndrome and ulcerative colitis. Pain. 2005;115(3):398-409.

106. Naliboff BD, Berman S, Suyenobu B, Labus JS, Chang L, Stains J, et al. Longitudinal Change in Perceptual and Brain Activation Response to Visceral Stimuli in Irritable Bowel Syndrome Patients. Gastroenterology. 2006;131(2):352-65.

107. Berman SM, Naliboff BD, Suyenobu B, Labus JS, Stains J, Ohning G, et al. Reduced brainstem inhibition during anticipated pelvic visceral pain correlates with enhanced brain response to the visceral stimulus in women with irritable bowel syndrome. The Journal of neuroscience : the official journal of the Society for Neuroscience. 2008;28(2):349-59.

108. Davis KD, Pope G, Chen J, Kwan CL, Crawley AP, Diamant NE. Cortical thinning in IBS: implications for homeostatic, attention, and pain processing. Neurology. 2008;70(2):153-4.

109. Ringel Y, Drossman DA, Leserman JL, Suyenobu BY, Wilber K, Lin W, et al. Effect of abuse history on pain reports and brain responses to aversive visceral stimulation: an FMRI study. Gastroenterology. 2008;134(2):396-404.

110. Blankstein U, Chen J, Diamant NE, Davis KD. Altered brain structure in irritable bowel syndrome: potential contributions of pre-existing and disease-driven factors. Gastroenterology. 2010;138(5):1783-9.

111. Elsenbruch S, Rosenberger C, Bingel U, Forsting M, Schedlowski M, Gizewski ER. Patients with irritable bowel syndrome have altered emotional modulation of neural responses to visceral stimuli. Gastroenterology. 2010;139(4):1310-9.

112. Elsenbruch S, Rosenberger C, Enck P, Forsting M, Schedlowski M, Gizewski ER. Affective disturbances modulate the neural processing of visceral pain stimuli in irritable bowel syndrome: an fMRI study. Gut. 2010;59(4):489-95.

113. Hall GBC, Kamath MV, Collins S, Ganguli S, Spaziani R, Miranda KL, et al. Heightened central affective response to visceral sensations of pain and discomfort in IBS. Neurogastroenterology \& Motility. 2010;22(3):276e80.

114. Seminowicz DA, Labus JS, Bueller JA, Tillisch K, Naliboff BD, Bushnell MC, et al. Regional gray matter density changes in brains of patients with irritable bowel syndrome. Gastroenterology. 2010;139(1):48-57.e2.

115. Chen JY, Blankstein U, Diamant NE, Davis KD. White matter abnormalities in irritable bowel syndrome and relation to individual factors. Brain research. 2011;1392:121-31.

116. Ellingson BM, Mayer E, Harris RJ, Ashe-McNally C, Naliboff BD, Labus JS, et al. Diffusion tensor imaging detects microstructural reorganization in the brain associated with chronic irritable bowel syndrome. Pain. 2013;154(9):1528-41.

117. Labus JS, Hubbard CS, Bueller J, Ebrat B, Tillisch K, Chen M, et al. Impaired emotional learning and involvement of the corticotropin-releasing factor signaling system in patients with irritable bowel syndrome. Gastroenterology. 2013;145(6):1253-61.e1-3.

118. Irimia A, Labus JS, Torgerson CM, Van Horn JD, Mayer EA. Altered viscerotopic cortical innervation in patients with irritable bowel syndrome. Neurogastroenterol Motil. 2015;27(8):1075-81.

119. Labus JS, Dinov ID, Jiang Z, Ashe-McNalley C, Zamanyan A, Shi Y, et al. Irritable bowel syndrome in female patients is associated with alterations in structural brain networks. Pain. 2014;155(1):137-49.

120. Ke J, Qi R, Liu C, Xu Q, Wang F, Zhang L, et al. Abnormal regional homogeneity in patients with irritable bowel syndrome: A resting-state functional MRI study. Neurogastroenterol Motil. 2015;27(12):1796-803. 121. Ma X, Li S, Tian J, Jiang G, Wen H, Wang T, et al. Altered brain spontaneous activity and connectivity network in irritable bowel syndrome patients: A resting-state fMRI study. Clinical neurophysiology : official journal of the International Federation of Clinical Neurophysiology. 2015;126(6):1190-7.

122. Hong JY, Naliboff B, Labus JS, Gupta A, Kilpatrick LA, Ashe-McNalley C, et al. Altered brain responses in subjects with irritable bowel syndrome during cued and uncued pain expectation. Neurogastroenterol Motil. 2016;28(1):127-38. 
123. Liu X, Silverman A, Kern M, Ward BD, Li SJ, Shaker R, et al. Excessive coupling of the salience network with intrinsic neurocognitive brain networks during rectal distension in adolescents with irritable bowel syndrome: a preliminary report. Neurogastroenterol Motil. 2016;28(1):43-53.

124. Chua CS, Bai CH, Shiao CY, Hsu CY, Cheng CW, Yang KC, et al. Negative correlation of cortical thickness with the severity and duration of abdominal pain in Asian women with irritable bowel syndrome. PLoS One. 2017;12(8):e0183960.

125. Fang J, Li S, Li M, Chan Q, Ma X, Su H, et al. Altered white matter microstructure identified with tractbased spatial statistics in irritable bowel syndrome: a diffusion tensor imaging study. Brain Imaging Behav. 2017;11(4):1110-6.

126. Guleria A, Karyampudi A, Singh R, Khetrapal CL, Verma A, Ghoshal UC, et al. Mapping of Brain Activations to Rectal Balloon Distension Stimuli in Male Patients with Irritable Bowel Syndrome Using Functional Magnetic Resonance Imaging. J Neurogastroenterol Motil. 2017;23(3):415-27.

127. Kano M, Muratsubaki T, Morishita J, Kono K, Mugikura S, Takase K, et al. Influence of Uncertain Anticipation on Brain Responses to Aversive Rectal Distension in Patients With Irritable Bowel Syndrome. Psychosom Med. 2017;79(9):988-99.

128. Kano M, Muratsubaki T, Van Oudenhove L, Morishita J, Yoshizawa M, Kohno K, et al. Altered brain and gut responses to corticotropin-releasing hormone $(\mathrm{CRH})$ in patients with irritable bowel syndrome. Scientific Reports. 2017;7:12425.

129. Hubbard CS, Becerra L, Heinz N, Ludwick A, Rasooly T, Wu R, et al. Abdominal Pain, the Adolescent and Altered Brain Structure and Function. PloS one. 2016;11(5):e0156545-e.

130. Hubbard CS, Becerra L, Heinz N, Ludwick A, Rasooly T, Yendiki A, et al. Microstructural White Matter Abnormalities in the Dorsal Cingulum of Adolescents with IBS. eNeuro. 2018;5(4).

131. Icenhour A, Witt ST, Elsenbruch S, Lowen M, Engstrom M, Tillisch K, et al. Brain functional connectivity is associated with visceral sensitivity in women with Irritable Bowel Syndrome. NeuroImage Clinical. 2017;15:449-57.

132. Bednarska O, Icenhour A, Tapper S, Witt ST, Tisell A, Lundberg P, et al. Reduced excitatory neurotransmitter levels in anterior insulae are associated with abdominal pain in irritable bowel syndrome. Pain. 2019.

133. Bhatt RR, Gupta A, Labus JS, Zeltzer LK, Tsao JC, Shulman RJ, et al. Altered Brain Structure and Functional Connectivity and Its Relation to Pain Perception in Girls With Irritable Bowel Syndrome. Psychosom Med. 2019;81(2):146-54.

134. Labus JS, Osadchiy V, Hsiao EY, Tap J, Derrien M, Gupta A, et al. Evidence for an association of gut microbial Clostridia with brain functional connectivity and gastrointestinal sensorimotor function in patients with irritable bowel syndrome, based on tripartite network analysis. Microbiome. 2019;7(1):45.

135. Nan J, Yang W, Meng P, Huang W, Zheng Q, Xia Y, et al. Changes of the postcentral cortex in irritable bowel syndrome patients. Brain Imaging Behav. 2019.

136. Chen M, Lee G, Kwong LN, Lamont S, Chaves C. Cerebral white matter lesions in patients with Crohn's disease. Journal of neuroimaging : official journal of the American Society of Neuroimaging. 2012;22(1):38-41.

137. Liu P, Li R, Bao C, Wei Y, Fan Y, Liu Y, et al. Altered topological patterns of brain functional networks in Crohn's disease. Brain Imaging Behav. 2018;12(5):1466-78.

138. Hou J, Mohanty R, Nair VA, Dodd K, Beniwal-Patel P, Saha S, et al. Alterations in resting-state functional connectivity in patients with Crohn's disease in remission. Sci Rep. 2019;9(1):7412.

139. Thomann AK, Reindl W, Wustenberg T, Kmuche D, Ebert MP, Szabo K, et al. Aberrant brain structural large-scale connectome in Crohn's disease. Neurogastroenterol Motil. 2019;31(6):e13593.

140. Agostini A, Filippini N, Cevolani D, Agati R, Leoni C, Tambasco R, et al. Brain functional changes in patients with ulcerative colitis: A functional magnetic resonance imaging study on emotional processing. Inflammatory Bowel Diseases. 2010;17(8):1769-77.

141. Agostini A, Benuzzi F, Filippini N, Bertani A, Scarcelli A, Farinelli V, et al. New insights into the brain involvement in patients with Crohn's disease: a voxel-based morphometry study. Neurogastroenterol Motil. 2013;25(2):147-e82.

142. Hong J-Y, Labus JS, Jiang Z, Ashe-Mcnalley C, Dinov I, Gupta A, et al. Regional Neuroplastic Brain Changes in Patients with Chronic Inflammatory and Non-Inflammatory Visceral Pain. PLoS ONE. 2014;9(1):e84564.

143. Nan J, Liu J, Zhang D, Yang Y, Yan X, Yin Q, et al. Altered intrinsic regional activity and corresponding brain pathways reflect the symptom severity of functional dyspepsia. Neurogastroenterology \& Motility. 2014;26(5):660-9. 
144. Zikou AK, Kosmidou M, Astrakas LG, Tzarouchi LC, Tsianos E, Argyropoulou MI. Brain involvement in patients with inflammatory bowel disease: a voxel-based morphometry and diffusion tensor imaging study. European radiology. 2014;24(10):2499-506.

145. Bao CH, Liu P, Liu HR, Wu LY, Shi Y, Chen WF, et al. Alterations in brain grey matter structures in patients with crohn's disease and their correlation with psychological distress. Journal of Crohn's \& colitis. 2015;9(7):532-40.

146. Bao C, Liu P, Liu H, Jin X, Calhoun VD, Wu L, et al. Different brain responses to electro-acupuncture and moxibustion treatment in patients with Crohn's disease. Sci Rep. 2016;6:36636.

147. Qi R, Liu C, Ke J, Xu Q, Zhong J, Wang F, et al. Intrinsic brain abnormalities in irritable bowel syndrome and effect of anxiety and depression. Brain Imaging and Behavior. 2016;10(4):1127-34.

148. Qi R, Ke J, Schoepf UJ, Varga-Szemes A, Milliken CM, Liu C, et al. Topological Reorganization of the Default Mode Network in Irritable Bowel Syndrome. Molecular neurobiology. 2016;53(10):6585-93.

149. Rubio A, Pellissier S, Van Oudenhove L, Ly HG, Dupont P, Tack J, et al. Brain responses to uncertainty about upcoming rectal discomfort in quiescent Crohn's disease - a fMRI study. Neurogastroenterol Motil. 2016;28(9):1419-32.

150. Thomann AK, Thomann PA, Wolf RC, Hirjak D, Schmahl C, Ebert MP, et al. Altered Markers of Brain Development in Crohn's Disease with Extraintestinal Manifestations - A Pilot Study. PLoS One. 2016;11(9):e0163202.

151. Bao C, Liu P, Shi Y, Wu L, Jin X, Zeng X, et al. Differences in brain gray matter volume in patients with Crohn's disease with and without abdominal pain. Oncotarget. 2017;8(55):93624-32.

152. Guleria A, Karyampudi A, Singh R, Khetrapal CL, Verma A, Ghoshal UC, et al. Mapping of Brain Activations to Rectal Balloon Distension Stimuli in Male Patients with Irritable Bowel Syndrome Using Functional Magnetic Resonance Imaging. Journal of Neurogastroenterology and Motility. 2017;23(3):415-27.

153. Longarzo M, Quarantelli M, Aiello M, Romano M, Del Prete A, Cimminiello C, et al. The influence of interoceptive awareness on functional connectivity in patients with irritable bowel syndrome. Brain Imaging Behav. 2017;11(4):1117-28.

154. Pennisi M, Lanza G, Cantone M, Ricceri R, Ferri R, D'Agate CC, et al. Cortical involvement in celiac disease before and after long-term gluten-free diet: A Transcranial Magnetic Stimulation study. PloS one. 2017;12(5):e0177560-e.

155. Thomann AK, Griebe M, Thomann PA, Hirjak D, Ebert MP, Szabo K, et al. Intrinsic neural network dysfunction in quiescent Crohn's Disease. Sci Rep. 2017;7(1):11579.

156. Wang D, Zhang X, Zhang X, Huang Z, Song Y. Magnetic resonance imaging analysis of brain function in patients with irritable bowel syndrome. BMC Gastroenterology. 2017;17(1):148.

157. Bao C, Liu P, Liu H, Jin X, Shi Y, Wu L, et al. Difference in regional neural fluctuations and functional connectivity in Crohn's disease: a resting-state functional MRI study. Brain Imaging Behav. 2018.

158. Lv K, Song W, Tang R, Pan Z, Zhang Y, Xu Y, et al. Neurotransmitter alterations in the anterior cingulate cortex in Crohn's disease patients with abdominal pain: A preliminary MR spectroscopy study. NeuroImage : Clinical. 2018;20:793-9.

159. Currie S, Hadjivassiliou M, Clark MJR, Sanders DS, Wilkinson ID, Griffiths PD, et al. Should we be 'nervous' about coeliac disease? Brain abnormalities in patients with coeliac disease referred for neurological opinion. Journal of Neurology, Neurosurgery \&amp;amp; Psychiatry. 2012;83(12):1216.

160. Bilgic B, Aygun D, Arslan AB, Bayram A, Akyuz F, Sencer S, et al. Silent neurological involvement in biopsy-defined coeliac patients. Neurological Sciences. 2013;34(12):2199-204.

161. Liu P, Qin W, Wang J, Zeng F, Zhou G, Wen H, et al. Identifying Neural Patterns of Functional Dyspepsia Using Multivariate Pattern Analysis: A Resting-State fMRI Study. PLos ONE. 2013;8(7).

162. Mak ADP, Northoff G, Yeung DKW, Chu WCW, Hui SCN, Cheung C, et al. Increased Glutamate in Somatosensory Cortex in Functional Dyspepsia. Sci Rep. 2017;7(1):3926.

163. Ly HG, Ceccarini J, Weltens N, Bormans G, Van Laere K, Tack J, et al. Increased cerebral cannabinoid1 receptor availability is a stable feature of functional dyspepsia: a [F]MK-9470 PET study. Psychotherapy and psychosomatics. 2015;84(3):149-58.

164. Zeng F, Qin W, Liang F, Liu J, Tang Y, Liu X, et al. Abnormal Resting Brain Activity in Patients With Functional Dyspepsia Is Related to Symptom Severity. Gastroenterology. 2011;141(2):499-506.

165. Zeng F, Lan L, Tang Y, Liu M, Liu X, Song W, et al. Cerebral responses to puncturing at different acupoints for treating meal-related functional dyspepsia. Neurogastroenterol Motil. 2015;27(4):559-68.

166. Zeng F, Sun R, He Z, Chen Y, Lei D, Yin T, et al. Altered Functional Connectivity of the Amygdala and Sex Differences in Functional Dyspepsia. Clinical and translational gastroenterology. 2019;10(6):e00046. 
167. Mazaheri M, Afshar H, Nikneshan S, Adibi P. Cognitive emotion regulation strategies in patients with functional dyspepsia and healthy controls - A comparative study. Adv Biomed Res. 2016;5:196.

168. Nan J, Zhang L, Zhu F, Tian X, Zheng Q, Deneen KM, et al. Topological Alterations of the Intrinsic Brain Network in Patients with Functional Dyspepsia. J Neurogastroenterol Motil. 2016;22(1):118-28.

169. Nan J, Liu J, Mu J, Dun W, Zhang M, Gong Q, et al. Brain-based Correlations Between Psychological Factors and Functional Dyspepsia. J Neurogastroenterol Motil. 2015;21(1):103-10.

170. Liu P, Wang G, Zeng F, Liu Y, Fan Y, Wei Y, et al. Abnormal brain structure implicated in patients with functional dyspepsia. Brain Imaging Behav. 2018;12(2):459-66.

171. Caracheo BF, Grewal JJS, Seamans JK. Persistent Valence Representations by Ensembles of Anterior Cingulate Cortex Neurons. Front Syst Neurosci. 2018;12:51.

172. Apkarian AV, Bushnell MC, Treede RD, Zubieta JK. Human brain mechanisms of pain perception and regulation in health and disease. European journal of pain (London, England). 2005;9(4):463-84.

173. Gilbert DT, Wilson TD. Prospection: Experiencing the Future. Science. 2007;317(5843):1351-4.

174. Hashemi MM, Gladwin TE, de Valk NM, Zhang W, Kaldewaij R, van Ast V, et al. Neural Dynamics of Shooting Decisions and the Switch from Freeze to Fight. Sci Rep. 2019;9(1):4240.

175. Piche T, Ducrotte P, Sabate JM, Coffin B, Zerbib F, Dapoigny M, et al. Impact of functional bowel symptoms on quality of life and fatigue in quiescent Crohn disease and irritable bowel syndrome. Neurogastroenterol Motil. 2010;22(6):626-e174.

176. Bryant RV, van Langenberg DR, Holtmann GJ, Andrews JM. Functional gastrointestinal disorders in inflammatory bowel disease: impact on quality of life and psychological status. Journal of gastroenterology and hepatology. 2011;26(5):916-23.

177. Rhudy JL, Meagher MW. Fear and anxiety: divergent effects on human pain thresholds. Pain. 2000;84(1):65-75.

178. Carlsson K, Andersson J, Petrovic P, Petersson KM, Ohman A, Ingvar M. Predictability modulates the affective and sensory-discriminative neural processing of pain. NeuroImage. 2006;32(4):1804-14.

179. Rubio A, Van Oudenhove L, Pellissier S, Ly HG, Dupont P, Lafaye de Micheaux H, et al. Uncertainty in anticipation of uncomfortable rectal distension is modulated by the autonomic nervous system--a fMRI study in healthy volunteers. NeuroImage. 2015;107:10-22.

180. Tillisch K, Mayer EA, Labus JS. Quantitative Meta-Analysis Identifies Brain Regions Activated during Rectal Distension in Irritable Bowel Syndrome. Gastroenterology. 2011;140(1):91-100.

181. Berman SM, Naliboff BD, Chang L, Fitzgerald L, Antolin T, Camplone A, et al. Enhanced preattentive central nervous system reactivity in irritable bowel syndrome. Am J Gastroenterol. 2002;97(11):2791-7.

182. Blomhoff S, Jacobsen MB, Spetalen S, Dahm A, Malt UF. Perceptual hyperreactivity to auditory stimuli in patients with irritable bowel syndrome. Scandinavian journal of gastroenterology. 2000;35(6):583-9.

183. Rothman DL, Behar KL, Hyder F, Shulman RG. In vivo NMR studies of the glutamate neurotransmitter flux and neuroenergetics: implications for brain function. Annual review of physiology. 2003;65:401-27.

184. Gabbay V, Bradley KA, Mao X, Ostrover R, Kang G, Shungu DC. Anterior cingulate cortex gammaaminobutyric acid deficits in youth with depression. Translational psychiatry. 2017;7(8):e1216.

185. Ernst J, Hock A, Henning A, Seifritz E, Boeker H, Grimm S. Increased pregenual anterior cingulate glucose and lactate concentrations in major depressive disorder. Mol Psychiatry. 2017;22(1):113-9.

186. Fjell AM, Walhovd KB. Structural brain changes in aging: courses, causes and cognitive consequences. Reviews in the neurosciences. 2010;21(3):187-221.

187. Vidal-Pineiro D, Parker N, Shin J, French L, Jackowski A, Mowinckel A, et al. Cellular correlates of cortical thinning throughout the lifespan. bioRxiv. 2019:585786.

188. Russell MD, Barrick TR, Howe FA, Sofat N. Reduced anterior cingulate grey matter volume in painful hand osteoarthritis. Rheumatology international. 2018.

189. Jutzeler CR, Huber E, Callaghan MF, Luechinger R, Curt A, Kramer JL, et al. Association of pain and CNS structural changes after spinal cord injury. Sci Rep. 2016;6:18534.

190. Burgmer M, Gaubitz M, Konrad C, Wrenger M, Hilgart S, Heuft G, et al. Decreased gray matter volumes in the cingulo-frontal cortex and the amygdala in patients with fibromyalgia. Psychosom Med. 2009;71(5):56673.

191. Watanabe K, Hirano S, Kojima K, Nagashima K, Mukai H, Sato T, et al. Altered cerebral blood flow in the anterior cingulate cortex is associated with neuropathic pain. Journal of neurology, neurosurgery, and psychiatry. 2018;89(10):1082-7.

192. van Velzen LS, Schmaal L, Milaneschi Y, van Tol MJ, van der Wee NJA, Veltman DJ, et al. Immunometabolic dysregulation is associated with reduced cortical thickness of the anterior cingulate cortex. Brain Behav Immun. 2017;60:361-8. 
193. Kohler O, Krogh J, Mors O, Benros ME. Inflammation in Depression and the Potential for AntiInflammatory Treatment. Current neuropharmacology. 2016;14(7):732-42.

194. Wise T, Radua J, Via E, Cardoner N, Abe O, Adams TM, et al. Common and distinct patterns of greymatter volume alteration in major depression and bipolar disorder: evidence from voxel-based meta-analysis. Molecular psychiatry. 2017;22(10):1455-63.

195. Bushnell MC, Ceko M, Low LA. Cognitive and emotional control of pain and its disruption in chronic pain. Nature reviews Neuroscience. 2013;14(7):502-11.

196. Chassaing B, Aitken JD, Malleshappa M, Vijay-Kumar M. Dextran Sulfate Sodium (DSS)-Induced Colitis in Mice. Current protocols in immunology / edited by John E Coligan [et al]. 2014;104:Unit-15.25.

197. Morris GP, Beck PL, Herridge MS, Depew WT, Szewczuk MR, Wallace JL. Hapten-induced model of chronic inflammation and ulceration in the rat colon. Gastroenterology. 1989;96(3):795-803.

198. Qin L, Wu X, Block ML, Liu Y, Breese GR, Hong JS, et al. Systemic LPS causes chronic neuroinflammation and progressive neurodegeneration. Glia. 2007;55(5):453-62.

199. Frost JL, Schafer DP. Microglia: Architects of the Developing Nervous System. Trends in Cell Biology. 2016;26(8):587-97.

200. Squarzoni P, Oller G, Hoeffel G, Pont-Lezica L, Rostaing P, Low D, et al. Microglia Modulate Wiring of the Embryonic Forebrain. Cell Reports. 2014;8(5):1271-9.

201. Wake H, Moorhouse AJ, Jinno S, Kohsaka S, Nabekura J. Resting Microglia Directly Monitor the Functional State of Synapses \&lt;em\&gt;In Vivo\&lt;/em\&gt; and Determine the Fate of Ischemic Terminals. The Journal of Neuroscience. 2009;29(13):3974.

202. Parkhurst Christopher N, Yang G, Ninan I, Savas Jeffrey N, Yates John R, Lafaille Juan J, et al. Microglia Promote Learning-Dependent Synapse Formation through Brain-Derived Neurotrophic Factor. Cell. 2013;155(7):1596-609.

203. Hong S, Dissing-Olesen L, Stevens B. New insights on the role of microglia in synaptic pruning in health and disease. Current opinion in neurobiology. 2016;36:128-34.

204. Burda JE, Sofroniew MV. Reactive gliosis and the multicellular response to CNS damage and disease. Neuron. 2014;81(2):229-48.

205. Chesnokova V, Pechnick RN, Wawrowsky K. Chronic peripheral inflammation, hippocampal neurogenesis, and behavior. Brain Behav Immun. 2016;58:1-8.

206. Cunningham C, Dunne A, Lopez-Rodriguez AB. Astrocytes: Heterogeneous and Dynamic Phenotypes in Neurodegeneration and Innate Immunity. The Neuroscientist. 2018:1073858418809941.

207. Verkhratsky A, Nedergaard M. Physiology of Astroglia. Physiological reviews. 2018;98(1):239-389.

208. Zamanian JL, Xu L, Foo LC, Nouri N, Zhou L, Giffard RG, et al. Genomic analysis of reactive astrogliosis. The Journal of neuroscience : the official journal of the Society for Neuroscience. 2012;32(18):6391410 .

209. Liddelow SA, Guttenplan KA, Clarke LE, Bennett FC, Bohlen CJ, Schirmer L, et al. Neurotoxic reactive astrocytes are induced by activated microglia. Nature. 2017;541:481.

210. Aspelund A, Antila S, Proulx ST, Karlsen TV, Karaman S, Detmar M, et al. A dural lymphatic vascular system that drains brain interstitial fluid and macromolecules. The Journal of experimental medicine. 2015;212(7):991-9.

211. Louveau A, Smirnov I, Keyes TJ, Eccles JD, Rouhani SJ, Peske JD, et al. Structural and functional features of central nervous system lymphatic vessels. Nature. 2015;523(7560):337-41.

212. Goldmann T, Wieghofer P, Jordão MJ, Prutek F, Hagemeyer N, Frenzel K, et al. Origin, fate and dynamics of macrophages at central nervous system interfaces. Nature immunology. 2016;17(7):797-805.

213. Song C, Nicholson JD, Clark SM, Li X, Keegan AD, Tonelli LH. Expansion of brain T cells in homeostatic conditions in lymphopenic Rag2(-/-) mice. Brain Behav Immun. 2016;57:161-72.

214. Feng Y, He X, Luo S, Chen X, Long S, Liang F, et al. Chronic colitis induces meninges traffic of gutderived T cells, unbalances M1 and M2 microglia/macrophage and increases ischemic brain injury in mice. Brain research. 2019;1707:8-17.

215. Louveau A, Herz J, Alme MN, Salvador AF, Dong MQ, Viar KE, et al. CNS lymphatic drainage and neuroinflammation are regulated by meningeal lymphatic vasculature. Nature neuroscience. 2018;21(10):138091.

216. Daglas M, Draxler DF, Ho H, McCutcheon F, Galle A, Au AE, et al. Activated CD8(+) T Cells Cause Long-Term Neurological Impairment after Traumatic Brain Injury in Mice. Cell Rep. 2019;29(5):1178-91.e6.

217. Silver R, Curley JP. Mast cells on the mind: new insights and opportunities. Trends Neurosci. 2013;36(9):513-21. 
218. Ribatti D. The crucial role of mast cells in blood-brain barrier alterations. Experimental cell research. 2015;338(1):119-25.

219. Maślińska D, Laure-Kamionowska M, Gujski M, Ciurzynska G, Wojtecka-Lukasik E. Post-infectional distribution and phenotype of mast cells penetrating human brains. Inflammation Research. 2005;54(1):S15-S6.

220. Nava F, Caputi AP. Central effects of cromoglycate sodium salt in rats treated with lipopolysaccharide. European journal of pharmacology. 1999;367(2-3):351-9.

221. Dong H, Zhang X, Wang Y, Zhou X, Qian Y, Zhang S. Suppression of Brain Mast Cells Degranulation Inhibits Microglial Activation and Central Nervous System Inflammation. Molecular neurobiology. 2017;54(2):997-1007.

222. Buckley CD, Gilroy DW, Serhan CN. Proresolving lipid mediators and mechanisms in the resolution of acute inflammation. Immunity. 2014;40(3):315-27.

223. Meduri GU, Chrousos GP. General Adaptation in Critical Illness: Glucocorticoid Receptor-alpha Master Regulator of Homeostatic Corrections. Frontiers in endocrinology. 2020;11:161-.

224. Kim CC, Nakamura MC, Hsieh CL. Brain trauma elicits non-canonical macrophage activation states. Journal of Neuroinflammation. 2016;13(1):117.

225. Chen Z, Jalabi W, Hu W, Park HJ, Gale JT, Kidd GJ, et al. Microglial displacement of inhibitory synapses provides neuroprotection in the adult brain. Nat Commun. 2014;5:4486.

226. Xia C-Y, Zhang S, Gao Y, Wang Z-Z, Chen N-H. Selective modulation of microglia polarization to M2 phenotype for stroke treatment. International immunopharmacology. 2015;25(2):377-82.

227. Loane DJ, Kumar A. Microglia in the TBI brain: The good, the bad, and the dysregulated. Experimental neurology. 2016;275 Pt 3(0 3):316-27.

228. Song GJ, Suk K. Pharmacological Modulation of Functional Phenotypes of Microglia in Neurodegenerative Diseases. Frontiers in aging neuroscience. 2017;9:139-.

229. Mathys H, Adaikkan C, Gao F, Young JZ, Manet E, Hemberg M, et al. Temporal Tracking of Microglia Activation in Neurodegeneration at Single-Cell Resolution. Cell Rep. 2017;21(2):366-80.

230. Elmore MR, Najafi AR, Koike MA, Dagher NN, Spangenberg EE, Rice RA, et al. Colony-stimulating factor 1 receptor signaling is necessary for microglia viability, unmasking a microglia progenitor cell in the adult brain. Neuron. 2014;82(2):380-97.

231. Rice RA, Spangenberg EE, Yamate-Morgan H, Lee RJ, Arora RPS, Hernandez MX, et al. Elimination of Microglia Improves Functional Outcomes Following Extensive Neuronal Loss in the Hippocampus. The Journal of Neuroscience. 2015;35(27):9977.

232. Jin W-N, Shi SX-Y, Li Z, Li M, Wood K, Gonzales RJ, et al. Depletion of microglia exacerbates postischemic inflammation and brain injury. Journal of cerebral blood flow and metabolism : official journal of the International Society of Cerebral Blood Flow and Metabolism. 2017;37(6):2224-36.

233. Szalay G, Martinecz B, Lénárt N, Környei Z, Orsolits B, Judák L, et al. Microglia protect against brain injury and their selective elimination dysregulates neuronal network activity after stroke. Nature communications. 2016;7:11499-.

234. Condello C, Yuan P, Schain A, Grutzendler J. Microglia constitute a barrier that prevents neurotoxic protofibrillar Abeta42 hotspots around plaques. Nat Commun. 2015;6:6176.

235. Spangenberg EE, Lee RJ, Najafi AR, Rice RA, Elmore MRP, Blurton-Jones M, et al. Eliminating microglia in Alzheimer's mice prevents neuronal loss without modulating amyloid- $\beta$ pathology. Brain : a journal of neurology. 2016;139(Pt 4):1265-81.

236. Sofroniew MV, Vinters HV. Astrocytes: biology and pathology. Acta Neuropathol. 2010;119(1):7-35.

237. Zador Z, Stiver S, Wang V, Manley GT. Role of aquaporin-4 in cerebral edema and stroke. Handbook of experimental pharmacology. 2009(190):159-70.

238. Bush TG, Puvanachandra N, Horner CH, Polito A, Ostenfeld T, Svendsen CN, et al. Leukocyte infiltration, neuronal degeneration, and neurite outgrowth after ablation of scar-forming, reactive astrocytes in adult transgenic mice. Neuron. 1999;23(2):297-308.

239. Anderson MA, Burda JE, Ren Y, Ao Y, O'Shea TM, Kawaguchi R, et al. Astrocyte scar formation aids central nervous system axon regeneration. Nature. 2016;532(7598):195-200.

240. Norden DM, Fenn AM, Dugan A, Godbout JP. TGF $\beta$ produced by IL-10 redirected astrocytes attenuates microglial activation. Glia. 2014;62(6):881-95.

241. Shechter R, London A, Varol C, Raposo C, Cusimano M, Yovel G, et al. Infiltrating Blood-Derived Macrophages Are Vital Cells Playing an Anti-inflammatory Role in Recovery from Spinal Cord Injury in Mice. PLoS medicine. 2009;6(7):e1000113. 
242. Shinozaki Y, Shibata K, Yoshida K, Shigetomi E, Gachet C, Ikenaka K, et al. Transformation of Astrocytes to a Neuroprotective Phenotype by Microglia via P2Y1 Receptor Downregulation. Cell Rep. 2017;19(6):1151-64.

243. Zonis S, Pechnick RN, Ljubimov VA, Mahgerefteh M, Wawrowsky K, Michelsen KS, et al. Chronic intestinal inflammation alters hippocampal neurogenesis. Journal of Neuroinflammation. 2015;12(1):65.

244. Han Y, Zhao T, Cheng X, Zhao M, Gong SH, Zhao YQ, et al. Cortical Inflammation is Increased in a DSS-Induced Colitis Mouse Model. Neuroscience bulletin. 2018.

245. Abautret-Daly Á, Dempsey E, Parra-Blanco A, Medina C, Harkin A. Gut-brain actions underlying comorbid anxiety and depression associated with inflammatory bowel disease. Acta Neuropsychiatrica. 2018;30(5):275-96.

246. Dempsey E, Abautret-Daly Á, Docherty NG, Medina C, Harkin A. Persistent central inflammation and region specific cellular activation accompany depression- and anxiety-like behaviours during the resolution phase of experimental colitis. Brain, Behavior, and Immunity. 2019.

247. Hassan AM, Jain P, Reichmann F, Mayerhofer R, Farzi A, Schuligoi R, et al. Repeated predictable stress causes resilience against colitis-induced behavioral changes in mice. Frontiers in Behavioral Neuroscience. 2014;8:386.

248. Reichmann F, Hassan AM, Farzi A, Jain P, Schuligoi R, Holzer P. Dextran sulfate sodium-induced colitis alters stress-associated behaviour and neuropeptide gene expression in the amygdala-hippocampus network of mice. Scientific Reports. 2015;5:9970.

249. Gadotti VM, Andonegui G, Zhang Z, M'Dahoma S, Baggio CH, Chen L, et al. Neuroimmune Responses Mediate Depression-Related Behaviors following Acute Colitis. iScience. 2019;16:12-21.

250. Riazi K, Galic MA, Kuzmiski JB, Ho W, Sharkey KA, Pittman QJ. Microglial activation and TNFalpha production mediate altered CNS excitability following peripheral inflammation. Proc Natl Acad Sci U S A. 2008;105(44):17151-6.

251. Heydarpour P, Rahimian R, Fakhfouri G, Khoshkish S, Fakhraei N, Salehi-Sadaghiani M, et al. Behavioral despair associated with a mouse model of Crohn's disease: Role of nitric oxide pathway. Progress in neuro-psychopharmacology \& biological psychiatry. 2016;64:131-41.

252. Haj-Mirzaian A, Amiri S, Amini-Khoei H, Hosseini MJ, Haj-Mirzaian A, Momeny M, et al. Anxietyand Depressive-Like Behaviors are Associated with Altered Hippocampal Energy and Inflammatory Status in a Mouse Model of Crohn's Disease. Neuroscience. 2017;366:124-37.

253. Jang SE, Lim SM, Jeong JJ, Jang HM, Lee HJ, Han MJ, et al. Gastrointestinal inflammation by gut microbiota disturbance induces memory impairment in mice. Mucosal Immunol. 2018;11(2):369-79.

254. Wang J, Tu J, Cao B, Mu L, Yang X, Cong M, et al. Astrocytic 1-Lactate Signaling Facilitates AmygdalaAnterior Cingulate Cortex Synchrony and Decision Making in Rats. Cell Reports. 2017;21(9):2407-18.

255. Zhang G, Zhao BX, Hua R, Kang J, Shao BM, Carbonaro TM, et al. Hippocampal microglial activation and glucocorticoid receptor down-regulation precipitate visceral hypersensitivity induced by colorectal distension in rats. Neuropharmacology. 2016;102:295-303.

256. Stellwagen D, Malenka RC. Synaptic scaling mediated by glial TNF-alpha. Nature. 2006;440(7087):10549.

257. Onufriev MV, Freiman SV, Peregud DI, Kudryashova IV, Tishkina AO, Stepanichev MY, et al. Neonatal Proinflammatory Stress Induces Accumulation of Corticosterone and Interleukin-6 in the Hippocampus of Juvenile Rats: Potential Mechanism of Synaptic Plasticity Impairments. Biochemistry Biokhimiia. 2017;82(3):27581.

258. Xu Y, Cui SY, Ma Q, Shi J, Yu Y, Li JX, et al. trans-Resveratrol Ameliorates Stress-Induced Irritable Bowel Syndrome-Like Behaviors by Regulation of Brain-Gut Axis. Frontiers in pharmacology. 2018;9:631.

259. Lee HJ, Jeong JJ, Han MJ, Kim DH. Lactobacillus plantarum C29 Alleviates TNBS-Induced Memory Impairment in Mice. Journal of microbiology and biotechnology. 2018;28(1):175-9.

260. Bercik P, Verdu EF, Foster JA, Macri J, Potter M, Huang X, et al. Chronic gastrointestinal inflammation induces anxiety-like behavior and alters central nervous system biochemistry in mice. Gastroenterology. 2010;139(6):2102-12.e1.

261. Gareau MG, Wine E, Rodrigues DM, Cho JH, Whary MT, Philpott DJ, et al. Bacterial infection causes stress-induced memory dysfunction in mice. Gut. 2011;60(3):307.

262. Zhang JC, Wu J, Fujita Y, Yao W, Ren Q, Yang C, et al. Antidepressant effects of TrkB ligands on depression-like behavior and dendritic changes in mice after inflammation. The international journal of neuropsychopharmacology. 2014;18(4).

263. Berton O, McClung CA, Dileone RJ, Krishnan V, Renthal W, Russo SJ, et al. Essential role of BDNF in the mesolimbic dopamine pathway in social defeat stress. Science. 2006;311(5762):864-8. 
264. Lapchak PA, Araujo DM, Hefti F. Systemic interleukin-1 beta decreases brain-derived neurotrophic factor messenger RNA expression in the rat hippocampal formation. Neuroscience. 1993;53(2):297-301.

265. Bercik P, Denou E, Collins J, Jackson W, Lu J, Jury J, et al. The intestinal microbiota affect central levels of brain-derived neurotropic factor and behavior in mice. Gastroenterology. 2011;141(2):599-609, .e1-3.

266. Jang HM, Lee KE, Kim DH. The Preventive and Curative Effects of Lactobacillus reuteri NK33 and Bifidobacterium adolescentis NK98 on Immobilization Stress-Induced Anxiety/Depression and Colitis in Mice. Nutrients. 2019;11(4).

267. Hoogland ICM, Houbolt C, van Westerloo DJ, van Gool WA, van de Beek D. Systemic inflammation and microglial activation: systematic review of animal experiments. Journal of neuroinflammation. 2015;12:114-

268. Eijkelkamp N, Kavelaars A, Elsenbruch S, Schedlowski M, Holtmann G, Heijnen CJ. Increased visceral sensitivity to capsaicin after DSS-induced colitis in mice: spinal cord c-Fos expression and behavior. American Journal of Physiology-Gastrointestinal and Liver Physiology. 2007;293(4):G749-G57.

269. Bercik P, Park AJ, Sinclair D, Khoshdel A, Lu J, Huang X, et al. The anxiolytic effect of Bifidobacterium longum NCC3001 involves vagal pathways for gut-brain communication. Neurogastroenterology and motility : the official journal of the European Gastrointestinal Motility Society. 2011;23(12):1132-9.

270. Painsipp E, Herzog H, Sperk G, Holzer P. Sex-dependent control of murine emotional-affective behaviour in health and colitis by peptide $Y Y$ and neuropeptide $Y$. British journal of pharmacology. 2011;163(6):1302-14.

271. Reichmann F, Painsipp E, Holzer P. Environmental enrichment and gut inflammation modify stressinduced c-Fos expression in the mouse corticolimbic system. PLoS One. 2013;8(1):e54811.

272. Jain P, Hassan AM, Koyani CN, Mayerhofer R, Reichmann F, Farzi A, et al. Behavioral and molecular processing of visceral pain in the brain of mice: impact of colitis and psychological stress. Front Behav Neurosci. 2015;9:177.

273. Lapointe TK, Basso L, Iftinca MC, Flynn R, Chapman K, Dietrich G, et al. TRPV1 sensitization mediates postinflammatory visceral pain following acute colitis. American Journal of Physiology-Gastrointestinal and Liver Physiology. 2015;309(2):G87-G99.

274. Emge JR, Huynh K, Miller EN, Kaur M, Reardon C, Barrett KE, et al. Modulation of the microbiota-gutbrain axis by probiotics in a murine model of inflammatory bowel disease. American Journal of PhysiologyGastrointestinal and Liver Physiology. 2016;310(11):G989-G98.

275. Do J, Woo J. From Gut to Brain: Alteration in Inflammation Markers in the Brain of Dextran Sodium Sulfate-induced Colitis Model Mice. Clinical psychopharmacology and neuroscience : the official scientific journal of the Korean College of Neuropsychopharmacology. 2018;16(4):422-33.

276. Hilel AS, Gysemans B, Lisboa MEM, Heymanns AC, Freiberger V, Ventura L, et al. Dextran Sulphate of Sodium-induced colitis in mice: antihyperalgesic effects of ethanolic extract of Citrus reticulata and potential damage to the central nervous system. Anais da Academia Brasileira de Ciencias. 2018;90(3):3139-45.

277. Nyuyki KD, Cluny NL, Swain MG, Sharkey KA, Pittman QJ. Altered Brain Excitability and Increased Anxiety in Mice With Experimental Colitis: Consideration of Hyperalgesia and Sex Differences. Frontiers in Behavioral Neuroscience. 2018;12:58.

278. Wei D, Zhao N, Xie L, Huang B, Zhuang Z, Tang Y, et al. Electroacupuncture and Moxibustion Improved Anxiety Behavior in DSS-Induced Colitis Mice. Gastroenterology research and practice. 2019;2019:2345890.

279. Kresse AE, Million M, Saperas E, Taché Y. Colitis induces CRF expression in hypothalamic magnocellular neurons and blunts CRF gene response to stress in rats. American Journal of PhysiologyGastrointestinal and Liver Physiology. 2001;281(5):G1203-G13.

280. Welch MG, Welch-Horan TB, Anwar M, Anwar N, Ludwig RJ, Ruggiero DA. Brain effects of chronic IBD in areas abnormal in autism and treatment by single neuropeptides secretin and oxytocin. Journal of molecular neuroscience : MN. 2005;25(3):259-74.

281. Gharedaghi MH, Rahimian R, Dehpour AR, Yousefzadeh-Fard Y, Mohammadi-Farani A. Dinitrobenzene sulphonic acid-induced colitis impairs spatial recognition memory in mice: roles of N-methyl Daspartate receptors and nitric oxide. Psychopharmacology. 2015;232(16):3081-90.

282. Ait-Belgnaoui A, Eutamene H, Houdeau E, Bueno L, Fioramonti J, Theodorou V. Lactobacillus farciminis treatment attenuates stress-induced overexpression of Fos protein in spinal and supraspinal sites after colorectal distension in rats. Neurogastroenterol Motil. 2009;21(5):567-73, e18-9.

283. Gibney SM, Gosselin RD, Dinan TG, Cryan JF. Colorectal distension-induced prefrontal cortex activation in the Wistar-Kyoto rat: implications for irritable bowel syndrome. Neuroscience. 2010;165(3):675-83. 
284. Liu SB, Zhang MM, Cheng LF, Shi J, Lu JS, Zhuo M. Long-term upregulation of cortical glutamatergic AMPA receptors in a mouse model of chronic visceral pain. Molecular brain. 2015;8(1):76.

285. Wang J, Zhang X, Cao B, Liu J, Li Y. Facilitation of synaptic transmission in the anterior cingulate cortex in viscerally hypersensitive rats. Cerebral cortex (New York, NY : 1991). 2015;25(4):859-68.

286. Cao B, Wang J, Mu L, Poon DC, Li Y. Impairment of decision making associated with disruption of phase-locking in the anterior cingulate cortex in viscerally hypersensitive rats. Exp Neurol. 2016;286:21-31.

287. Ji NN, Kang J, Hua R, Zhang YM. Involvement of dopamine system in the regulation of the brain corticotropin-releasing hormone in paraventricular nucleus in a rat model of chronic visceral pain. Neurological research. 2018;40(8):650-7.

288. Lu Y, Westlund KN. Effects of baclofen on colon inflammation-induced Fos, CGRP and SP expression in spinal cord and brainstem. Brain research. 2001;889(1):118-30.

289. Lyte M, Li W, Opitz N, Gaykema RPA, Goehler LE. Induction of anxiety-like behavior in mice during the initial stages of infection with the agent of murine colonic hyperplasia Citrobacter rodentium. Physiology \& Behavior. 2006;89(3):350-7.

290. Holder MK, Peters NV, Whylings J, Fields CT, Gewirtz AT, Chassaing B, et al. Dietary emulsifiers consumption alters anxiety-like and social-related behaviors in mice in a sex-dependent manner. Sci Rep. 2019;9(1):172.

291. Gao J, Wu X, Owyang C, Li Y. Enhanced responses of the anterior cingulate cortex neurones to colonic distension in viscerally hypersensitive rats. The Journal of Physiology. 2005;570(1):169-83.

292. Li Y, Zhang X, Liu H, Cao Z, Chen S, Cao B, et al. Phosphorylated CaMKII post-synaptic binding to NR2B subunits in the anterior cingulate cortex mediates visceral pain in visceral hypersensitive rats. Journal of neurochemistry. 2012;121(4):662-71.

293. Suzuki A, Stern Sarah A, Bozdagi O, Huntley George W, Walker Ruth H, Magistretti Pierre J, et al. Astrocyte-Neuron Lactate Transport Is Required for Long-Term Memory Formation. Cell. 2011;144(5):810-23.

294. Bento AF, Leite DFP, Marcon R, Claudino RF, Dutra RC, Cola M, et al. Evaluation of chemical mediators and cellular response during acute and chronic gut inflammatory response induced by dextran sodium sulfate in mice. Biochemical pharmacology. 2012;84(11):1459-69.

295. Butcher SK, O'Carroll CE, Wells CA, Carmody RJ. Toll-Like Receptors Drive Specific Patterns of Tolerance and Training on Restimulation of Macrophages. Frontiers in immunology. 2018;9:933-.

296. Norden DM, Trojanowski PJ, Villanueva E, Navarro E, Godbout JP. Sequential activation of microglia and astrocyte cytokine expression precedes increased Iba-1 or GFAP immunoreactivity following systemic immune challenge. Glia. 2016;64(2):300-16.

297. Biesmans S, Acton PD, Cotto C, Langlois X, Ver Donck L, Bouwknecht JA, et al. Effect of stress and peripheral immune activation on astrocyte activation in transgenic bioluminescent Gfap-luc mice. Glia. 2015;63(7):1126-37.

298. Perez-Dominguez M, Avila-Munoz E, Dominguez-Rivas E, Zepeda A. The detrimental effects of lipopolysaccharide-induced neuroinflammation on adult hippocampal neurogenesis depend on the duration of the pro-inflammatory response. Neural regeneration research. 2019;14(5):817-25.

299. Matisz CE, Vicentini FA, Hirota SA, Sharkey KA, Gruber AJ. Behavioral adaptations in a relapsing mouse model of colitis. Physiology \& Behavior. 2020;216:112802.

300. Tse D, Langston RF, Kakeyama M, Bethus I, Spooner PA, Wood ER, et al. Schemas and Memory Consolidation. Science. 2007;316(5821):76-82.

301. Passingham R, Wise SP. The Neurobiology of the Prefrontal Cortex: Anatomy, Evolution, and the Origin of Insight: Oxford University Press; 2012.

302. Mashhoori A, Hashemnia S, McNaughton BL, Euston DR, Gruber AJ. Rat anterior cingulate cortex recalls features of remote reward locations after disfavoured reinforcements. eLife. 2018;7:e29793.

303. Hayden BY, Pearson JM, Platt ML. Fictive reward signals in the anterior cingulate cortex. Science. 2009;324(5929):948-50.

304. Sawamoto N, Honda M, Okada T, Hanakawa T, Kanda M, Fukuyama H, et al. Expectation of pain enhances responses to nonpainful somatosensory stimulation in the anterior cingulate cortex and parietal operculum/posterior insula: an event-related functional magnetic resonance imaging study. The Journal of neuroscience : the official journal of the Society for Neuroscience. 2000;20(19):7438-45.

305. Critchley HD, Mathias CJ, Josephs O, O’Doherty J, Zanini S, Dewar BK, et al. Human cingulate cortex and autonomic control: converging neuroimaging and clinical evidence. Brain. 2003;126(10):2139-52.

306. Gianaros PJ, Derbyshire SWG, May JC, Siegle GJ, Gamalo MA, Jennings JR. Anterior cingulate activity correlates with blood pressure during stress. Psychophysiology. 2005;42(6):627-35. 
307. Wood JD, Alpers DH, Andrews PLR. Fundamentals of neurogastroenterology. Gut. 1999;45(suppl 2):II6-II16.

308. Browning KN, Travagli RA. Central nervous system control of gastrointestinal motility and secretion and modulation of gastrointestinal functions. Comprehensive Physiology. 2014;4(4):1339-68.

309. Herman JP, McKlveen JM, Solomon MB, Carvalho-Netto E, Myers B. Neural regulation of the stress response: glucocorticoid feedback mechanisms. Brazilian journal of medical and biological research $=$ Revista brasileira de pesquisas medicas e biologicas. 2012;45(4):292-8.

310. Martin TD, Chan SS, Hart AR. Environmental factors in the relapse and recurrence of inflammatory bowel disease: a review of the literature. Digestive diseases and sciences. 2015;60(5):1396-405.

311. Qin HY, Cheng CW, Tang XD, Bian ZX. Impact of psychological stress on irritable bowel syndrome. World J Gastroenterol. 2014;20(39):14126-31.

312. O'Malley D, Quigley EM, Dinan TG, Cryan JF. Do interactions between stress and immune responses lead to symptom exacerbations in irritable bowel syndrome? Brain Behav Immun. 2011;25(7):1333-41.

313. Lennon EM, Maharshak N, Elloumi H, Borst L, Plevy SE, Moeser AJ. Early Life Stress Triggers Persistent Colonic Barrier Dysfunction and Exacerbates Colitis in Adult IL-10(-/-) Mice. Inflammatory bowel diseases. 2013;19(4):712-9.

314. Øines E, Murison R, Mrdalj J, Grønli J, Milde AM. Neonatal maternal separation in male rats increases intestinal permeability and affects behavior after chronic social stress. Physiology \& Behavior. 2012;105(4):105866.

315. Cameron HL, Perdue MH. Stress Impairs Murine Intestinal Barrier Function: Improvement by Glucagon-Like Peptide-2. Journal of Pharmacology and Experimental Therapeutics. 2005;314(1):214.

316. Chen BR, Du LJ, He HQ, Kim JJ, Zhao Y, Zhang YW, et al. Fructo-oligosaccharide intensifies visceral hypersensitivity and intestinal inflammation in a stress-induced irritable bowel syndrome mouse model. World J Gastroenterol. 2017;23(47):8321-33.

317. Williams CL, Villar RG, Peterson JM, Burks TF. Stress-induced changes in intestinal transit in the rat: a model for irritable bowel syndrome. Gastroenterology. 1988;94(3):611-21.

318. Larauche M, Kiank C, Tache Y. Corticotropin releasing factor signaling in colon and ileum: regulation by stress and pathophysiological implications. Journal of physiology and pharmacology : an official journal of the Polish Physiological Society. 2009;60 Suppl 7(Suppl 7):33-46.

319. Greenwood-Van Meerveld B, Johnson AC. Stress-Induced Chronic Visceral Pain of Gastrointestinal Origin. Front Syst Neurosci. 2017;11:86-.

320. Reber SO, Obermeier F, Straub HR, Falk W, Neumann ID. Chronic Intermittent Psychosocial Stress (Social Defeat/Overcrowding) in Mice Increases the Severity of an Acute DSS-Induced Colitis and Impairs Regeneration. Endocrinology. 2006;147(10):4968-76.

321. Deng Q, Chen H, Liu Y, Xiao F, Guo L, Liu D, et al. Psychological stress promotes neutrophil infiltration in colon tissue through adrenergic signaling in DSS-induced colitis model. Brain, Behavior, and Immunity. 2016;57:243-54.

322. Çetinel Ş, Hancıoğlu S, Şener E, Üner C, Kılıç M, Şener G, et al. Oxytocin treatment alleviates stressaggravated colitis by a receptor-dependent mechanism. Regulatory Peptides. 2010;160(1):146-52.

323. Gue M, Bonbonne C, Fioramonti J, More J, Del Rio-Lacheze C, Comera C, et al. Stress-induced enhancement of colitis in rats: CRF and arginine vasopressin are not involved. American Journal of PhysiologyGastrointestinal and Liver Physiology. 1997;272(1):G84-G91.

324. Koh S-J, Kim JW, Kim BG, Lee KL, Kim JS. Restraint stress induces and exacerbates intestinal inflammation in interleukin-10 deficient mice. World Journal of Gastroenterology : WJG. 2015;21(28):8580-7.

325. Mackos AR, Galley JD, Eubank TD, Easterling RS, Parry NM, Fox JG, et al. Social stress-enhanced severity of Citrobacter rodentium induced colitis is CCL2-dependent and attenuated by probiotic Lactobacillus reuteri. Mucosal immunology. 2016;9(2):515-26.

326. Matsunaga H, Hokari R, Ueda T, Kurihara C, Hozumi H, Higashiyama M, et al. Physiological stress exacerbates murine colitis by enhancing proinflammatory cytokine expression that is dependent on IL-18. American Journal of Physiology-Gastrointestinal and Liver Physiology. 2011;301(3):G555-G64.

327. Reber SO, Obermeier F, Straub RH, Veenema AH, Neumann ID. Aggravation of DSS-induced colitis after chronic subordinate colony (CSC) housing is partially mediated by adrenal mechanisms. Stress. 2008;11(3):225-34.

328. Schultz M, Lai CC, Lindstroem AL, Stein K, Donaldson G, Thompson-Fawcett M, et al. Aggravation of Established Colitis in Specific Pathogen-free IL-10 Knockout Mice by Restraint Stress Is Not Mediated by Increased Colonic Permeability. Journal of Crohn's and Colitis. 2015;9(9):754-62. 
329. Veenema AH, Reber SO, Selch S, Obermeier F, Neumann ID. Early Life Stress Enhances the Vulnerability to Chronic Psychosocial Stress and Experimental Colitis in Adult Mice. Endocrinology. 2008;149(6):2727-36.

330. Xu Y, Hunt NH, Bao S. The effect of restraint stress on experimental colitis is IFN- $\gamma$ independent. Journal of Neuroimmunology. 2008;200(1):53-61.

331. Ghia JE, Blennerhassett P, Deng Y, Verdu EF, Khan WI, Collins SM. Reactivation of Inflammatory Bowel Disease in a Mouse Model of Depression. Gastroenterology. 2009;136(7):2280-8.e4.

332. Qiu BS, Vallance BA, Blennerhassett PA, Collins SM. The role of CD4+ lymphocytes in the susceptibility of mice to stress-induced reactivation of experimental colitis. Nature Medicine. 1999;5:1178.

333. Tannock GW, Savage DC. Influences of dietary and environmental stress on microbial populations in the murine gastrointestinal tract. Infect Immun. 1974;9(3):591-8.

334. Molina-Torres G, Rodriguez-Arrastia M, Roman P, Sanchez-Labraca N, Cardona D. Stress and the gut microbiota-brain axis. Behavioural pharmacology. 2019;30(2 and 3-Spec Issue):187-200.

335. Galley JD, Nelson MC, Yu Z, Dowd SE, Walter J, Kumar PS, et al. Exposure to a social stressor disrupts the community structure of the colonic mucosa-associated microbiota. BMC Microbiology. 2014;14(1):189.

336. Hughes DT, Sperandio V. Inter-kingdom signalling: communication between bacteria and their hosts. Nature reviews Microbiology. 2008;6(2):111-20.

337. Moloney RD, O'Mahony SM, Dinan TG, Cryan JF. Stress-induced visceral pain: toward animal models of irritable-bowel syndrome and associated comorbidities. Frontiers in psychiatry. 2015;6:15-.

338. Straub RH, Wiest R, Strauch UG, Härle P, Schölmerich J. The role of the sympathetic nervous system in intestinal inflammation. Gut. 2006;55(11):1640-9.

339. Elenkov IJ, Wilder RL, Chrousos GP, Vizi ES. The sympathetic nerve--an integrative interface between two supersystems: the brain and the immune system. Pharmacological reviews. 2000;52(4):595-638.

340. Straub RH, Mayer M, Kreutz M, Leeb S, Schölmerich J, Falk W. Neurotransmitters of the sympathetic nerve terminal are powerful chemoattractants for monocytes. Journal of leukocyte biology. 2000;67(4):553-8.

341. Marra S, Burnett M, Hoffman-Goetz L. Intravenous catecholamine administration affects mouse intestinal lymphocyte number and apoptosis. J Neuroimmunol. 2005;158(1-2):76-85.

342. Spengler RN, Allen RM, Remick DG, Strieter RM, Kunkel SL. Stimulation of alpha-adrenergic receptor augments the production of macrophage-derived tumor necrosis factor. J Immunol. 1990;145(5):1430-4.

343. Straub RH, Pongratz G, Günzler C, Michna A, Baier S, Kees F, et al. Immunoregulation of IL-6 secretion by endogenous and exogenous adenosine and by exogenous purinergic agonists in splenic tissue slices. J Neuroimmunol. 2002;125(1-2):73-81.

344. Schweingruber N, Reichardt SD, Lühder F, Reichardt HM. Mechanisms of glucocorticoids in the control of neuroinflammation. Journal of neuroendocrinology. 2012;24(1):174-82.

345. Sorrells SF, Caso JR, Munhoz CD, Sapolsky RM. The stressed CNS: when glucocorticoids aggravate inflammation. Neuron. 2009;64(1):33-9.

346. Munhoz CD, Lepsch LB, Kawamoto EM, Malta MB, Lima Lde S, Avellar MC, et al. Chronic unpredictable stress exacerbates lipopolysaccharide-induced activation of nuclear factor-kappaB in the frontal cortex and hippocampus via glucocorticoid secretion. The Journal of neuroscience : the official journal of the Society for Neuroscience. 2006;26(14):3813-20.

347. Sorrells SF, Munhoz CD, Manley NC, Yen S, Sapolsky RM. Glucocorticoids increase excitotoxic injury and inflammation in the hippocampus of adult male rats. Neuroendocrinology. 2014;100(2-3):129-40.

348. Frank MG, Baratta MV, Sprunger DB, Watkins LR, Maier SF. Microglia serve as a neuroimmune substrate for stress-induced potentiation of CNS pro-inflammatory cytokine responses. Brain Behav Immun. 2007;21(1):47-59.

349. Duque EdA, Munhoz CD. The Pro-inflammatory Effects of Glucocorticoids in the Brain. Frontiers in endocrinology. 2016;7:78-.

350. David DJ, Samuels BA, Rainer Q, Wang J-W, Marsteller D, Mendez I, et al. Neurogenesis-dependent and -independent effects of fluoxetine in an animal model of anxiety/depression. Neuron. 2009;62(4):479-93.

351. Snyder JS, Soumier A, Brewer M, Pickel J, Cameron HA. Adult hippocampal neurogenesis buffers stress responses and depressive behaviour. Nature. 2011;476(7361):458-61.

352. Anacker C, Zunszain PA, Cattaneo A, Carvalho LA, Garabedian MJ, Thuret S, et al. Antidepressants increase human hippocampal neurogenesis by activating the glucocorticoid receptor. Mol Psychiatry. 2011;16(7):738-50.

353. Anderson RM, Glanz RM, Johnson SB, Miller MM, Romig-Martin SA, Radley JJ. Prolonged corticosterone exposure induces dendritic spine remodeling and attrition in the rat medial prefrontal cortex. The Journal of comparative neurology. 2016;524(18):3729-46. 
354. Goehler LE, Gaykema RP, Nguyen KT, Lee JE, Tilders FJ, Maier SF, et al. Interleukin-1beta in immune cells of the abdominal vagus nerve: a link between the immune and nervous systems? The Journal of neuroscience : the official journal of the Society for Neuroscience. 1999;19(7):2799-806.

355. Lal S, Kirkup AJ, Brunsden AM, Thompson DG, Grundy D. Vagal afferent responses to fatty acids of different chain length in the rat. American journal of physiology Gastrointestinal and liver physiology. 2001;281(4):G907-15.

356. Tubbs RS RE, Shoja MM, Loukas M, Barbaro N, Spinner RJ. Vol 1: History, Embryology, Anatomy, Imaging, and Diagnostics. Cambridge, Massachusetts: : Academic Press; 2015.

357. Hosoi T, Okuma Y, Matsuda T, Nomura Y. Novel pathway for LPS-induced afferent vagus nerve activation: possible role of nodose ganglion. Autonomic neuroscience : basic \& clinical. 2005;120(1-2):104-7.

358. Harris GW. The hypothalamus and endocrine glands. British medical bulletin. 1950;6(4):345-50.

359. Bonaz B, Sinniger V, Pellissier S. The Vagus Nerve in the Neuro-Immune Axis: Implications in the Pathology of the Gastrointestinal Tract. Front Immunol. 2017;8:1452.

360. Tracey KJ. The inflammatory reflex. Nature. 2002;420(6917):853-9.

361. Manabe N, Tanaka T, Hata J, Kusunoki H, Haruma K. Pathophysiology underlying irritable bowel syndrome--from the viewpoint of dysfunction of autonomic nervous system activity. Journal of smooth muscle research = Nihon Heikatsukin Gakkai kikanshi. 2009;45(1):15-23.

362. Mogilevski T, Burgell R, Aziz Q, Gibson PR. Review article: the role of the autonomic nervous system in the pathogenesis and therapy of IBD. Alimentary pharmacology \& therapeutics. 2019;50(7):720-37.

363. Salvioli B, Pellegatta G, Malacarne M, Pace F, Malesci A, Pagani M, et al. Autonomic nervous system dysregulation in irritable bowel syndrome. Neurogastroenterol Motil. 2015;27(3):423-30.

364. Tominaga K, Fujikawa Y, Tsumoto C, Kadouchi K, Tanaka F, Kamata N, et al. Disorder of autonomic nervous system and its vulnerability to external stimulation in functional dyspepsia. Journal of clinical biochemistry and nutrition. 2016;58(2):161-5.

365. Won E, Kim Y-K. Stress, the Autonomic Nervous System, and the Immune-kynurenine Pathway in the Etiology of Depression. Current neuropharmacology. 2016;14(7):665-73.

366. Hu MX, Lamers F, de Geus EJ, Penninx BW. Differential Autonomic Nervous System Reactivity in Depression and Anxiety During Stress Depending on Type of Stressor. Psychosom Med. 2016;78(5):562-72.

367. Ghia J-E, Blennerhassett P, Collins SM. Impaired parasympathetic function increases susceptibility to inflammatory bowel disease in a mouse model of depression. The Journal of Clinical Investigation. 2008;118(6):2209-18.

368. Payne SC, Furness JB, Burns O, Sedo A, Hyakumura T, Shepherd RK, et al. Anti-inflammatory Effects of Abdominal Vagus Nerve Stimulation on Experimental Intestinal Inflammation. Frontiers in neuroscience. 2019;13:418-.

369. Bonaz B, Sinniger V, Hoffmann D, Clarençon D, Mathieu N, Dantzer C, et al. Chronic vagus nerve stimulation in Crohn's disease: a 6-month follow-up pilot study. Neurogastroenterol Motil. 2016;28(6):948-53.

370. Chakravarthy K, Chaudhry H, Williams K, Christo PJ. Review of the Uses of Vagal Nerve Stimulation in Chronic Pain Management. Current pain and headache reports. 2015;19(12):54.

371. Dedovic K, Duchesne A, Andrews J, Engert V, Pruessner JC. The brain and the stress axis: The neural correlates of cortisol regulation in response to stress. NeuroImage. 2009;47(3):864-71.

372. Qi X-R, Kamphuis W, Wang S, Wang Q, Lucassen PJ, Zhou J-N, et al. Aberrant stress hormone receptor balance in the human prefrontal cortex and hypothalamic paraventricular nucleus of depressed patients. Psychoneuroendocrinology. 2013;38(6):863-70.

373. Wolf OT, Convit A, de Leon MJ, Caraos C, Qadri SF. Basal hypothalamo-pituitary-adrenal axis activity and corticotropin feedback in young and older men: relationships to magnetic resonance imaging-derived hippocampus and cingulate gyrus volumes. Neuroendocrinology. 2002;75(4):241-9.

374. MacLullich AMJ, Ferguson KJ, Wardlaw JM, Starr JM, Deary IJ, Seckl JR. Smaller Left Anterior Cingulate Cortex Volumes Are Associated with Impaired Hypothalamic-Pituitary-Adrenal Axis Regulation in Healthy Elderly Men. The Journal of Clinical Endocrinology \& Metabolism. 2006;91(4):1591-4.

375. Touj S, Houle S, Ramla D, Jeffrey-Gauthier R, Hotta H, Bronchti G, et al. Sympathetic regulation and anterior cingulate cortex volume are altered in a rat model of chronic back pain. Neuroscience. 2017;352:9-18.

376. Quevedo K, Doty J, Roos L, Anker JJ. The cortisol awakening response and anterior cingulate cortex function in maltreated depressed versus non-maltreated depressed youth. Psychoneuroendocrinology. 2017;86:87-95.

377. Kano M, Muratsubaki T, Van Oudenhove L, Morishita J, Yoshizawa M, Kohno K, et al. Altered brain and gut responses to corticotropin-releasing hormone $(\mathrm{CRH})$ in patients with irritable bowel syndrome. Scientific reports. 2017;7(1):12425-. 
378. Fox MD, Buckner RL, White MP, Greicius MD, Pascual-Leone A. Efficacy of transcranial magnetic stimulation targets for depression is related to intrinsic functional connectivity with the subgenual cingulate. Biological psychiatry. 2012;72(7):595-603.

379. Iseger TA, van Bueren NER, Kenemans JL, Gevirtz R, Arns M. A frontal-vagal network theory for Major Depressive Disorder: Implications for optimizing neuromodulation techniques. Brain Stimulation. 2020;13(1):19.

380. Badran BW, Dowdle LT, Mithoefer OJ, LaBate NT, Coatsworth J, Brown JC, et al. Neurophysiologic effects of transcutaneous auricular vagus nerve stimulation (taVNS) via electrical stimulation of the tragus: A concurrent taVNS/fMRI study and review. Brain stimulation. 2018;11(3):492-500.

381. Sanvanson P, Li Z, Mei L, Kounev V, Kern M, Ward BD, et al. Interplay of spinal and vagal pathways on esophageal acid-related anterior cingulate cortex functional networks in rats. American journal of physiology Gastrointestinal and liver physiology. 2019;316(5):G615-G22.

382. Cao B, Wang J, Shahed M, Jelfs B, Chan RH, Li Y. Vagus Nerve Stimulation Alters Phase Synchrony of the Anterior Cingulate Cortex and Facilitates Decision Making in Rats. Sci Rep. 2016;6:35135.

383. Bravo JA, Forsythe P, Chew MV, Escaravage E, Savignac HM, Dinan TG, et al. Ingestion of Lactobacillus strain regulates emotional behavior and central GABA receptor expression in a mouse via the vagus nerve. Proc Natl Acad Sci U S A. 2011;108(38):16050-5.

384. Bockus H, J Bank S, Wilkinson A. Neurogenic mucous colitis. The American Journal of the Medical Sciences, .176:813-29.

385. Pellissier S, Dantzer C, Canini F, Mathieu N, Bonaz B. Psychological adjustment and autonomic disturbances in inflammatory bowel diseases and irritable bowel syndrome. Psychoneuroendocrinology. 2010;35(5):653-62.

386. Collins SM. Interrogating the Gut-Brain Axis in the Context of Inflammatory Bowel Disease: A Translational Approach. Inflammatory bowel diseases. 2020;26(4):493-501.

387. Mayer EA. Gut feelings: the emerging biology of gut-brain communication. Nature reviews Neuroscience. 2011;12(8):453-66.

388. Lamb CA, Kennedy NA, Raine T, Hendy PA, Smith PJ, Limdi JK, et al. British Society of Gastroenterology consensus guidelines on the management of inflammatory bowel disease in adults. Gut. 2019;68(Suppl 3):s1-s106.

389. Camilleri M. Management Options for Irritable Bowel Syndrome. Mayo Clinic proceedings. 2018;93(12):1858-72.

390. Talley NJ, Ford AC. Functional Dyspepsia. The New England journal of medicine. 2015;373(19):1853-

63.

391. De Vries D, Merten N, Stingl J, Breteler M. The effect of proton pump inhibitors on cognition and brain volume in the Rhineland study. Revue d'Épidémiologie et de Santé Publique. 2018;66:S427-S8.

392. Kulak-Bejda A, Bejda G, Waszkiewicz N. Antidepressants for irritable bowel syndrome-A systematic review. Pharmacological reports : PR. 2017;69(6):1366-79.

393. Macer BJ, Prady SL, Mikocka-Walus A. Antidepressants in Inflammatory Bowel Disease: A Systematic Review. Inflamm Bowel Dis. 2017;23(4):534-50.

394. Talley NJ, Herrick L, Locke GR. Antidepressants in functional dyspepsia. Expert review of gastroenterology \& hepatology. 2010;4(1):5-8.

395. Lu Y, Chen M, Huang Z, Tang C. Antidepressants in the Treatment of Functional Dyspepsia: A Systematic Review and Meta-Analysis. PLoS One. 2016;11(6):e0157798.

396. Fattahian E, Hajhashemi V, Rabbani M, Minaiyan M, Mahzouni P. Anti-inflammatory Effect of Amitriptyline on Ulcerative Colitis in Normal and Reserpine-Induced Depressed Rats. Iranian journal of pharmaceutical research : IJPR. 2016;15(Suppl):125-37.

397. Koh SJ, Kim JW, Kim BG, Lee KL, Im JP, Kim JS. Fluoxetine inhibits hyperresponsive lamina propria mononuclear cells and bone marrow-derived dendritic cells, and ameliorates chronic colitis in IL-10-deficient mice. Digestive diseases and sciences. 2015;60(1):101-8.

398. Varghese AK, Verdu EF, Bercik P, Khan WI, Blennerhassett PA, Szechtman H, et al. Antidepressants attenuate increased susceptibility to colitis in a murine model of depression. Gastroenterology. 2006;130(6):174353.

399. Miyaoka T, Wake R, Furuya M, Liaury K, Ieda M, Kawakami K, et al. Minocycline as adjunctive therapy for patients with unipolar psychotic depression: an open-label study. Progress in neuro-psychopharmacology \& biological psychiatry. 2012;37(2):222-6.

400. Cowen PJ, Browning M. What has serotonin to do with depression? World psychiatry : official journal of the World Psychiatric Association (WPA). 2015;14(2):158-60. 
401. Wang Q, Liu D, Song P, Zou M-H. Tryptophan-kynurenine pathway is dysregulated in inflammation, and immune activation. Frontiers in bioscience (Landmark edition). 2015;20:1116-43.

402. Chou YH, Hsieh WC, Chen LC, Lirng JF, Wang SJ. Association between the serotonin transporter and cytokines: Implications for the pathophysiology of bipolar disorder. J Affect Disord. 2016;191:29-35.

403. Galecki P, Mossakowska-Wojcik J, Talarowska M. The anti-inflammatory mechanism of antidepressants - SSRIs, SNRIs. Progress in neuro-psychopharmacology \& biological psychiatry. 2018;80(Pt C):291-4.

404. Tack J, Broekaert D, Fischler B, Van Oudenhove L, Gevers AM, Janssens J. A controlled crossover study of the selective serotonin reuptake inhibitor citalopram in irritable bowel syndrome. Gut. 2006;55(8):1095-103.

405. Masand PS, Pae CU, Krulewicz S, Peindl K, Mannelli P, Varia IM, et al. A double-blind, randomized, placebo-controlled trial of paroxetine controlled-release in irritable bowel syndrome. Psychosomatics. 2009;50(1):78-86.

406. Trinkley KE, Nahata MC. Treatment of irritable bowel syndrome. Journal of Clinical Pharmacy and Therapeutics. 2011;36(3):275-82.

407. Gershon MD, Tack J. The serotonin signaling system: from basic understanding to drug development for functional GI disorders. Gastroenterology. 2007;132(1):397-414.

408. Chial HJ, Camilleri M, Burton D, Thomforde G, Olden KW, Stephens D. Selective effects of serotonergic psychoactive agents on gastrointestinal functions in health. American journal of physiology Gastrointestinal and liver physiology. 2003;284(1):G130-7.

409. Fung TC, Vuong HE, Luna CDG, Pronovost GN, Aleksandrova AA, Riley NG, et al. Intestinal serotonin and fluoxetine exposure modulate bacterial colonization in the gut. Nat Microbiol. 2019;4(12):2064-73.

410. McVey Neufeld KA, Bienenstock J, Bharwani A, Champagne-Jorgensen K, Mao Y, West C, et al. Oral selective serotonin reuptake inhibitors activate vagus nerve dependent gut-brain signalling. Sci Rep. 2019;9(1):14290.

411. Schmidt FM, Kirkby KC, Lichtblau N. Inflammation and Immune Regulation as Potential Drug Targets in Antidepressant Treatment. Current neuropharmacology. 2016;14(7):674-87.

412. Hayley S. Toward an anti-inflammatory strategy for depression. Front Behav Neurosci. 2011;5:19.

413. Pizzagalli DA. Frontocingulate dysfunction in depression: toward biomarkers of treatment response. Neuropsychopharmacology. 2011;36(1):183-206.

414. Godlewska BR, Browning M, Norbury R, Igoumenou A, Cowen PJ, Harmer CJ. Predicting Treatment Response in Depression: The Role of Anterior Cingulate Cortex. The international journal of neuropsychopharmacology. 2018;21(11):988-96.

415. Branchi I, Santarelli S, Capoccia S, Poggini S, D'Andrea I, Cirulli F, et al. Antidepressant treatment outcome depends on the quality of the living environment: a pre-clinical investigation in mice. PloS one. 2013;8(4):e62226-e.

416. Santarelli L, Saxe M, Gross C, Surget A, Battaglia F, Dulawa S, et al. Requirement of hippocampal neurogenesis for the behavioral effects of antidepressants. Science. 2003;301(5634):805-9.

417. Castrén E, Hen R. Neuronal plasticity and antidepressant actions. Trends in neurosciences. 2013;36(5):259-67.

418. Willard SL, Uberseder B, Clark A, Daunais JB, Johnston WD, Neely D, et al. Long term sertraline effects on neural structures in depressed and nondepressed adult female nonhuman primates. Neuropharmacology. 2015;99:369-78.

419. Morris LS, Costi S, Tan A, Stern ER, Charney DS, Murrough JW. Ketamine normalizes subgenual cingulate cortex hyper-activity in depression. Neuropsychopharmacology. 2020;45(6):975-81.

420. Chen MH, Li CT, Lin WC, Hong CJ, Tu PC, Bai YM, et al. Persistent antidepressant effect of low-dose ketamine and activation in the supplementary motor area and anterior cingulate cortex in treatment-resistant depression: A randomized control study. J Affect Disord. 2018;225:709-14.

421. Zhou H, Zhang Q, Martinez E, Dale J, Hu S, Zhang E, et al. Ketamine reduces aversion in rodent pain models by suppressing hyperactivity of the anterior cingulate cortex. Nature communications. 2018;9(1):3751-.

422. Zhu X, Li P, Hao X, Wei K, Min S, Luo J, et al. Ketamine-mediated alleviation of electroconvulsive shock-induced memory impairment is associated with the regulation of neuroinflammation and soluble amyloid-beta peptide in depressive-like rats. Neuroscience letters. 2015;599:32-7.

423. Li Y, Shen R, Wen G, Ding R, Du A, Zhou J, et al. Effects of Ketamine on Levels of Inflammatory Cytokines IL-6, IL-1beta, and TNF-alpha in the Hippocampus of Mice Following Acute or Chronic Administration. Frontiers in pharmacology. 2017;8:139.

424. Yang C, Shirayama Y, Zhang JC, Ren Q, Yao W, Ma M, et al. R-ketamine: a rapid-onset and sustained antidepressant without psychotomimetic side effects. Translational psychiatry. 2015;5:e632. 
425. Ly C, Greb AC, Cameron LP, Wong JM, Barragan EV, Wilson PC, et al. Psychedelics Promote Structural and Functional Neural Plasticity. Cell reports. 2018;23(11):3170-82.

426. Osório Fde L, Sanches RF, Macedo LR, Santos RG, Maia-de-Oliveira JP, Wichert-Ana L, et al. Antidepressant effects of a single dose of ayahuasca in patients with recurrent depression: a preliminary report. Revista brasileira de psiquiatria (Sao Paulo, Brazil : 1999). 2015;37(1):13-20.

427. Carhart-Harris RL, Bolstridge M, Rucker J, Day CM, Erritzoe D, Kaelen M, et al. Psilocybin with psychological support for treatment-resistant depression: an open-label feasibility study. The lancet Psychiatry. 2016;3(7):619-27.

428. Griffiths RR, Johnson MW, Carducci MA, Umbricht A, Richards WA, Richards BD, et al. Psilocybin produces substantial and sustained decreases in depression and anxiety in patients with life-threatening cancer: A randomized double-blind trial. Journal of psychopharmacology (Oxford, England). 2016;30(12):1181-97.

429. Flanagan TW, Nichols CD. Psychedelics as anti-inflammatory agents. International review of psychiatry (Abingdon, England). 2018;30(4):363-75.

430. Barrett E, Ross RP, O'Toole PW, Fitzgerald GF, Stanton C. gamma-Aminobutyric acid production by culturable bacteria from the human intestine. Journal of applied microbiology. 2012;113(2):411-7.

431. Petra AI, Panagiotidou S, Hatziagelaki E, Stewart JM, Conti P, Theoharides TC. Gut-Microbiota-Brain Axis and Its Effect on Neuropsychiatric Disorders With Suspected Immune Dysregulation. Clinical therapeutics. 2015;37(5):984-95.

432. Wenzel TJ, Gates EJ, Ranger AL, Klegeris A. Short-chain fatty acids (SCFAs) alone or in combination regulate select immune functions of microglia-like cells. Molecular and cellular neurosciences. 2020;105:103493.

433. Dalile B, Van Oudenhove L, Vervliet B, Verbeke K. The role of short-chain fatty acids in microbiotagut-brain communication. Nature Reviews Gastroenterology \& Hepatology. 2019;16(8):461-78.

434. He Y, Kosciolek T, Tang J, Zhou Y, Li Z, Ma X, et al. Gut microbiome and magnetic resonance spectroscopy study of subjects at ultra-high risk for psychosis may support the membrane hypothesis. European Psychiatry. 2018;53:37-45.

435. Goloshchapov OV, Olekhnovich EI, Sidorenko SV, Moiseev IS, Kucher MA, Fedorov DE, et al. Longterm impact of fecal transplantation in healthy volunteers. BMC microbiology. 2019;19(1):312-.

436. Li SS, Zhu A, Benes V, Costea PI, Hercog R, Hildebrand F, et al. Durable coexistence of donor and recipient strains after fecal microbiota transplantation. Science. 2016;352(6285):586-9.

437. Cammarota G, Masucci L, Ianiro G, Bibbo S, Dinoi G, Costamagna G, et al. Randomised clinical trial: faecal microbiota transplantation by colonoscopy vs. vancomycin for the treatment of recurrent Clostridium difficile infection. Alimentary pharmacology \& therapeutics. 2015;41(9):835-43.

438. Paramsothy S, Kamm MA, Kaakoush NO, Walsh AJ, van den Bogaerde J, Samuel D, et al. Multidonor intensive faecal microbiota transplantation for active ulcerative colitis: a randomised placebo-controlled trial. Lancet (London, England). 2017;389(10075):1218-28.

439. van Beurden YH, van Gils T, van Gils NA, Kassam Z, Mulder CJ, Aparicio-Pages N. Serendipity in Refractory Celiac Disease: Full Recovery of Duodenal Villi and Clinical Symptoms after Fecal Microbiota Transfer. Journal of gastrointestinal and liver diseases : JGLD. 2016;25(3):385-8.

440. Kelly JR, Borre Y, O' Brien C, Patterson E, El Aidy S, Deane J, et al. Transferring the blues: Depressionassociated gut microbiota induces neurobehavioural changes in the rat. Journal of Psychiatric Research. 2016;82:109-18.

441. Zhao W, Hu Y, Li C, Li N, Zhu S, Tan X, et al. Transplantation of fecal microbiota from patients with alcoholism induces anxiety/depression behaviors and decreases brain mGluR1/PKC $\varepsilon$ levels in mouse. BioFactors. 2020;46(1):38-54.

442. Luczynski P, Tramullas M, Viola M, Shanahan F, Clarke G, O'Mahony S, et al. Microbiota regulates visceral pain in the mouse. eLife. 2017;6:e25887.

443. Luo Y, Zeng B, Zeng L, Du X, Li B, Huo R, et al. Gut microbiota regulates mouse behaviors through glucocorticoid receptor pathway genes in the hippocampus. Translational psychiatry. 2018;8(1):187.

444. Kurokawa S, Kishimoto T, Mizuno S, Masaoka T, Naganuma M, Liang K-c, et al. The effect of fecal microbiota transplantation on psychiatric symptoms among patients with irritable bowel syndrome, functional diarrhea and functional constipation: An open-label observational study. Journal of Affective Disorders. 2018;235:506-12.

445. Kilincarslan S, Evrensel A. The effect of fecal microbiota transplantation on psychiatric symptoms among patients with inflammatory bowel disease: an experimental study. Actas espanolas de psiquiatria. 2020;48(1):1-7. 
446. Witte AV, Kerti L, Hermannstädter HM, Fiebach JB, Schreiber SJ, Schuchardt JP, et al. Long-chain omega-3 fatty acids improve brain function and structure in older adults. Cerebral cortex (New York, NY : 1991). 2014;24(11):3059-68.

447. Bauer I, Hughes M, Rowsell R, Cockerell R, Pipingas A, Crewther S, et al. Omega-3 supplementation improves cognition and modifies brain activation in young adults. Human psychopharmacology. 2014;29(2):13344.

448. Zamroziewicz MK, Paul EJ, Rubin RD, Barbey AK. Anterior cingulate cortex mediates the relationship between O3PUFAs and executive functions in APOE e4 carriers. Frontiers in aging neuroscience. 2015;7:87-.

449. Calvert EL, Houghton LA, Cooper P, Morris J, Whorwell PJ. Long-term improvement in functional dyspepsia using hypnotherapy. Gastroenterology. 2002;123(6):1778-85.

450. Whorwell PJ, Prior A, Faragher EB. Controlled trial of hypnotherapy in the treatment of severe refractory irritable-bowel syndrome. Lancet (London, England). 1984;2(8414):1232-4.

451. Gonsalkorale WM, Houghton LA, Whorwell PJ. Hypnotherapy in irritable bowel syndrome: a largescale audit of a clinical service with examination of factors influencing responsiveness. Am J Gastroenterol. 2002;97(4):954-61.

452. Vidakovic-Vukic M. Hypnotherapy in the Treatment of Irritable Bowel Syndrome: Methods and Results in Amsterdam. Scandinavian journal of gastroenterology. 1999;34(230):49-51.

453. Peters SL, Muir JG, Gibson PR. Review article: gut-directed hypnotherapy in the management of irritable bowel syndrome and inflammatory bowel disease. Alimentary pharmacology \& therapeutics. 2015;41(11):1104-15.

454. Moser G. The role of hypnotherapy for the treatment of inflammatory bowel diseases. Expert review of gastroenterology \& hepatology. 2014;8(6):601-6.

455. Dehghanizade Z, Zargar Y, Mehrabizadeh Honarmand M, Kadkhodaie A, Eydi Baygi M. The effectiveness of cognitive behavior stress management on functional dyspepsia symptoms. Journal of advances in medical education \& professionalism. 2015;3(2):45-9.

456. Levy RL, van Tilburg MAL, Langer SL, Romano JM, Walker LS, Mancl LA, et al. Effects of a Cognitive Behavioral Therapy Intervention Trial to Improve Disease Outcomes in Children with Inflammatory Bowel Disease. Inflammatory Bowel Diseases. 2016;22(9):2134-48.

457. Bennebroek Evertsz F, Sprangers MAG, Sitnikova K, Stokkers PCF, Ponsioen CY, Bartelsman J, et al. Effectiveness of cognitive-behavioral therapy on quality of life, anxiety, and depressive symptoms among patients with inflammatory bowel disease: A multicenter randomized controlled trial. Journal of consulting and clinical psychology. 2017;85(9):918-25.

458. Hamilton J, Guthrie E, Creed F, Thompson D, Tomenson B, Bennett R, et al. A randomized controlled trial of psychotherapy in patients with chronic functional dyspepsia. Gastroenterology. 2000;119(3):661-9.

459. van den Brink G, Stapersma L, El Marroun H, Henrichs J, Szigethy EM, Utens EMWJ, et al. Effectiveness of disease-specific cognitive-behavioural therapy on depression, anxiety, quality of life and the clinical course of disease in adolescents with inflammatory bowel disease: study protocol of a multicentre randomised controlled trial (HAPPY-IBD). BMJ Open Gastroenterology. 2016;3(1):e000071.

460. Mikocka-Walus A, Bampton P, Hetzel D, Hughes P, Esterman A, Andrews JM. Cognitive-Behavioural Therapy for Inflammatory Bowel Disease: 24-Month Data from a Randomised Controlled Trial. International journal of behavioral medicine. 2017;24(1):127-35.

461. Li C, Hou Z, Liu Y, Ji Y, Xie L. Cognitive-behavioural therapy in patients with inflammatory bowel diseases: A systematic review and meta-analysis. International journal of nursing practice. 2019;25(1):e12699.

462. Streeter CC, Gerbarg PL, Saper RB, Ciraulo DA, Brown RP. Effects of yoga on the autonomic nervous system, gamma-aminobutyric-acid, and allostasis in epilepsy, depression, and post-traumatic stress disorder. Medical hypotheses. 2012;78(5):571-9.

463. DeBenedittis G, Cigada M, Bianchi A, Signorini MG, Cerutti S. Autonomic changes during hypnosis: a heart rate variability power spectrum analysis as a marker of sympatho-vagal balance. The International journal of clinical and experimental hypnosis. 1994;42(2):140-52.

464. Kok BE, Coffey KA, Cohn MA, Catalino LI, Vacharkulksemsuk T, Algoe SB, et al. How positive emotions build physical health: perceived positive social connections account for the upward spiral between positive emotions and vagal tone. Psychological science. 2013;24(7):1123-32.

465. Daban C, Martinez-Aran A, Cruz N, Vieta E. Safety and efficacy of Vagus Nerve Stimulation in treatment-resistant depression. A systematic review. Journal of Affective Disorders. 2008;110(1):1-15.

466. Kaniusas E, Kampusch S, Tittgemeyer M, Panetsos F, Gines RF, Papa M, et al. Current Directions in the Auricular Vagus Nerve Stimulation I - A Physiological Perspective. Frontiers in neuroscience. 2019;13:854-. 
467. Koopman FA, Chavan SS, Miljko S, Grazio S, Sokolovic S, Schuurman PR, et al. Vagus nerve stimulation inhibits cytokine production and attenuates disease severity in rheumatoid arthritis. Proceedings of the National Academy of Sciences of the United States of America. 2016;113(29):8284-9.

468. Lerman I, Davis B, Huang M, Huang C, Sorkin L, Proudfoot J, et al. Noninvasive vagus nerve stimulation alters neural response and physiological autonomic tone to noxious thermal challenge. PloS one. 2019;14(2):e0201212-e.

469. Lane RD, Weidenbacher H, Smith R, Fort C, Thayer JF, Allen JJ. Subgenual anterior cingulate cortex activity covariation with cardiac vagal control is altered in depression. J Affect Disord. 2013;150(2):565-70.

470. Smith R, Allen JJ, Thayer JF, Fort C, Lane RD. Increased association over time between regional frontal lobe BOLD change magnitude and cardiac vagal control with sertraline treatment for major depression. Psychiatry research. 2014;224(3):225-33.

471. Nakata H, Sakamoto K, Kakigi R. Meditation reduces pain-related neural activity in the anterior cingulate cortex, insula, secondary somatosensory cortex, and thalamus. Frontiers in psychology. 2014;5:1489.

472. Grant JA, Courtemanche J, Duerden EG, Duncan GH, Rainville P. Cortical thickness and pain sensitivity in zen meditators. Emotion (Washington, DC). 2010;10(1):43-53.

473. Franklin G, Carson AJ, Welch KA. Cognitive behavioural therapy for depression: systematic review of imaging studies. Acta Neuropsychiatr. 2016;28(2):61-74.

474. Jiang H, White MP, Greicius MD, Waelde LC, Spiegel D. Brain Activity and Functional Connectivity Associated with Hypnosis. Cerebral cortex (New York, NY : 1991). 2017;27(8):4083-93.

475. Heppner FL, Ransohoff RM, Becher B. Immune attack: the role of inflammation in Alzheimer disease. Nature reviews Neuroscience. 2015;16(6):358-72.

476. Lotankar S, Prabhavalkar KS, Bhatt LK. Biomarkers for Parkinson's Disease: Recent Advancement. Neuroscience bulletin. 2017;33(5):585-97.

477. Squassina A, Pisanu C, Vanni R. Mood Disorders, Accelerated Aging, and Inflammation: Is the Link Hidden in Telomeres? Cells. 2019;8(1):52.

478. Levenson RW, Sturm VE, Haase CM. Emotional and behavioral symptoms in neurodegenerative disease: a model for studying the neural bases of psychopathology. Annual review of clinical psychology. 2014;10:581-606. 